\title{
Validation of top-down, intelligent reservoir modeling using numerical reservoir simulation
}

Yorgi Gomez

West Virginia University

Follow this and additional works at: https://researchrepository.wvu.edu/etd

\section{Recommended Citation}

Gomez, Yorgi, "Validation of top-down, intelligent reservoir modeling using numerical reservoir simulation" (2010). Graduate Theses, Dissertations, and Problem Reports. 2148.

https://researchrepository.wvu.edu/etd/2148

This Thesis is protected by copyright and/or related rights. It has been brought to you by the The Research Repository @ WVU with permission from the rights-holder(s). You are free to use this Thesis in any way that is permitted by the copyright and related rights legislation that applies to your use. For other uses you must obtain permission from the rights-holder(s) directly, unless additional rights are indicated by a Creative Commons license in the record and/ or on the work itself. This Thesis has been accepted for inclusion in WVU Graduate Theses, Dissertations, and Problem Reports collection by an authorized administrator of The Research Repository @ WVU. For more information, please contact researchrepository@mail.wvu.edu. 


\title{
Validation of Top-Down, Intelligent Reservoir Modeling Using Numerical Reservoir Simulation
}

\author{
Yorgi Gomez \\ Thesis submitted to the \\ College of Engineering and Mineral Resources \\ at West Virginia University \\ in partial fulfillment of the requirements \\ for the degree of
}

MASTER OF SCIENCE

IN

PETROLEUM AND NATURAL GAS ENGINEERING

Shahab Mohaghegh, Ph.D., Chair

Razi Gaskari, Ph.D.

Sam Ameri, Ph.D.

Morgantown, West Virginia

2010

Keywords: Artificial Intelligence, Data Mining, Reservoir Management. 


\begin{abstract}
VALIDATION OF TOP-DOWN, INTELLIGENT RESERVOIR MODELING USING NUMERICAL RESERVOIR SIMULATION
\end{abstract}

\author{
Yorgi Gomez
}

The technique, that is named Top-Down Intelligent Reservoir Modeling, (not to be confused with BP's TDRM history matching technique), integrates traditional reservoir engineering analysis with Artificial Intelligence \& Data Mining (AI\&DM) technology to generate a full field model. The distinguishing feature of this novel technique is its incredibly low data requirement in order to perform analysis which leads to savings of time and research resources to obtain accurate predictions. It only requires field production rate and some well log data as porosity, thickness, and initial water saturation to start the analysis and provide complete development strategies of the field. Although it can incorporate almost any type and amount of data that is available in the modeling process to increase the accuracy and validity of the developed model.

In this work three different reservoir models with different characteristics and operational conditions have been generated using a commercial simulator and also using the proposed Top Down Modeling Method. The models were built with different PVTInitial reservoir conditions (saturated or under-saturated), a different number of wells, and different distributions of reservoir characteristics (introducing heterogeneity).

Production rates and well log data, which had been used in the commercial simulator to produce particular models. The same values of data were imported into Top Down Modeling Software (IPDA \& IDEA) to develop a new empirical reservoir model in order to validate the capabilities of Top Down Modeling in predicting production issues of an oil reservoir against the commercial simulator.

Investigation and validation of Top Down Modeling's capabilities included identification of the gas cap development within the formation, identification of infill locations by mapping the remaining reserves and prediction of the production performance for the newly drilled wells. Then the results of Top Down Modeling analysis were closer to the commercial simulation models/results. 
This goal is dedicated especially to my mother Aura Mantilla, my father Yorgi Gomez, my nona Felicita, my sisters Aurimar and Lisbeth.

7 all my family.

iii 


\section{Acknowledgements}

I would like to thank Jesus for giving me the power and courage in all steps of my life.

To my parents, Yorgi Gomez and Aura Montilva, my sisters, aunts, and cousins for their supports and for giving me the inspiration to accomplish another goal in my life.

Immense thanks to my advisor Dr. Shahab Mohaghegh for believing in my abilities. To me he has been a mentor whose advice improved my professional life.

I would like to extend my gratitude to Dr. Razi Gaskari for his supervision and cooperation. Also to Dr. Khashayar, Dr. Ilkin Bilgesu, Beverly Matheny and all the members of the deparment of Petroleum and Natural Gas Engineering at West Virginia

University. Special thanks to Dr. Sam Ameri for giving the privilege to become a "Mountaineer" and pursue a master degree from this great University.

To my research team members and friends Camilo, Ognjen, Cesar, Domingo, Daniel, Miguel, Jalal, Shohreh, Masoud, Saeed, Yasaman, Vida, Delal, and Eduardo.

Thanks to Computer Modeling Group (CMG) (1), Schlumberger (2), and Intelligent Solution Inc (IPDA \& IDEA) (3) for providing the software for this study.

Finally, to myself for accomplishing this step of my life and getting the challenge to proceed to the next steps. 


\section{Contents}

ABSTRACT

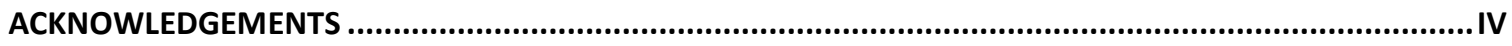

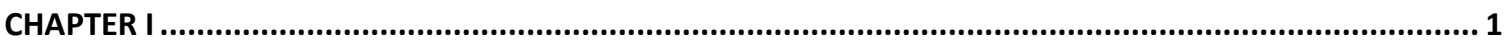

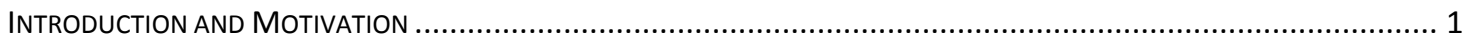

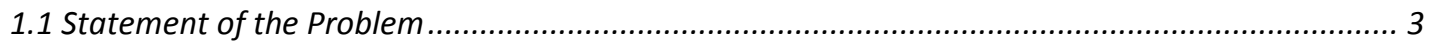

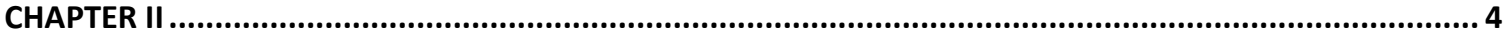

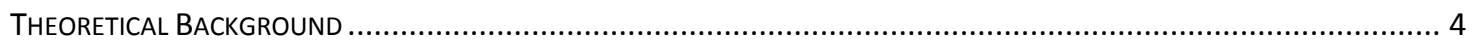

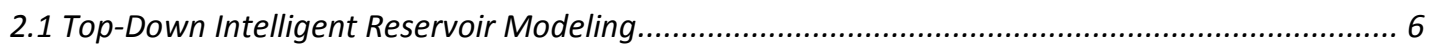

2.2 Top-Down Intelligent Reservoir Modeling work flow................................................................... 9

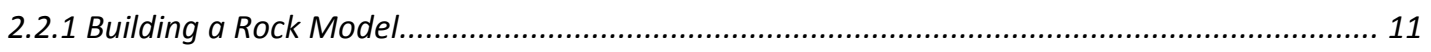

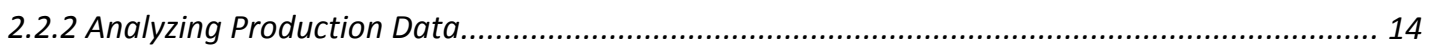

2.2.3 Preliminary Model (Fuzzy Pattern Recognition) ....................................................................... 17

2.2.4 Final Full Field Model (Time Successive - Predictive Model).................................................. 19

2.2.5 Calibration/Validation of Preliminary \& Final Models .......................................................... 21

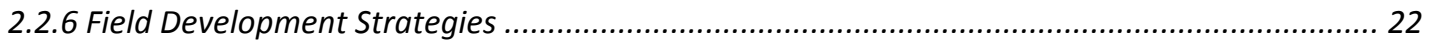

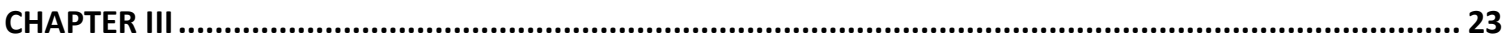

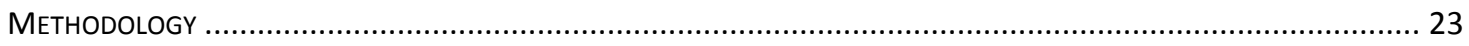

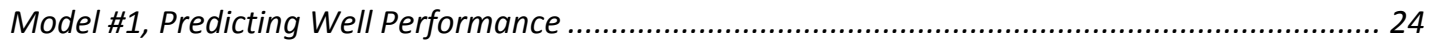

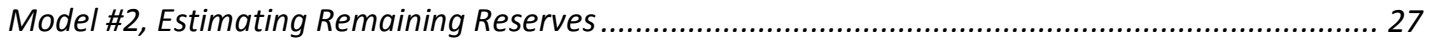

Model \#3, Identification of Gas Cap Development within the formation ......................................... 29

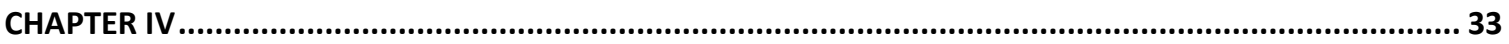

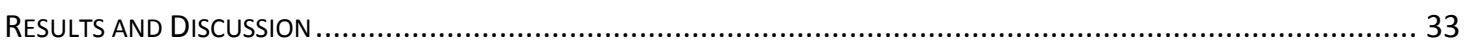

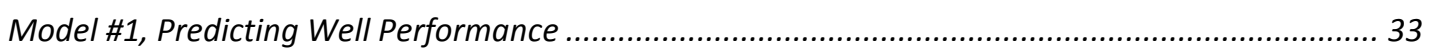

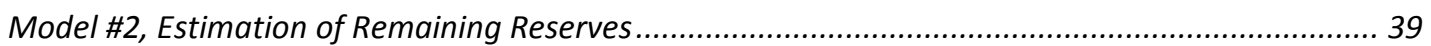

Model \#3, Identification of Gas Cap Development within the formation ........................................ 43

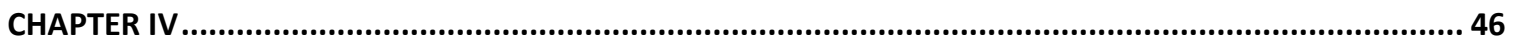

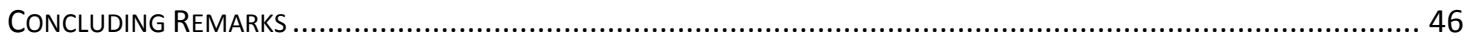

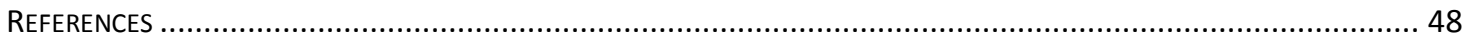

APPENDIX A 
APPENDIX B .

APPENDIX C 


\section{List of Tables}

Table 1. Production Data to be imported in Top Down Modeling. ........................................................ 11

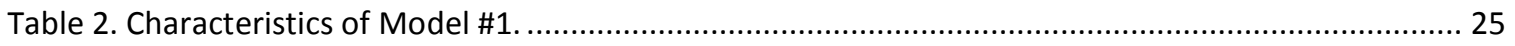

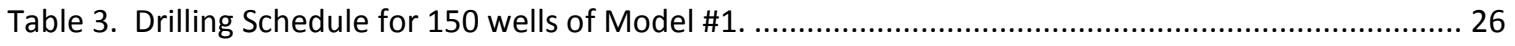

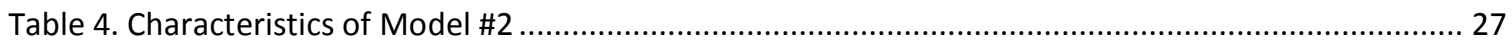

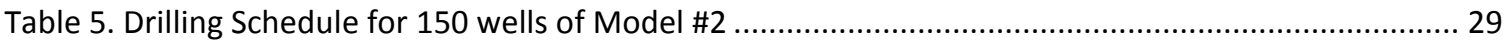

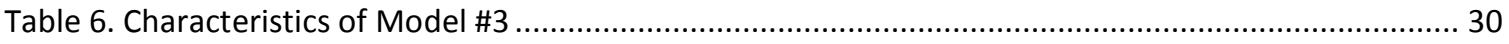

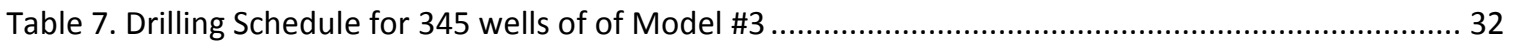




\section{List of Figures}

Figure 1. Traditional Finite Difference Simulator. (Bottom-Up approach)............................................... 5

Figure 2. Conception of Top-down Intelligent Reservoir Modeling. …..................................................... 6

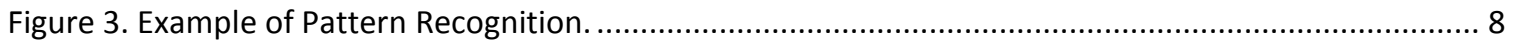

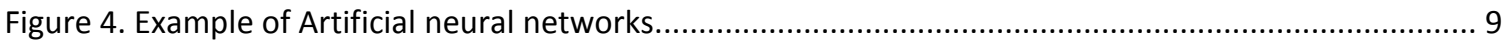

Figure 5. Top-down Intelligent Reservoir Modeling Workflow. ................................................................ 10

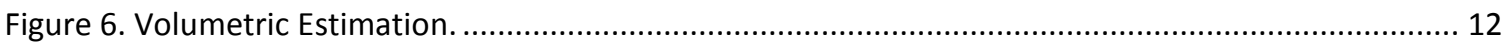

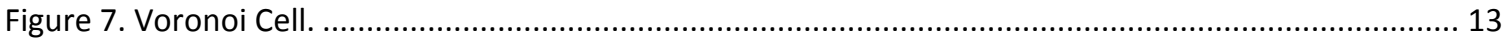

Figure 8. Populated Map of a Properties of the Reservoir...................................................................... 13

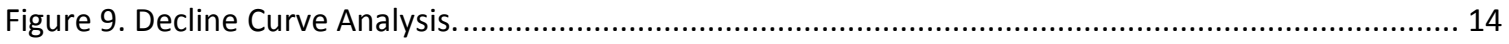

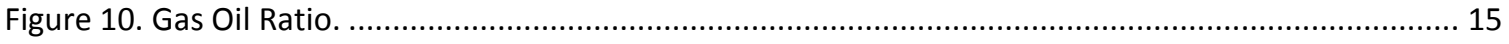

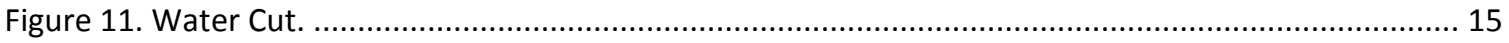

Figure 12. Type Curve.

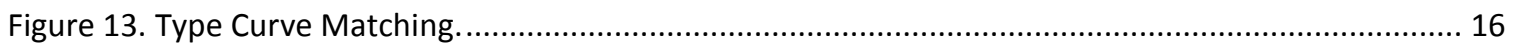

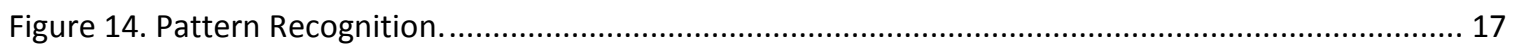

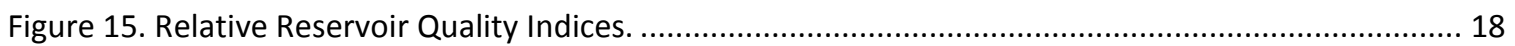

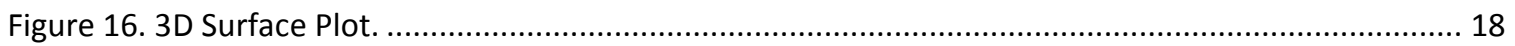

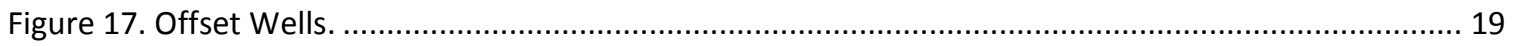

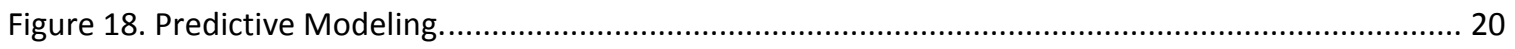

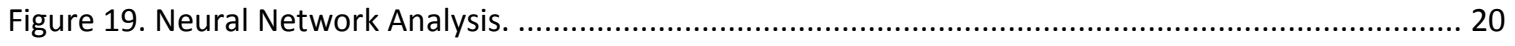

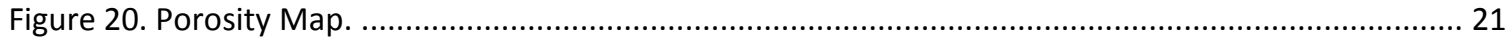

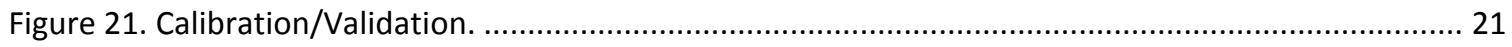

Figure 22. Different parameters of Reservoir Analysis........................................................................... 22

Figure 23. Drainage area changes of the Strategy for New Infill Locations............................................... 22

Figure 24. Flow-Chart of validation of Top-Down Intelligent Reservoir Modeling ...................................... 23

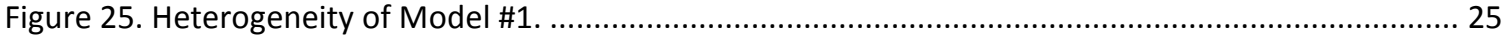

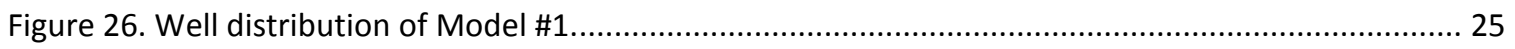

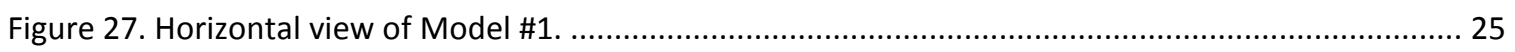

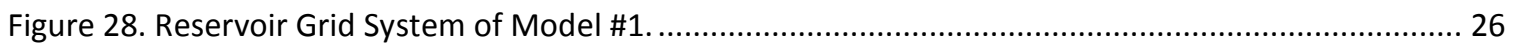

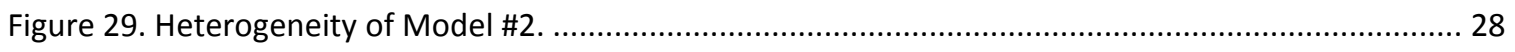

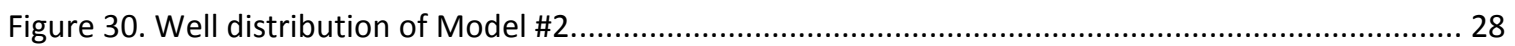

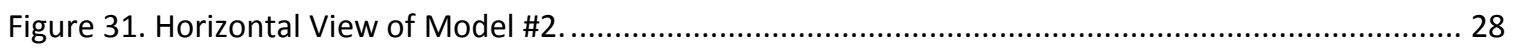

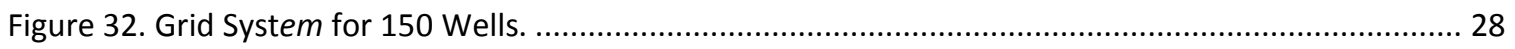

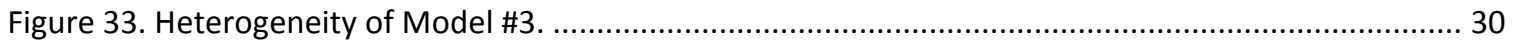


Figure 34. Well Distribution of Model \#3.

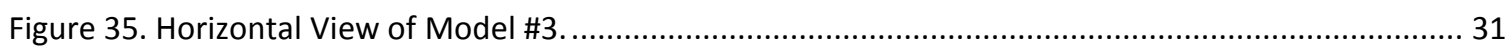

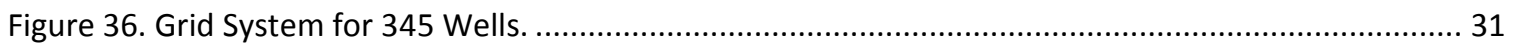

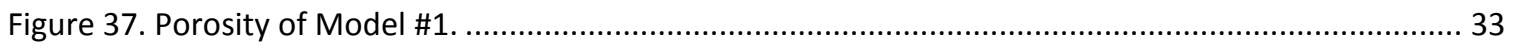

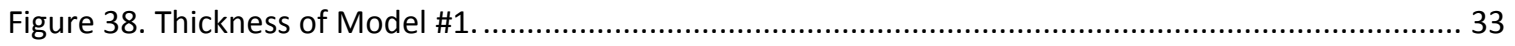

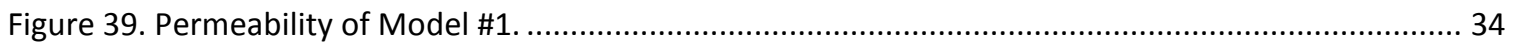

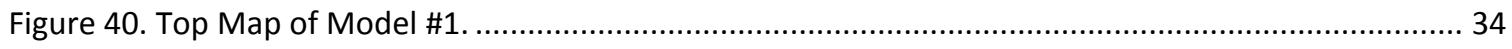

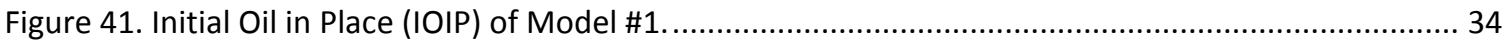

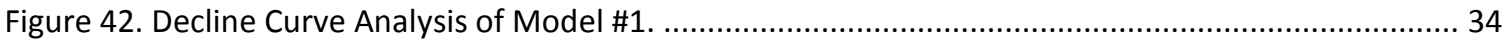

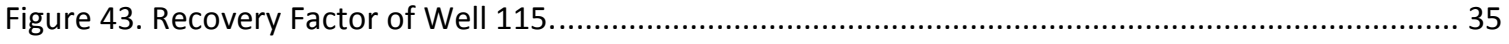

Figure 44. Wells used as blind test in this study for verification (red dots). ......................................... 36

Figure 45. Top Down Modeling predictions versus the actual (modeled) production profile................... 37

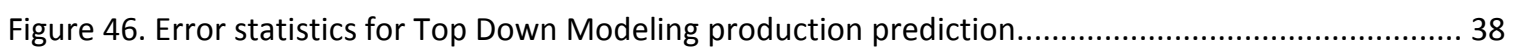

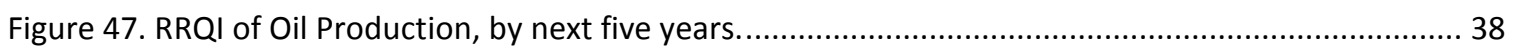

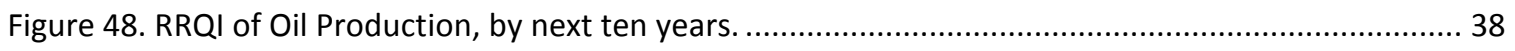

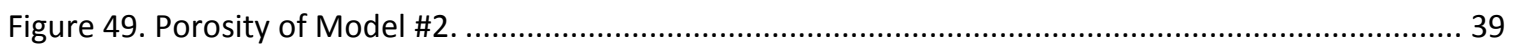

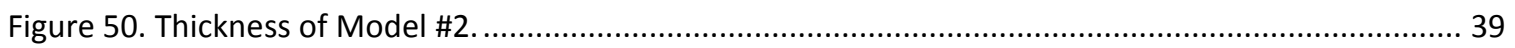

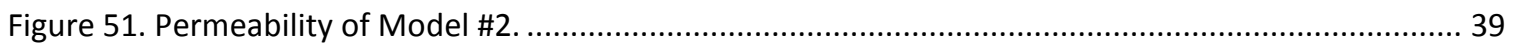

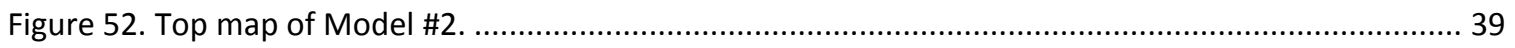

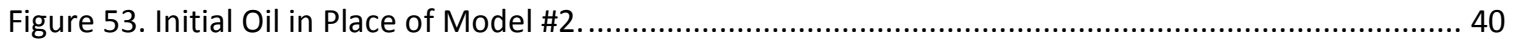

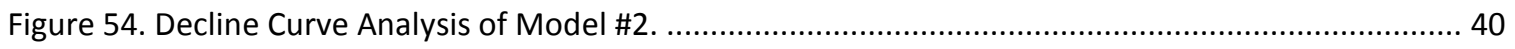

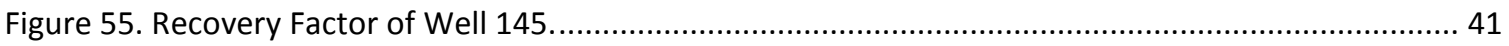

Figure 56. Map of remaining reserves from Top Down Modeling (left) compared to reservoir pressure distribution generated by the commercial simulator (right), both after one year of production by the 150 wells.

Figure 57. Map of remaining reserves from Top Down Modeling (left) compared to reservoir pressure distribution generated by the commercial simulator (right), both after three year of production by the 150 wells.

Figure 58. Map of remaining reserves from Top Down Modeling (left) compared to reservoir pressure distribution generated by the commercial simulator (right), both after ten year of production by the 150 wells.

Figure 60. Gas cap analysis by Top Down Modeling and comparison with the reservoir simulator. The gas cap formation is shown after 5 years of production.

Figure 59. GOR use Top Down Modeling (left) compared to GOR generated by the commercial simulator. 


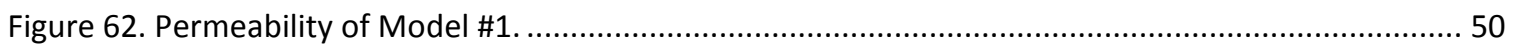

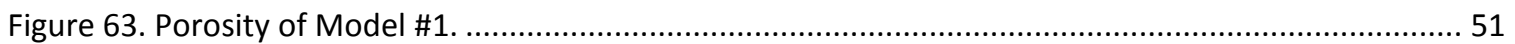

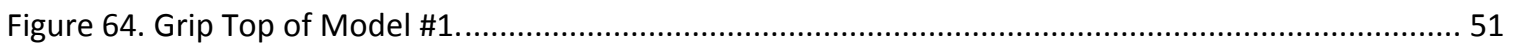

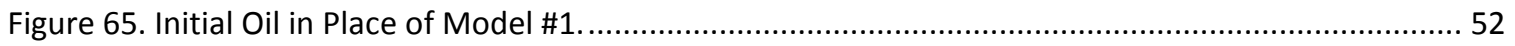

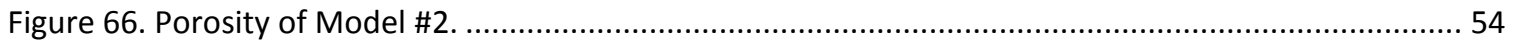

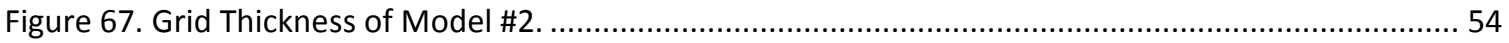

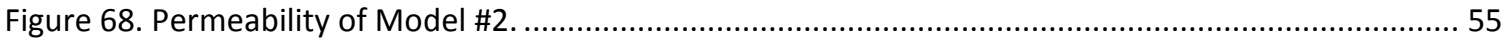

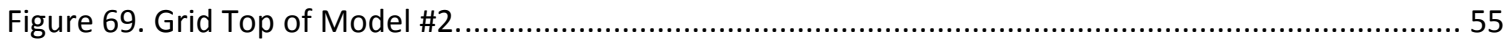

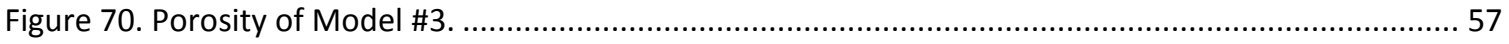

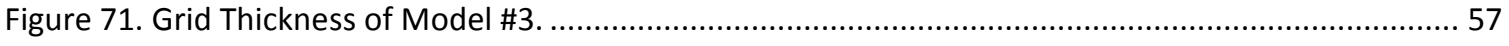

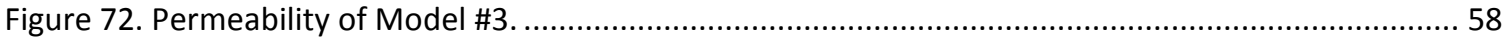

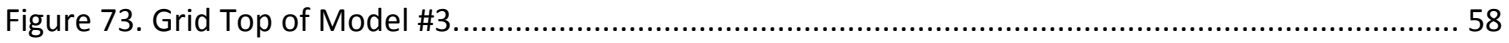




\section{Chapter I}

\section{Introduction and Motivation}

Recent changes in the global economy had a great influence on world energy policies and especially on Oil \& Gas Industry. This impact forced companies to look for new technologies that would enable them to better develop and exploit oil and gas reservoirs with lower expenses.

Research and development aim to integrate old and new techniques to acquire better empirical understanding of hydrocarbons flow mechanics throughout reservoirs. A full understanding of the fluid flow mechanics within the reservoir enables us to predict the reservoir depletion, calculate the remaining reserves, and identify proper infill locations. In the last decade, efficient techniques were developed to build reservoir models which allows us to analyze the reservoir behavior and eventually predict pressure change and distribution as well as fluid production. However, these techniques are based on complex numerical solutions of the fluid flow equations, and are highly demanding in terms of time, computing power, and man power which makes them highly expensive. Additionally, analytical approaches are limited to solutions where only a single-well analysis is performed.

In recent years, a new empirical modeling technique has been introduced. The technique is called Top-Down Intelligent Reservoir Modeling (4) (5) (6) which is an approach of full field with a different methodology. The main advantage of Top Down Modeling is its flexibility in data requirements. Top Down Modeling needs only production data and well logs (for some wells, not all) in order to start the analysis and build a full field model, representing savings in time and resources.

The Top Down modeling approach starts with conventional reservoir engineering techniques such as decline curve analysis, type curve matching, and production history matching. In the next step, single-well numerical simulation, estimation of volumetric 
reserves, and recovery factor calculations are performed. Based on all mentioned analysis a large spatial-temporal database is generated, that contains "snapshots" of the reservoir behavior, which are further maneuver with Artificial Intelligence \& Data Mining (AI\&DM) technology.

This novel technique also allows easier updating of the models with additional data such as core analysis, well tests, pressure, and seismic data which can significantly reduce the uncertainty associated with the results.

Top-Down Intelligent Reservoir Modeling uses Artificial Intelligence and Data Mining (7) (8) (9) techniques to deduce field-wide patterns from the large spatiotemporal database. The result of these analysis ends up with a full field model with impressive predictive capabilities.

The most important advantage of Top Down Modeling is its ability to integrate the single-well basis model with Fuzzy Pattern Recognition technology, in a configuration of artificial neural networks and data mining. This allows evaluation of different scenarios in order to come up with the best business and technical decisions. 


\subsection{Statement of the Problem}

Traditionally predictions of well performance are based on numerical approximations of the fluid mechanics phenomena by the use of specialized commercial software knows as model simulator.

The accuracy of the predictions obtained are highly dependent on the credibility of the input data. Better approximations are obtained if a wide variety of data is fed into the model as permeability, porosity, pressure, water-oil contact, gas-oil contact, etc. Furthermore, data sets required should cover great volumes and need to be experimentally obtained implying high costs and long periods of time.

More efficient methodologies are needed to provide equivalent accuracy in the predicted performance of the reservoir behavior. 


\section{Chapter II}

\section{Theoretical Background}

Engineers have studied the reservoirs for decades using classic reservoir engineering techniques such as decline curve analysis (DCA), type curve matching (TCM), production history matching (HM), estimation of volumetric reserves, and recovery factor. These techniques have high applicability for single-well analysis and are quite good for monitoring the overall field performance however when it comes to describe the entire reservoir behavior it is very difficult to represent it without considering the associated subjective.

Decline curve analysis is used to match records of production data in order to predict recoverable reserves and future production rates. Another more extensive technique is Type Curve Matching which is used to calculate additional parameters of the reservoir. Cox's type curves (10) developed for gas reservoirs, enable us to obtain parameters such as permeability, viscosity, skin factor, reservoir shape, and compressibility just by using the production data. Another technique is called single well history matching which is used to determine the overall variation of different parameter values. These parameters include permeability, porosity, initial pressure, drainage area, temperature, and saturations. It is obvious that each parameter has its own degree of uncertainty. However, when they are associated with one another each one provides its contribution to increase the grade of uncertainty which should be quantified.

A relevant study present by Poe (11) showed that it is possible to combine fieldwide properties with production analysis. However, the limitation in the combination is that it requires extraordinary amount of effort and time to analyze the reservoir' behavior.

A common approach to study the reservoir behavior is to start from Geology description (bottom) to Well Production/History Matching (up) by using a traditional finite difference simulator. This method describes the physical space of the field by an array of discrete cells (grid). 
Reservoir properties (shown in figure 1.a) are assigned to each of the grid cells in order to build a geo-cellular model of the reservoir (figure 1.b). After the geo-cellular model is created the next step is Up-scale the model (figure 1.c). Then the fluid flow within and from the reservoir must be analyzed. The flow is defined by three physical concepts: conservation of mass, isothermal fluid phase behavior, and the Darcy Law which are represented by historical field production and/or pressures data (figure 1.d). After that the flow records must be included in order to adjust some reservoir parameters, through the process of history matching (figure 1.e). After that model can be used to evaluate different production strategies of the field (figure 1.f). The following flow chart shows the integration of all processed mentioned above.

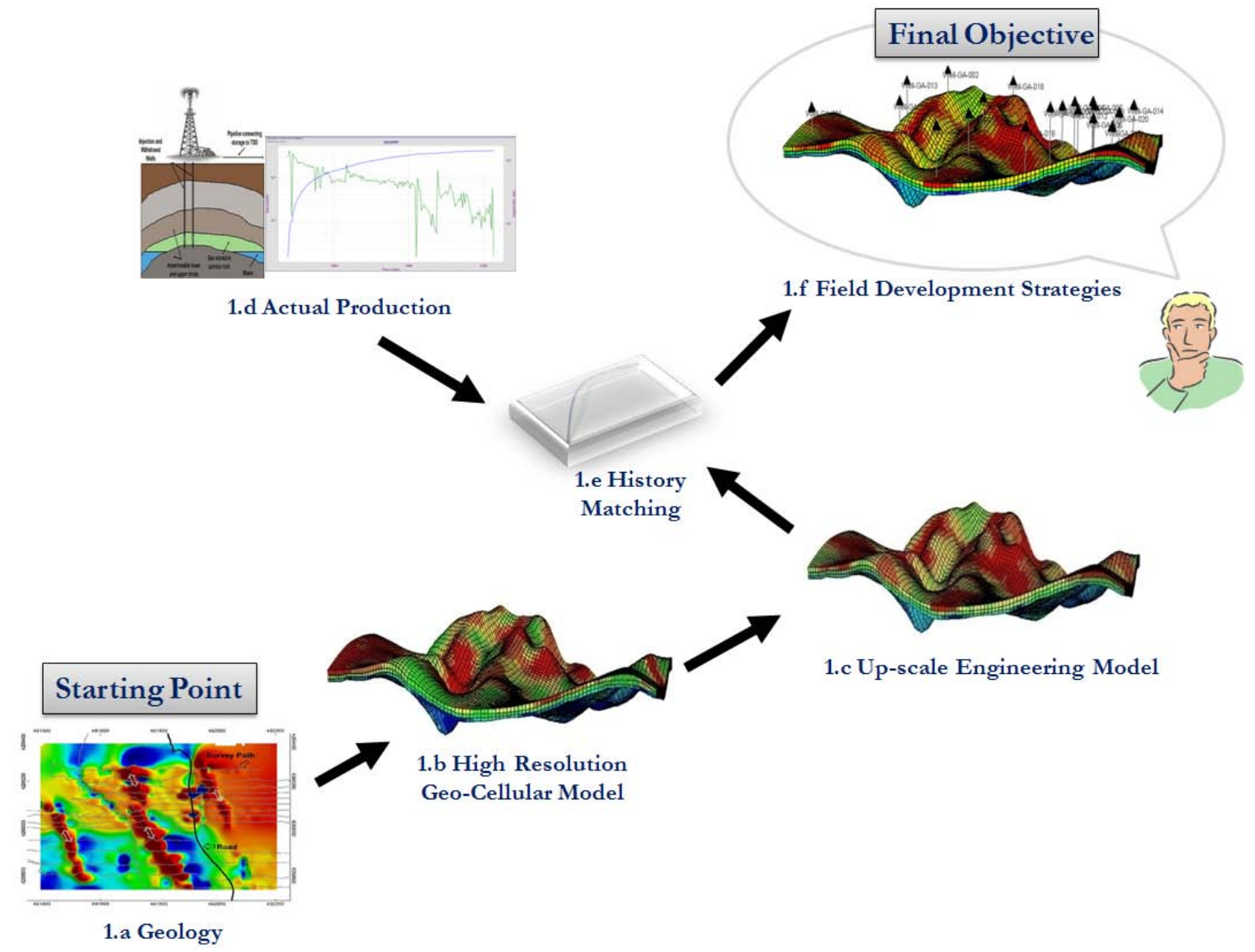

Figure 1. Traditional Finite Difference Simulator. (Bottom-Up approach).

A limitation of traditional finite difference simulator is that it requires significant investment in terms of time and resources. For instance sensitivity analysis, and history matching process, requires many expertise from engineers and geologists. 


\subsection{Top-Down Intelligent Reservoir Modeling}

In recent years, Mohaghegh introduced a new conception of the large spatiotemporal database of the reservoir behavior which begins from production rate (Up) to geology description (Bottom). It integrates the analysis of the production data, series of classic reservoir engineering techniques (decline curve analysis, type curve matching, and production history matching), estimation of volumetric reserve and calculation of recovery factor with Fuzzy Pattern Recognition technology in an ensemble of artificial neural networks. Figure 2 summarizes this conception:

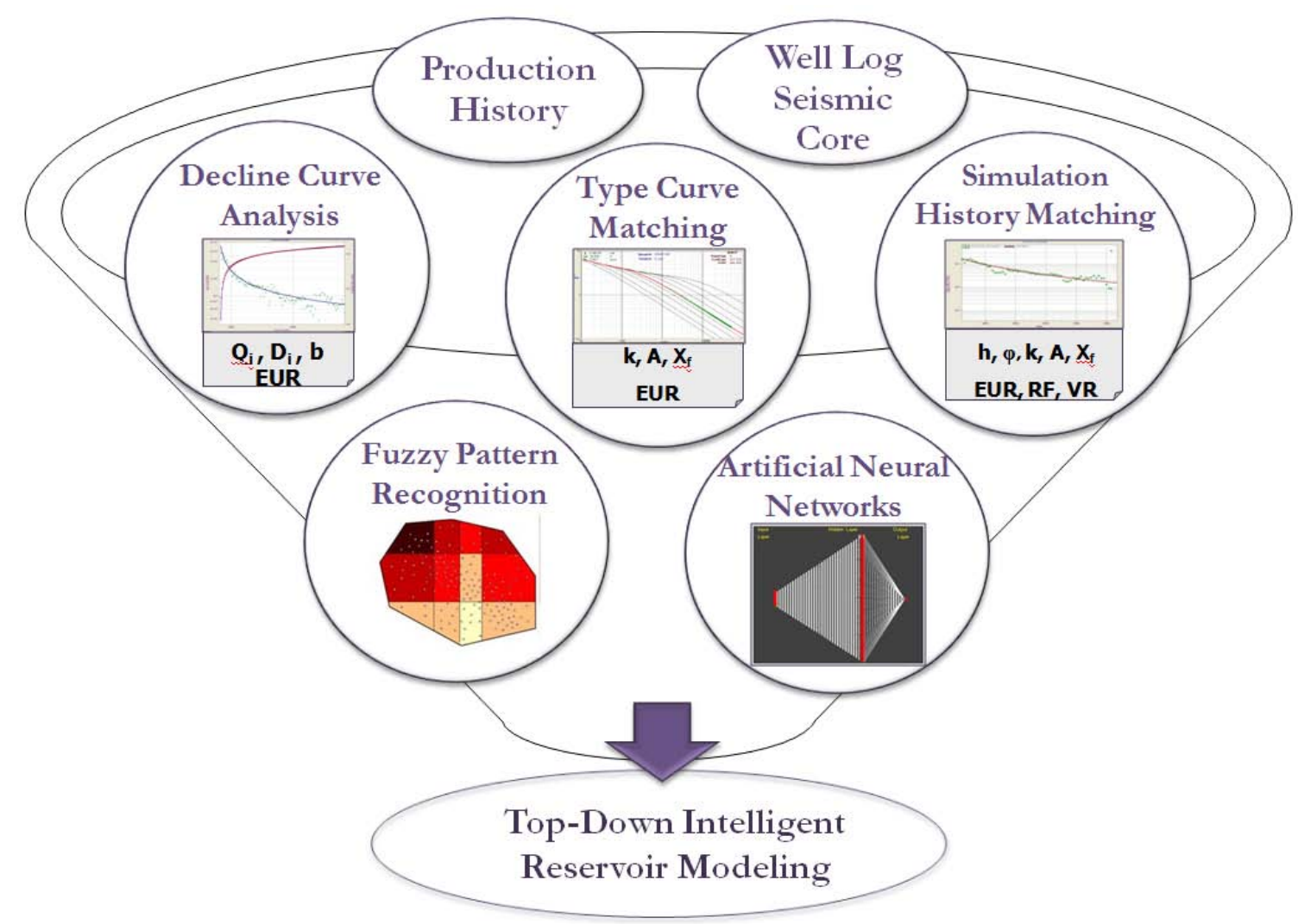

Figure 2. Conception of Top-down Intelligent Reservoir Modeling.

After classic reservoir engineering techniques are applied in Top Down Modeling the next step is to estimate volumetric reserve based on the drainage area of each well which provides an estimate of the initial hydrocarbon-in-place. The amount of hydrocarbon that is technically recoverable is called "Recover Factor". The recovery factor is expressed as a percent and can be calculated using the following equation: 


$$
R F=\frac{E U R}{N \text { or } G}
$$

Where:

EUR is Estimated Ultimate Recovery or recoverable hydrocarbon that is determined by dynamic properties of the reservoir.

$\mathbf{N}$ or $\mathbf{G}$ is the hydrocarbon originally in place and is determined by static properties of the reservoir used in the following Equations:

$N=\frac{V b \times \emptyset \times S o}{B o}$ or $G=\frac{V b \times \emptyset \times S g}{B g}$

Where:

Vb is the bulk reservoir volume which is calculated as 7758xAxh reservoir barred (RB) for oil and 43560xAxh cubic feet (cf) for gas

A is reservoir area, acres

$\mathbf{h}$ is average reservoir thickness, $\mathrm{ft}$

$\emptyset$ is average reservoir porosity, fraction

$\mathbf{S}$ is oil saturation or gas saturation, fraction

B is formation volume factor at initial reservoir pressure. For oil is RB/STB for gas is CF/SCF.

Another concept used in Top Down Modeling is Fuzzy Pattern Recognition (FPR) technology, which applies Fuzzy Logic and Pattern Recognition to integrate the total amount of data generated at this point. In a very general concept Pattern Recognition can be described as something similar to classification of data. Figure 3 shows an example of classification of data. By using FPR, the red dot can be associated to a specific class 1 or 2 with a valid criteria. 


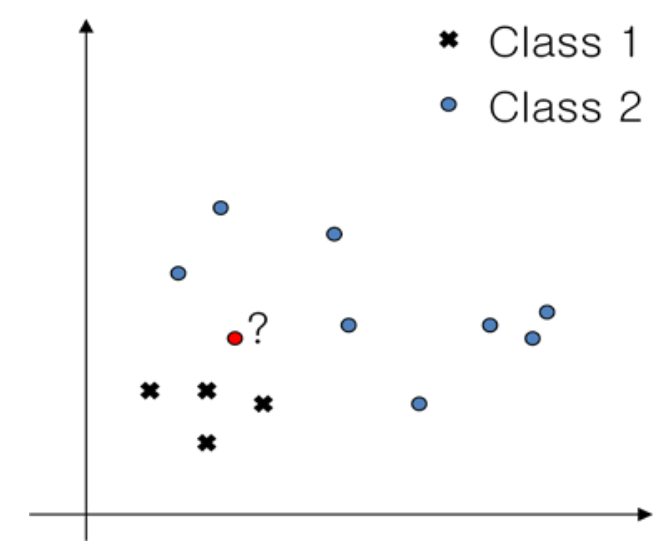

Figure 3. Example of Pattern Recognition.

Top Down Modeling uses this concept by generating different maps of the studied parameter. When Fuzzy Pattern Recognition is applied to the large spatio-temporal database that was previously generated, it is possible to identify the "sweet spots" in the reservoir. Sweet spots represent, for example, the zone of the reservoir with the highest remaining reserves, and/or locations for infill drilling with a high degree of certainty in success.

Another technique used is application of Artificial Neural Networks (ANN) which is used to ingrate all data generated in the previous tasks. ANN is defined as a composition of simple elements operating parallel with a performance that is similar to biological nervous systems. As in nature, the network function is determined largely by the connections between the elements. The neural network is trained to perform a particular function by adjusting the values of the connections (weights) between all elements in order to minimize the squared deviation between targeted and fitted values. Figure 4 shows one example of neural networks: 


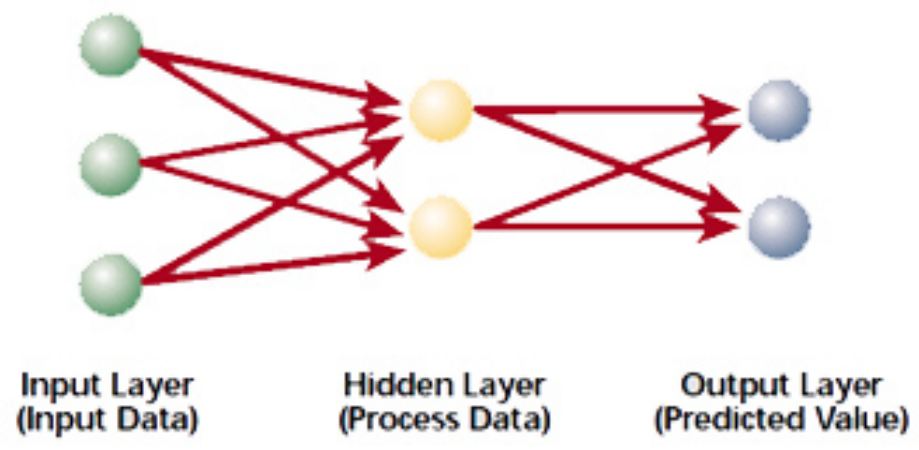

Figure 4. Example of Artificial neural networks.

Neural networks have layered structure. The first layer (input nodes) handles the input data, while the hidden layer is where the "weights" are added, this layer has the purpose to modify the data throughout the system (generates complex relationships between the input data and output data), finally the third element is the output layer of neutrons which creates the required output (it can be for example forecast oil production at any time).

\subsection{Top-Down Intelligent Reservoir Modeling work flow}

Top-Down Intelligent Reservoir Modeling work flow is in oppose direction to traditional finite difference simulator (geo-cellular model to history matching). First only production data (figure 5.a) and geology description (for example some well logs not all wells are need) are incorporated into volumetric and recovery factor calculations in order to obtain a preliminary model. Then, model generated at this point uses neural network modeling, fuzzy logic, and pattern recognition to develop the final model (validation and calibration are included in this process)( figure 5.b). Afterwards genetic optimization and data mining techniques are used to evaluate the different strategies of the final model (figure 5.c). Based on the data available is generate different realizations of the reservoir 
which can be quantify to reduce the uncertainty (figure 5.d). Figure 5 expresses a summarized view of this technique:

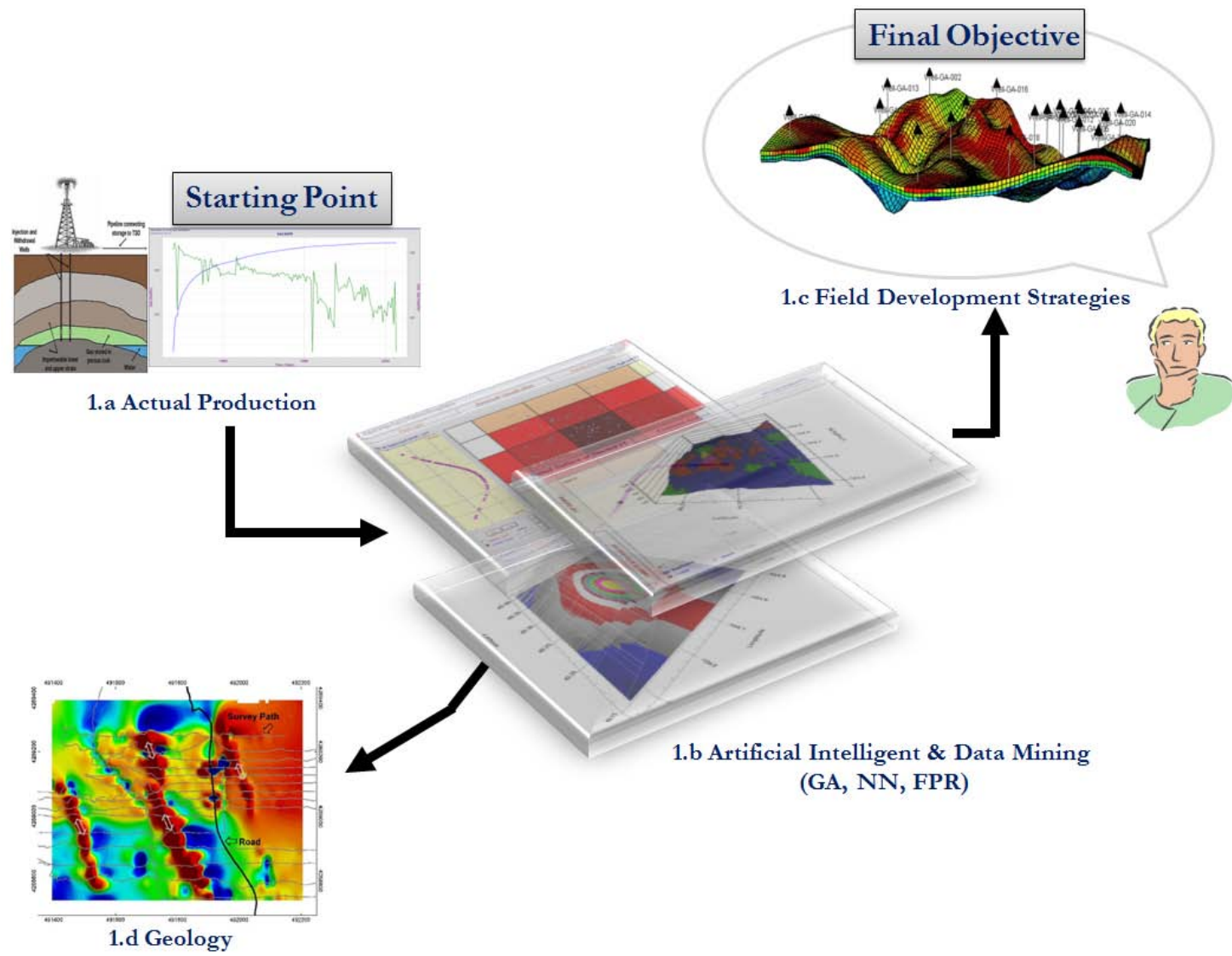

Figure 5. Top-down Intelligent Reservoir Modeling Workflow.

The main limitation of Top Down Modeling is that it is recommended to be used in fields with at least 50 wells and about five years of production history. This has to do with the fact that this technique requires production history and well log data in order to generate a large spatio-temporal database of static and dynamic behavior of the reservoir.

After the spatio-temporal database is completed, field-wide patterns are generated by applying the Artificial Intelligence and Data Mining techniques. The result from these patterns represents a full field model with impressive predictive capabilities. Incorporating other data such as core analysis, well tests, logs, pressure data and seismic data (if these data are available) will be reduced the full model's level of uncertainty. 
Top Down Modeling can be used as a complement to the conventional techniques to evaluate actual data coming from the traditional model or it can be used to develop a full field study. Below the workflow of this technique is shown:

- Building a Rock Model

- Analyzing Production Data

- Preliminary Model (Fuzzy Pattern Recognition)

- Final Full Field Model (Time Successive and Predictive Model)

- Calibration/Validation of Preliminary \& Final Models

- Field Development Strategies

\subsubsection{Building a Rock Model}

The rock model is used to generate a static model of the field. At this point the basic information incorporated are the locations (latitude and longitude) of each well (See Table 1).

Table 1. Production Data to be imported in Top Down Modeling.

\begin{tabular}{|c|c|c|c|c|c|c|}
\hline Well ID & Date & Longitude & Latitude & Oil Rate $(\mathrm{bbl} / \mathrm{m})$ & Gas Rate $(\mathrm{MSCF} / \mathrm{m})$ & Water Rate $(\mathrm{bbl} / \mathrm{m})$ \\
\hline Well-1001 & $1 / 31 / 2000$ & -86.3721511 & 38.3207756 & 2100.44 & 396.796 & 31.7061 \\
\hline Well-1001 & $2 / 29 / 2000$ & -86.3721511 & 38.3207756 & 1939.75 & 366.441 & 32.1618 \\
\hline Well-1001 & $3 / 31 / 2000$ & -86.3721511 & 38.3207756 & 1871.13 & 353.476 & 31.8691 \\
\hline Well-1001 & $4 / 30 / 2000$ & -86.3721511 & 38.3207756 & 1822.43 & 344.278 & 31.6271 \\
\hline Well-1001 & $5 / 31 / 2000$ & -86.3721511 & 38.3207756 & 1781.68 & 336.579 & 31.4011 \\
\hline Well-1001 & $6 / 30 / 2000$ & -86.3721511 & 38.3207756 & 1747.32 & 330.087 & 31.1966 \\
\hline Well-1001 & $7 / 31 / 2000$ & -86.3721511 & 38.3207756 & 1715.26 & 324.03 & 30.9953 \\
\hline Well-1001 & $8 / 31 / 2000$ & -86.3721511 & 38.3207756 & 1685.44 & 318.399 & 30.801 \\
\hline Well-1001 & $9 / 30 / 2000$ & -86.3721511 & 38.3207756 & 1658.05 & 313.224 & 30.6183 \\
\hline Well-1001 & $10 / 31 / 2000$ & -86.3721511 & 38.3207756 & 1630.91 & 308.098 & 30.4333 \\
\hline Well-1001 & $11 / 30 / 2000$ & -86.3721511 & 38.3207756 & 1605.44 & 303.284 & 30.2586 \\
\hline Well-1001 & $12 / 31 / 2000$ & -86.3721511 & 38.3207756 & 1579.91 & 298.462 & 30.0886 \\
\hline Well-1001 & $1 / 31 / 2001$ & -86.3721511 & 38.3207756 & 1554.79 & 293.717 & 29.9198 \\
\hline Well-1001 & $2 / 28 / 2001$ & -86.3721511 & 38.3207756 & 1532.4 & 289.488 & 29.7686 \\
\hline Well-1001 & $3 / 31 / 2001$ & -86.3721511 & 38.3207756 & 1508.02 & 284.881 & 29.6018 \\
\hline Well-1001 & $4 / 30 / 2001$ & -86.3721511 & 38.3207756 & 1484.64 & 280.466 & 29.4409 \\
\hline Well-1001 & $5 / 31 / 2001$ & -86.3721511 & 38.3207756 & 1460.76 & 275.953 & 29.275 \\
\hline Well-1001 & $6 / 30 / 2001$ & -86.3721511 & 38.3207756 & 1437.83 & 271.622 & 29.1146 \\
\hline Well-1001 & $7 / 31 / 2001$ & -86.3721511 & 38.3207756 & 1414.37 & 267.19 & 28.949 \\
\hline Well-1001 & $8 / 31 / 2001$ & -86.3721511 & 38.3207756 & 1391.1 & 262.794 & 28.7833 \\
\hline Well-1001 & $9 / 30 / 2001$ & -86.3721511 & 38.3207756 & 1368.75 & 258.572 & 28.6229 \\
\hline Well-1001 & $10 / 31 / 2001$ & -86.3721511 & 38.3207756 & 1345.88 & 254.252 & 28.457 \\
\hline Well-1001 & $11 / 30 / 2001$ & -86.3721511 & 38.3207756 & 1323.91 & 250.1 & 28.2961 \\
\hline Well-1001 & $12 / 31 / 2001$ & -86.3721511 & 38.3207756 & 1301.43 & 245.854 & 28.1295 \\
\hline Well-1001 & $1 / 31 / 2002$ & -86.3721511 & 38.3207756 & 1279.15 & 241.646 & 27.9626 \\
\hline Well-1001 & $2 / 28 / 2002$ & -86.3721511 & 38.3207756 & 1259.17 & 237.87 & 27.8116 \\
\hline Well-1001 & $3 / 31 / 2002$ & -86.3721511 & 38.3207756 & 1237.32 & 233.743 & 27.644 \\
\hline Well-1001 & $4 / 30 / 2002$ & -86.3721511 & 38.3207756 & 1216.36 & 229.784 & 27.4813 \\
\hline Well-1001 & $5 / 31 / 2002$ & -86.3721511 & 38.3207756 & 1194.94 & 225.738 & 27.3127 \\
\hline Well-1001 & $6 / 30 / 2002$ & -86.3721511 & 38.3207756 & 1174.44 & 221.864 & 27.1489 \\
\hline Well-1001 & $7 / 31 / 2002$ & -86.3721511 & 38.3207756 & 1153.5 & 217.91 & 26.9795 \\
\hline Well-1001 & $8 / 31 / 2002$ & -86.3721511 & 38.3207756 & 1132.82 & 214.002 & 26.8092 \\
\hline Well-1001 & $9 / 30 / 2002$ & -86.3721511 & 38.3207756 & 1113.03 & 210.263 & 26.644 \\
\hline
\end{tabular}


Visualization of the well locations in the field can be realized (See Figure 6). First the location of the wells are plotted (a), then the Cartesian grid is applied (b), and finally an outer boundary (structure map) is identified/created for the field (c). As a final step the Estimated Ultimate Drainage Area (EUDA) can be determined by using the Voronoi Theory (12) (d).

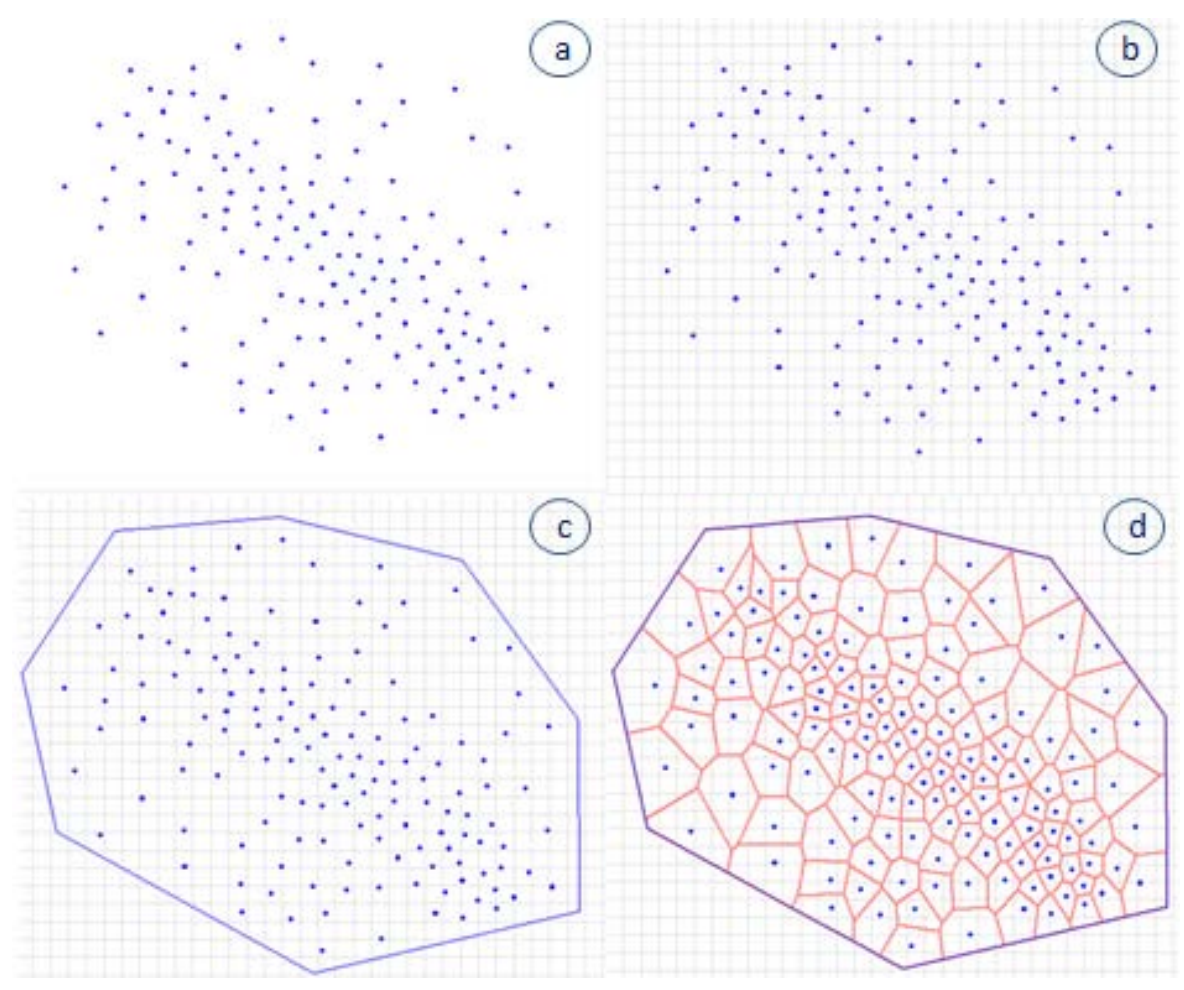

Figure 6. Volumetric Estimation.

Other parameters, such as production rate (oil, gas, and water), porosity, thickness, pressure, saturations, gamma ray, resistivity and other log values may also be imported at this point on an average value per well (if it is available). This information can later be used in other tasks.

Figure 7 shows a Voronoi cell (cream color) containing multiple Cartesian grids which can be the whole grid or a fraction of the grid. In order to take into account the 
contribution of all the grids and the grid portions included in a single Voronoi cell, wellbase characteristics are averaged over the entire Voronoi cell.

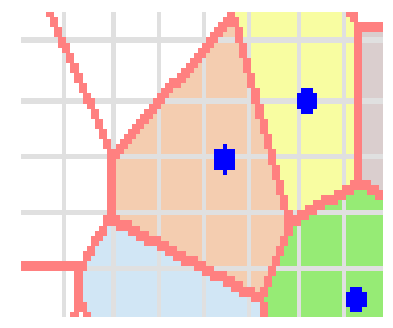

Figure 7. Voronoi Cell.

Subsequently the Voronio cells can be populated with different properties such as thickness, porosity, saturations, etc. As this task is completed, geo-statistics (kriging, cokriging and Sequential Gaussian Simulation - SGS) can be applied to generate the distribution of the parameter for every location in form of a spatial pattern.

Volumetric Reserve for each well can be estimated based on the EUDA, Porosity, Thickness, and Saturation. Also by using geo-statistics approach, multiple Geological Realizations can be computed and the "Uncertainties" associated with the volumetric reserve can also be quantified. One example that shows a populated map with kriging is shown in Figure 8:

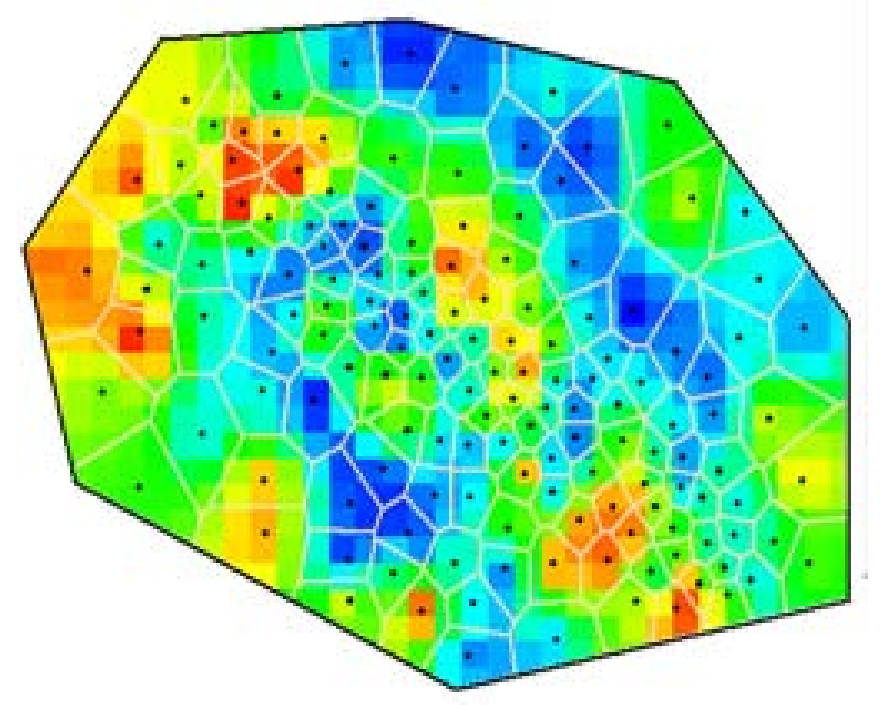

Figure 8. Populated Map of a Properties of the Reservoir. 
One advantage of Top Down Modeling is that if adequate information of distinct layers of the reservoir are available, the multi-layer model can be converted to 3-D modeling.

\subsubsection{Analyzing Production Data}

Incorporating the production data, the static model is converted to a dynamic model. This process is done by determining a model for the production rate and predicting its behavior. The corresponding analyses are DC, TCM, HM, Intelligent decline curve for Gas Oil Ratio, and Water Cut. Once these tasks are completed the prediction of Estimated Ultimate Recovery (EUR) can be performed. The following figures show an example of these curves:

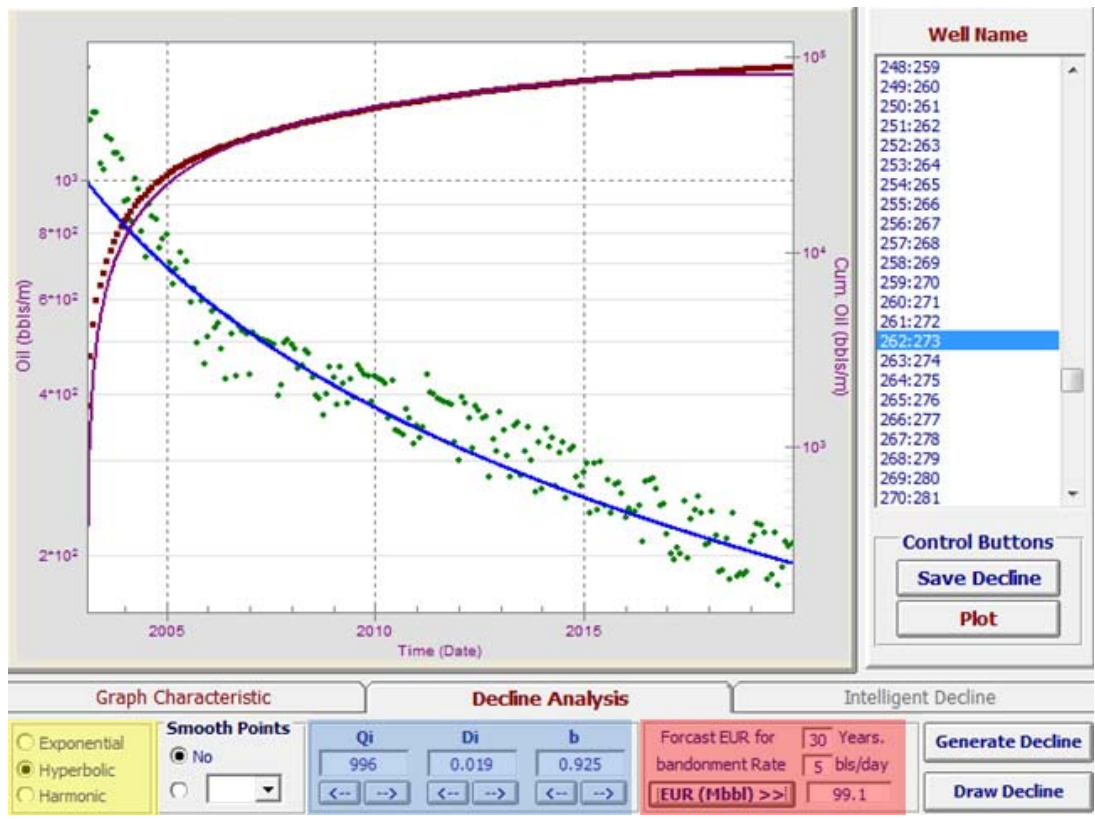

Figure 9. Decline Curve Analysis.

In Figure 9, the dots represent the actual production and the lines represent the fitted decline curves. (The blue line represents production rate and the red line represents cumulative production). The yellow area in Figure 9 shows three different types of curves that can be used, the blue area allows the adjustment of decline parameters, while the red area gives the forecast of EUR. 
Other curves like Gas oil ratio and Water Cut (See Figures 10, and 11 respectively) are generated automatically by using intelligent decline (empowered by Genetic Algorithms) .

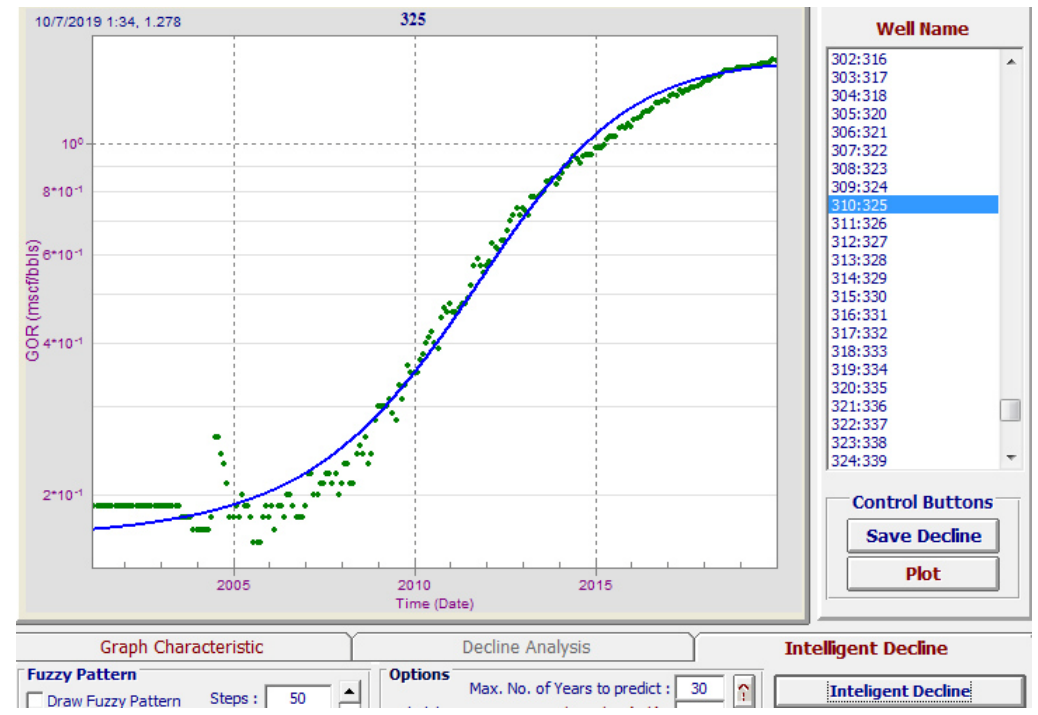

Figure 10. Gas Oil Ratio.

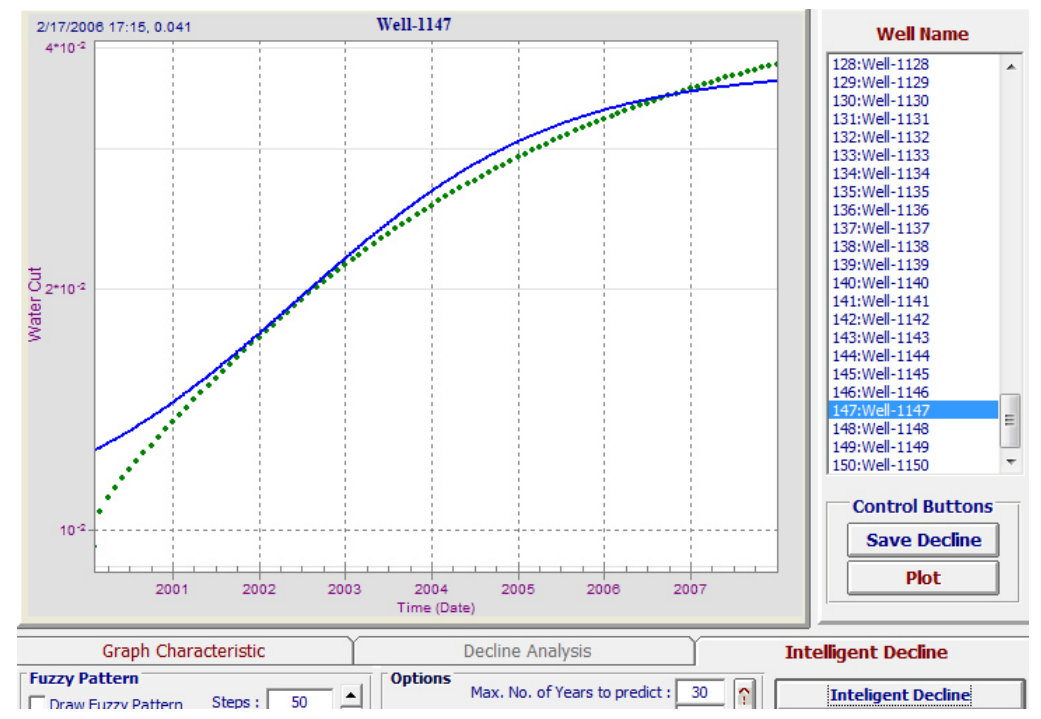

Figure 11. Water Cut.

Using Type Curve Matching additional parameters can be obtained such as permeability and fracture half-length, etc. Also the parameters which were estimated in 
previous steps, such as well drainage area and EUR, can be generated and compared with the previous values (See Figure 12).

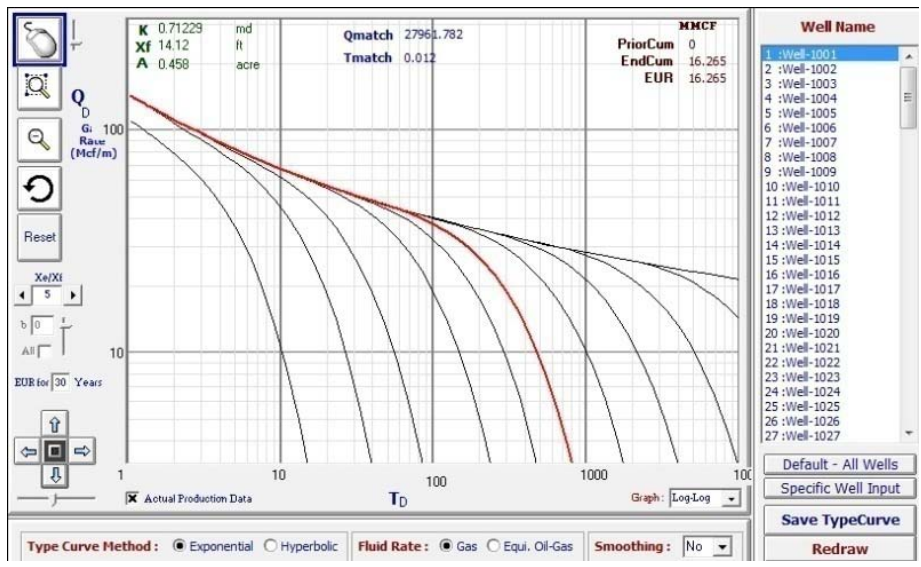

Figure 12. Type Curve.

The red line represents the production rate, while the black lines represent the type curves for each scenario. The parameters involved in this process are porosity, thickness, gas saturation, bottom-hole pressure, initial reservoir pressure, reservoir temperature, specific gas gravity, isotropicity, and drainage shape factor.

After these curves are generated and the properties are approximately quantified, the next step is to apply the Single Well History Matching which is used to adjust the estimated parameters from DC and TCM. The History Matching is finished when parameter value converges to the same value (See Figure 13).

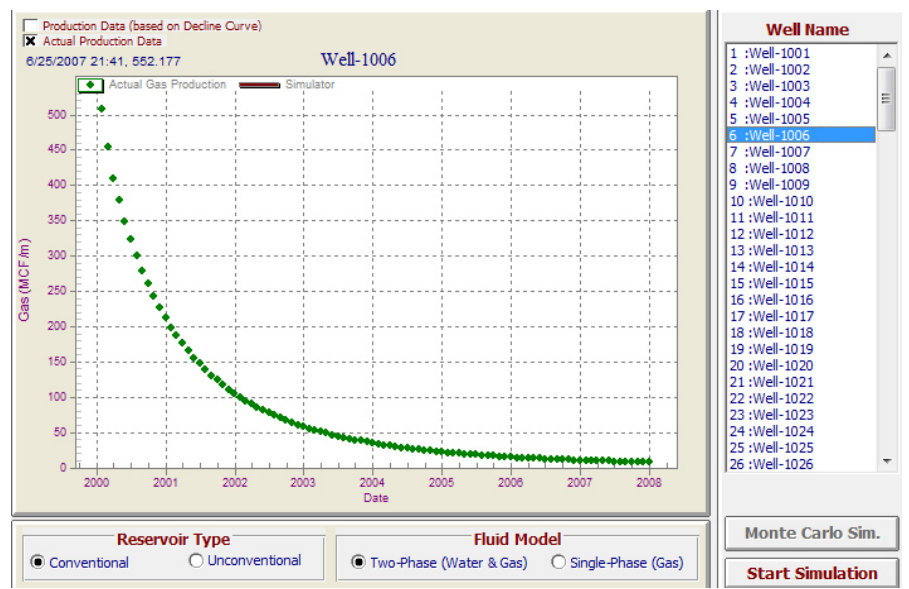

Figure 13. Type Curve Matching. 


\subsubsection{Preliminary Model (Fuzzy Pattern Recognition)}

The preliminary model is used to evaluate several production indicators such as:

- Initial Oil/Gas distribution

- Cumulative Production

- Remaining Reserves as a function of time

- Forecast EUR

- Permeability

- Drainage Area

- Fracture Half Length

- Identify underperformer wells

Fuzzy Pattern Recognition is used to classify different zones of the reservoir, for example Figure 14 shows 12 zones which are ranked in 5 groups/categories called Relative Reservoir Quality Index (RRQI). Dark brown zone indicates high values (zone of highest quality), while the light tan zone indicates the lowest values for the specific production indicator that is being analyzed.

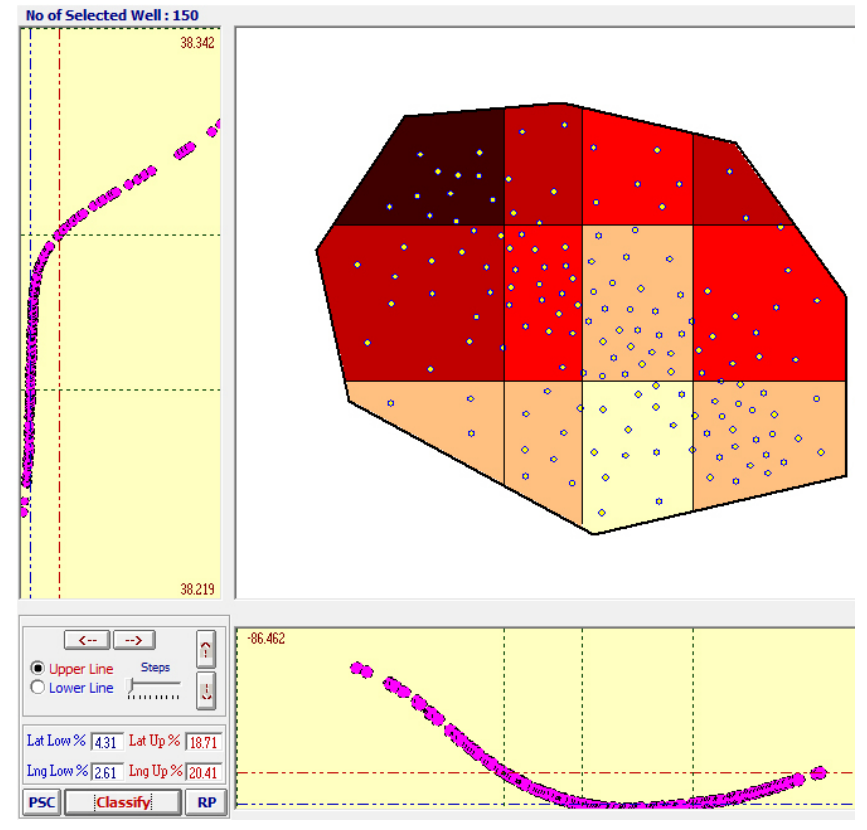

Figure 14. Pattern Recognition. 
Purple lines represent the patterns discovered by the FPR which are used to delineate the reservoir based on the studied parameter. Five RRQI provide average values of the studied parameter for the wells contained within that specific zone (See Figure 15).

\begin{tabular}{|c|c|c|c|c|}
\multirow{2}{*}{ Partition Type } & \multirow{2}{*}{ RRQI } & \multicolumn{3}{|c|}{ Production Rate as of [date]: 01/01/2016-0il } \\
\cline { 3 - 5 } & & Avg. Value & \# Wells & \% Wells \\
\hline High-High & 1 & 274.719 & 12 & 8 \\
\hline High-Mid & 2 & 218.998 & 24 & 16 \\
\hline High-Low \& Mid-Mid & 3 & 91.810 & 40 & 26.67 \\
\hline Mid-Low & 4 & 59.130 & 61 & 40.67 \\
\hline Low-Low & 5 & 16.517 & 13 & 8.67 \\
\hline & & & & \\
\hline Total Wells & & & 150 & 100 \\
\hline
\end{tabular}

Figure 15. Relative Reservoir Quality Indices.

In order to perform more detailed analysis of the parameters, the results from FPR can be plotted in a 3-Dimensional surface map (See Figure 16).

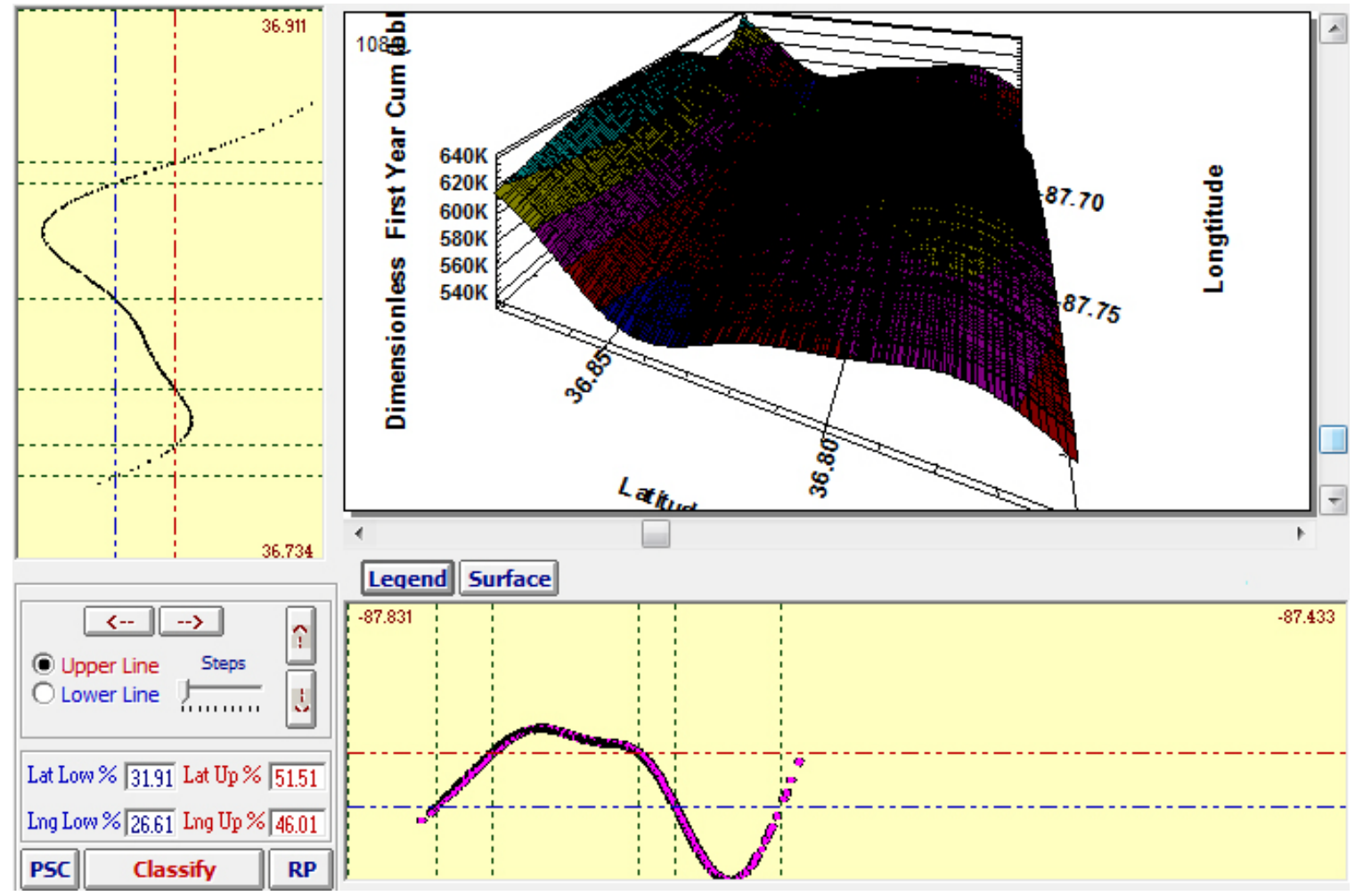

Figure 16. 3D Surface Plot. 


\subsubsection{Final Full Field Model (Time Successive - Predictive Model)}

After the preliminary model is generated, the next step is to apply the concept of time successive. Time successive uses static and dynamic data from two to five offset wells (closest in distance) to complete the required data for the well that is being analyzed. Figure 17 shows three different rings in which the closest wells can be selected. In this example the three red arrows point to the three closest offset wells to the wells that are being investigated.

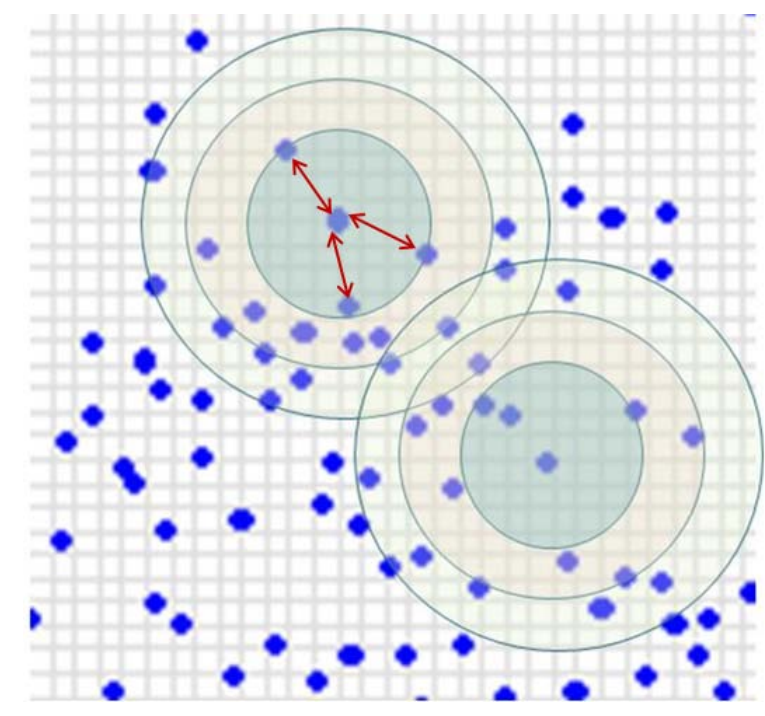

Figure 17. Offset Wells.

The data obtained from offset wells is:

- Well-based and grid-based information from the rock model (static, and spatial information)

- Results of production data analysis including actual monthly production data from the offset wells (temporal information)

- Results of preliminary modeling using fuzzy pattern recognition. 
Upon completion of the previous steps, the next step is to use Artificial Neural Networks to developed a predictive model. Figure 18 shows an example of the selection of the parameters that are used to predict the First Year Cumulative production:

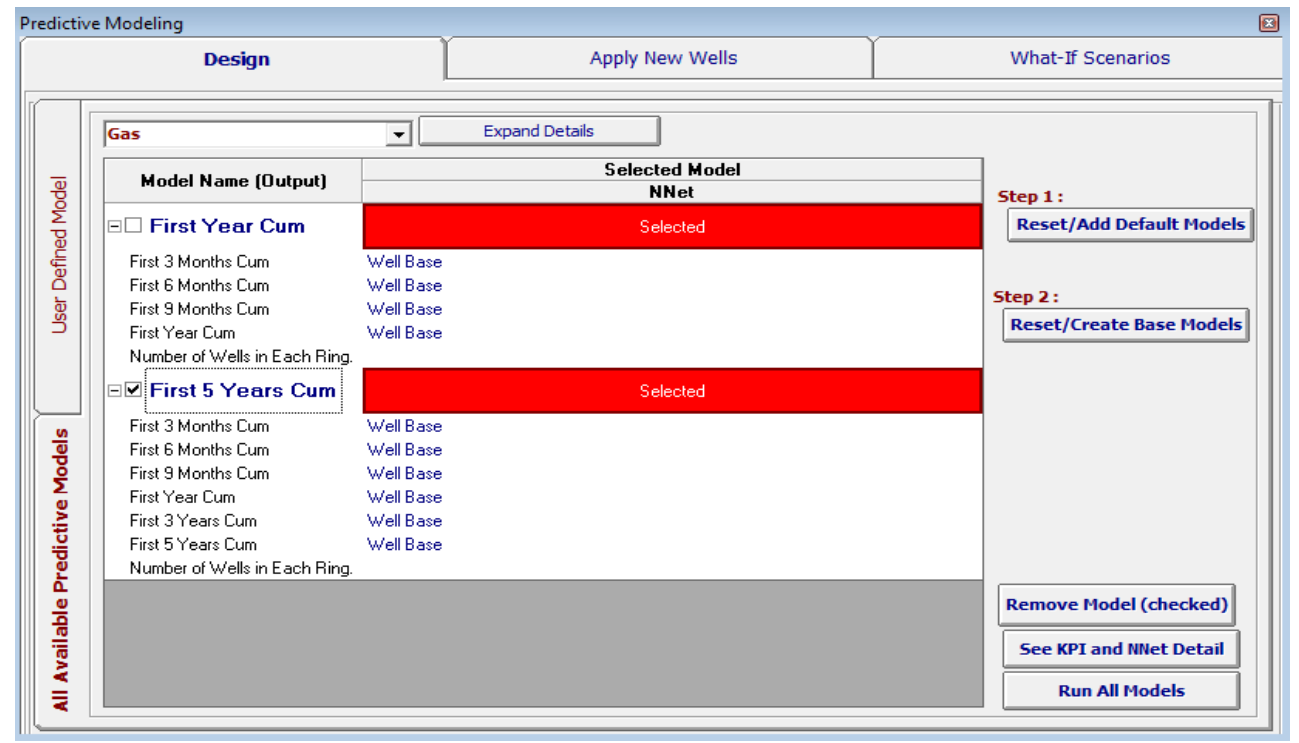

Figure 18. Predictive Modeling.

The predictive model is developed according to the specific requirements of the project. It must be trained, calibrated and verified. The following figures show an example of the process.
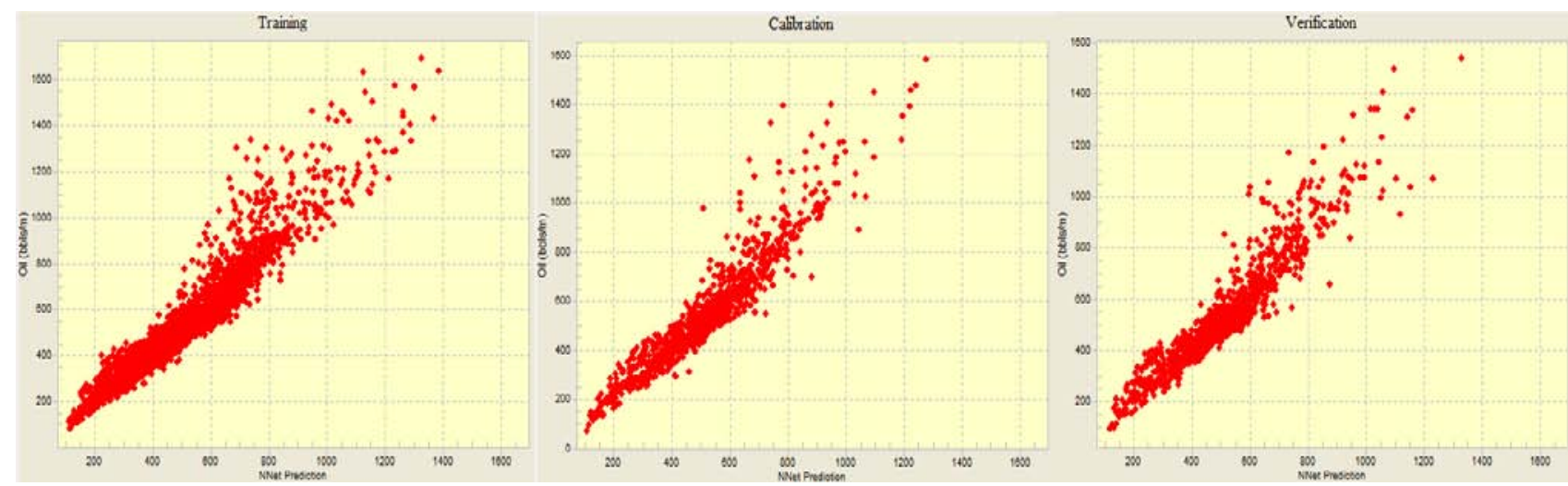

Figure 19. Neural Network Analysis. 
Subsequently the parameters and characteristics from the predictive model can be mapped for the entire field. Figure 20 shows an example of porosity mapping throughout the field:

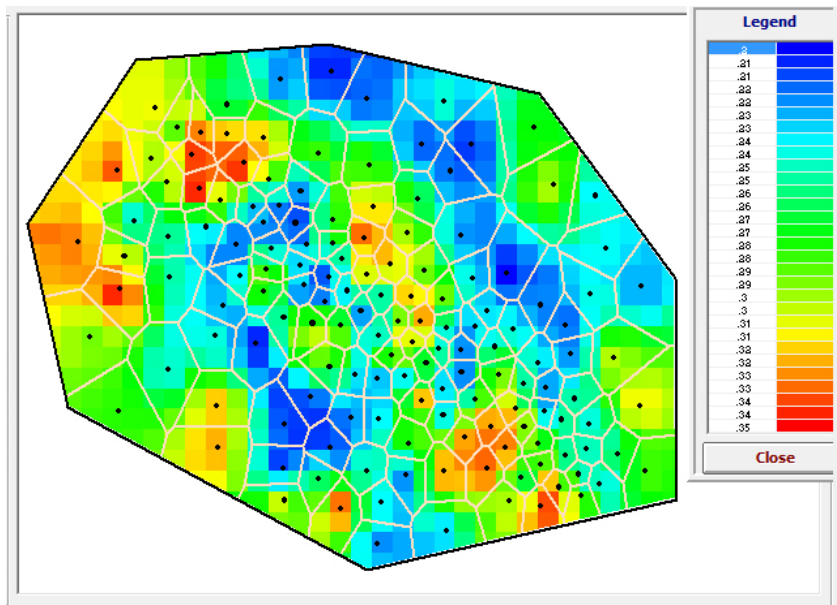

Figure 20. Porosity Map.

\subsubsection{Calibration/Validation of Preliminary \& Final Models}

In this part of the analysis few wells are randomly selected (suggestion is to select newly drilled wells) and removed from the model. The new model is run and the behavior of those removed wells are predicted and then compared to the behavior of the same wells in the initial model (including all the wells). As illustrated in Figure 21, some wells (left model) are removed and then compared with the initial model on the right.
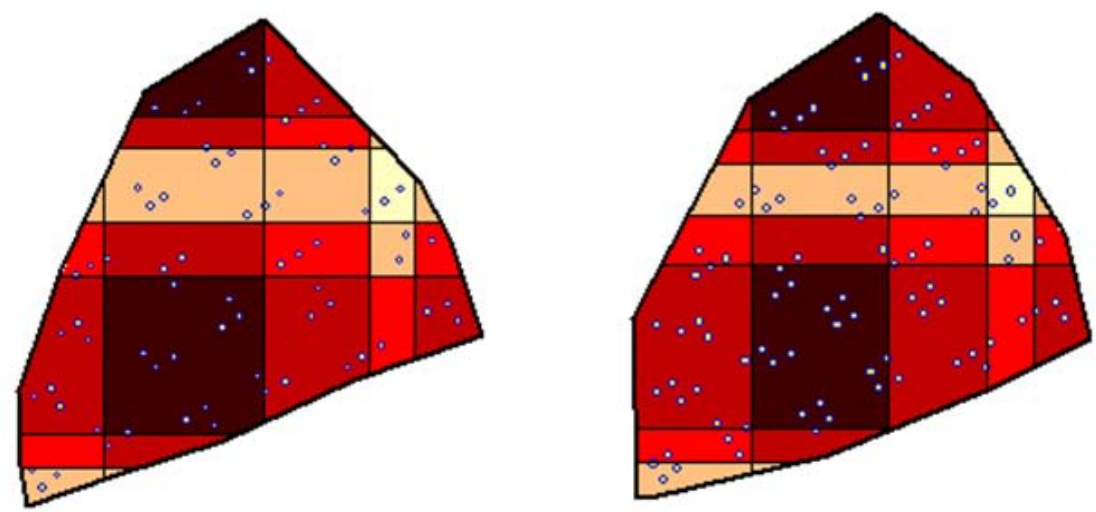

Figure 21. Calibration/Validation. 


\subsubsection{Field Development Strategies}

At this point different reservoir development strategies can be generated. These strategies can be visualized in different maps in order to identify the most appropriate area with the highest probability of success. As illustrated in Figure 22, several maps of different parameters and characteristics of the field are being compared according to the specific strategy of the project.
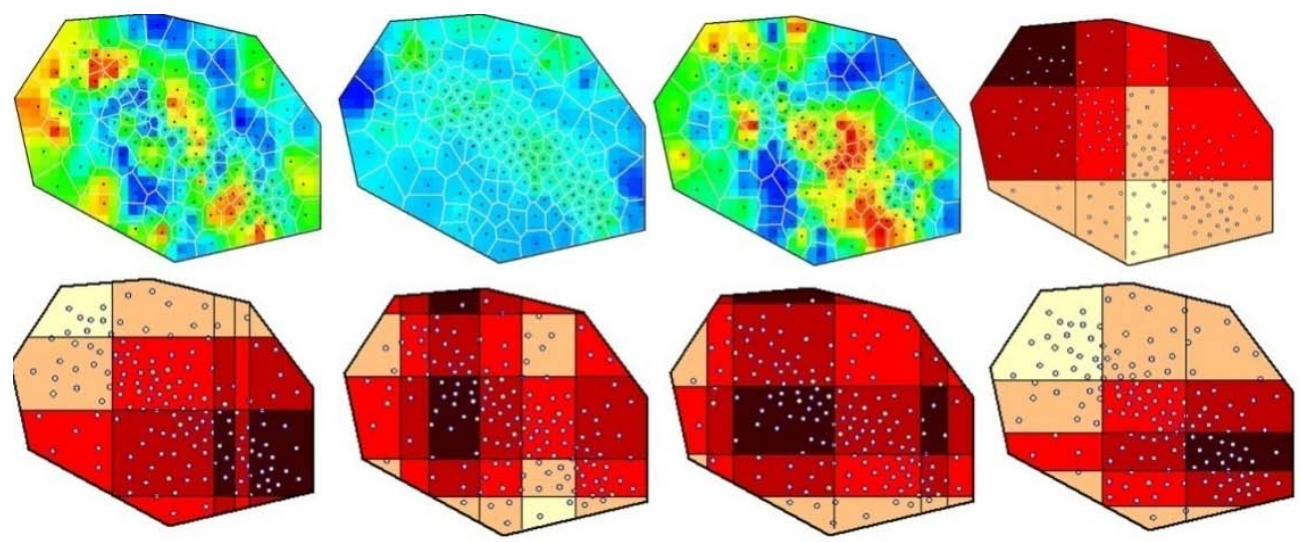

Figure 22. Different parameters of Reservoir Analysis.

After the strategy is established, for example new infill locations, the next step is to investigate its impact on the reservoir. As it is expected these new wells change the drainage area distribution within the field, which must be re-evaluated. Figure 23 shows this change in the drainage area, the figure on left shows the original reservoir (a), and the figure in the middle shows the three new wells and the new EUDA of the wells (b), and the figure on the right shows the final view of the reservoir (c). It should be mentioned that Top Down Modeling can be performed again with these new wells to observe the long term impact.
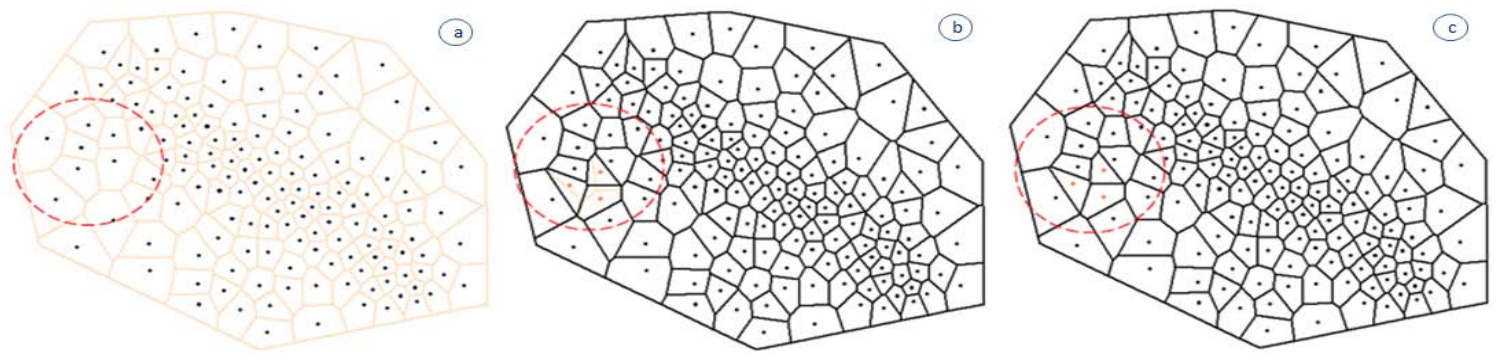

Figure 23. Drainage area changes of the Strategy for New Infill Locations. 


\section{Chapter III}

\section{Methodology}

The objective of this study is to investigate Top-Down, Intelligent Reservoir Modeling's capabilities when applied to oil reservoirs. In order to do that three reservoir models were built in a conventional numerical simulator. These models were produced for several years. The production rate and well log (porosity, thickness, and initial water saturation) data are extracted and used as inputs to the Top Down Modeling.

In each case an empirical full field model is developed and certain predictions are made according to the objectives of the specific model/study. The predictions from the Top Down Modeling are then compared to the reservoir simulation model results. A schematic diagram of this process is shown in the figure below.

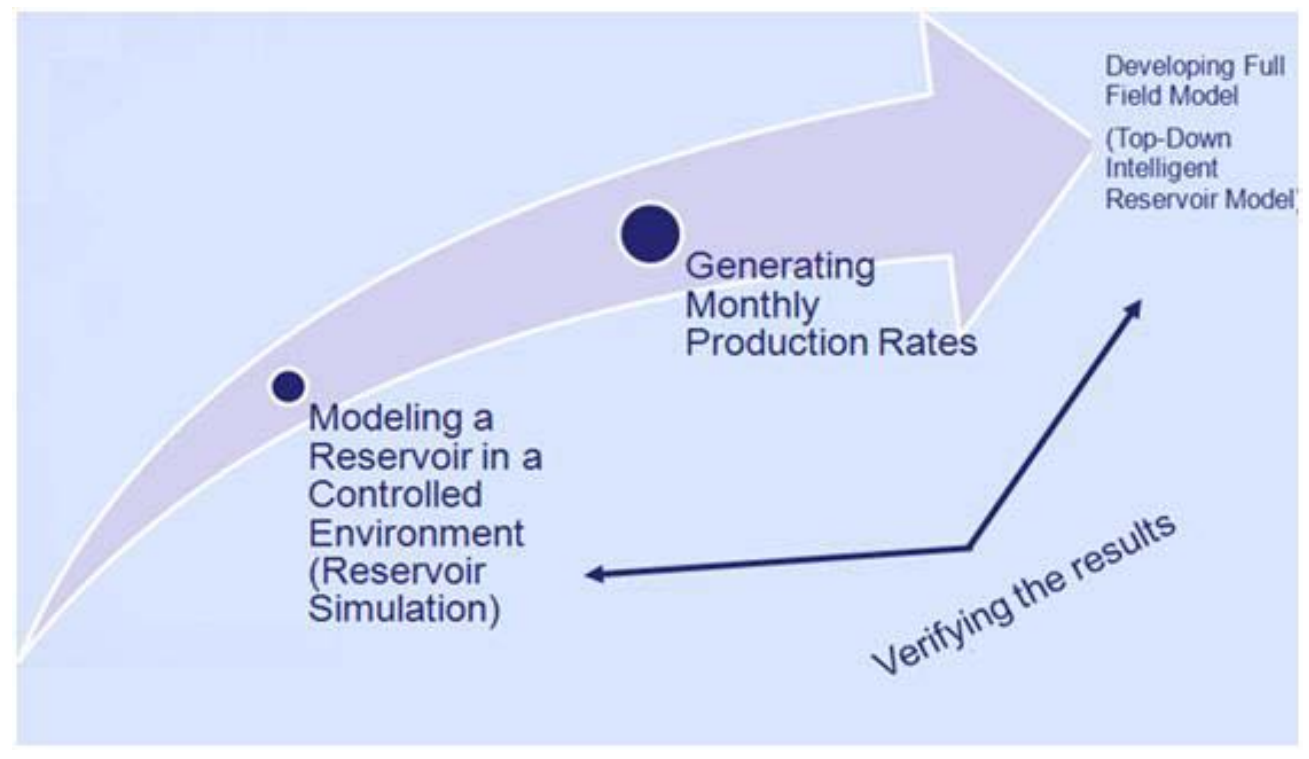

Figure 24. Flow-Chart of validation of Top-Down Intelligent Reservoir Modeling

The three models developed for this study have several features in common while differing in many other characteristics. For example all models are oil producing 
reservoirs with initial water and oil saturations of $35 \%$ and $65 \%$ respectively. The models were built with highly heterogeneous distribution for porosity, permeability, formation tops, and thickness in order to generate a complex distribution of reservoir characteristic. All wells in these models were vertical with $0.25 \mathrm{ft}$ open-hole completion, and they were producing with constant bottom-hole pressures.

Some activities that are performed during a Top Down Modeling analysis are common in all three models. The analysis includes well log data analysis, and production rate statistics. These statistics include 3, 6 and 9 months of cumulative productions as well as 1, 3, 5 and 10 years of cumulative productions. Conventional decline curve analysis is performed on all production rate data. Unconventional (intelligent) decline curve analysis is performed on data such as Gas Oil Ratio and Water Cut.

It is important to mention that each model had an independent objective which had been investigated and compared for both Top Down Modeling and the commercial reservoir simulator. In the following all three models will be explained in detail.

\section{Model \#1, Predicting Well Performance}

In this model the reservoir characteristics have been established with high diversity that makes it difficult to divide the field in different zones (High concentration of hydrocarbon to low hydrocarbon concentration). Permeability, porosity, formation tops and thickness distribution for the model is shown in appendix A.

The degree of heterogeneity that has been incorporated in this reservoir model can be observed in Table 2 and Figures 25 to 28. The model is black oil, the isotropicity is for $\mathrm{Kx}$ and $\mathrm{Ky}$, and the vertical permeability is considered as 0.1 of the horizontal permeability. The bottom hole pressure is 700 psi while the initial pressure of the reservoir is 2500 psi. 
Table 2. Characteristics of Model \#1.

\begin{tabular}{|lc|}
\hline \multicolumn{1}{|c|}{ Property } & Value \\
\hline Porosity (\%) & $20-35$ \\
\hline Permeability I and J (md) & $30-60$ \\
\hline Permeability k (md) & $3-6$ \\
\hline Thickness (ft) & $100-200$ \\
\hline Initial Reservoir Pressure (psi) & 2500 \\
\hline Bubble Point Pressure (psi) & 600 \\
\hline BHP (psi) & 700 \\
\hline Oil Saturation (\%) & 65 \\
\hline Water Saturation (\%) & 35 \\
\hline Depth (ft) & Top:2210 \\
\hline Total field size (acres) & Bottom:1190 \\
\hline
\end{tabular}

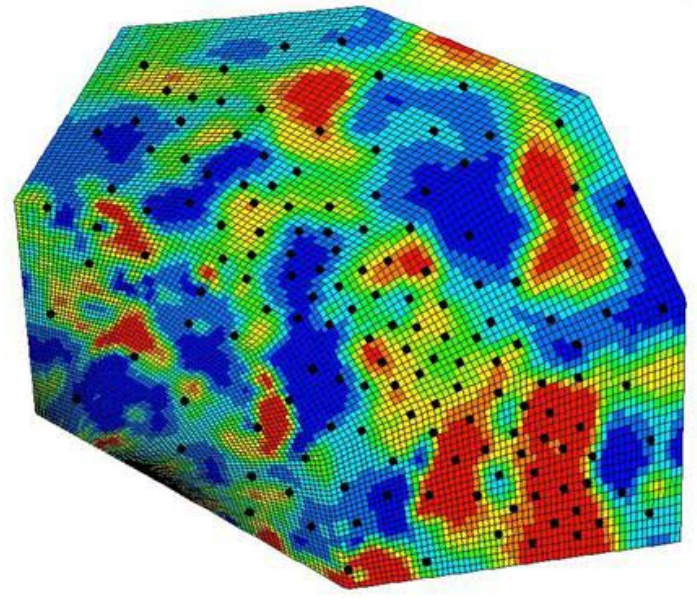

Figure 25. Heterogeneity of Model \#1.

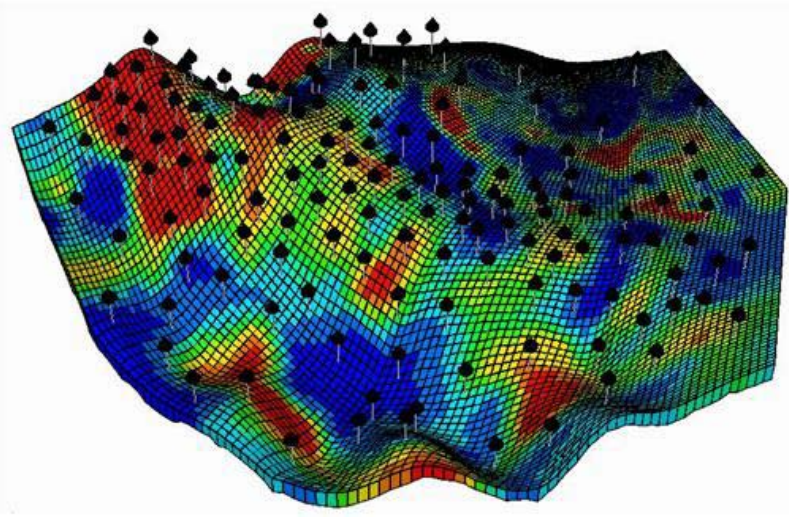

Figure 26. Well distribution of Model \#1.

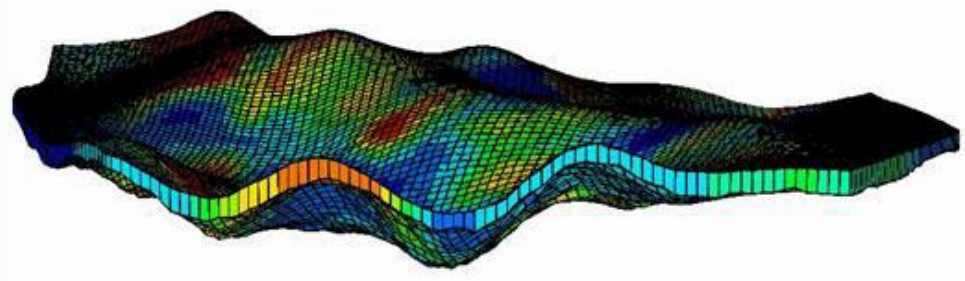

Figure 27. Horizontal view of Model \#1. 


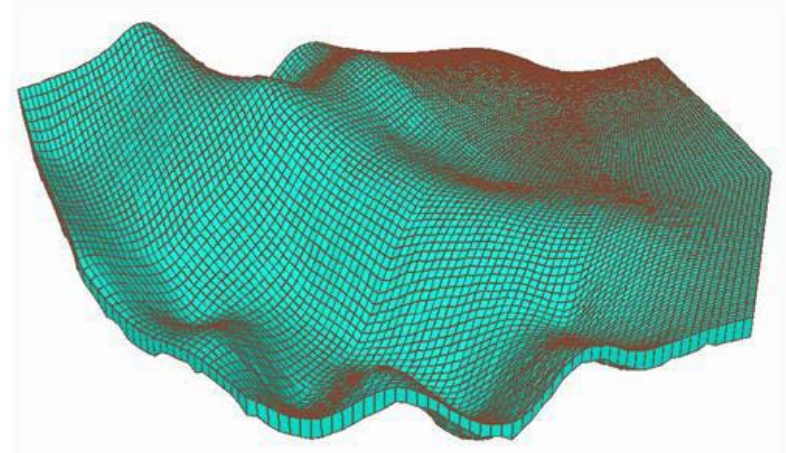

Figure 28. Reservoir Grid System of Model \#1.

In this model 150 wells were drilled in 10 groups. Table 3 summarizes this schedule.

Table 3. Drilling Schedule for 150 wells of Model \#1.

\begin{tabular}{|c|c|c|}
\hline Group & Wells & $\begin{array}{c}\text { Starting Operation } \\
\text { Date }\end{array}$ \\
\hline 1 & $\begin{array}{l}\text { Well-1001, Well-1002, Well-1003, Well-1004, Well-1005, Well-1006, } \\
\text { Well-1007, Well-1008, Well-1009, Well-1010, Well-1011, Well-1012, } \\
\text { Well-1013, Well-1014, Well-1015 }\end{array}$ & 01/01/2000 \\
\hline 2 & $\begin{array}{l}\text { Well-1016, Well-1017, Well-1018, Well-1019, Well-1020, Well-1021, } \\
\text { Well-1022, Well-1023, Well-1024, Well-1025, Well-1026, Well-1027, } \\
\text { Well-1028, Well-1029, Well-1030 }\end{array}$ & $05 / 15 / 2000$ \\
\hline 3 & $\begin{array}{l}\text { Well-1031, Well-1032, Well-1033, Well-1034, Well-1035, Well-1036, } \\
\text { Well-1037, Well-1038, Well-1039, Well-1040, Well-1041, Well-1042, } \\
\text { Well-1043, Well-1044, Well-1045 }\end{array}$ & $10 / 01 / 2000$ \\
\hline . & . & . \\
\hline . & . & . \\
\hline$\cdot$ & . & $\cdot$ \\
\hline 10 & $\begin{array}{l}\text { Well-1135, Well-1136, Well-1137, Well-1138, Well-1139, Well-1140, } \\
\text { Well-1141, Well-1142, Well-1143, Well-1144, Well-1145, Well-1146, } \\
\text { Well-1147, Well-1148, Well-1149, Well-1150 }\end{array}$ & 04/01/2005 \\
\hline
\end{tabular}




\section{Model \#2, Estimating Remaining Reserves}

The second model is used to investigate the capabilities of Top Down Modeling to estimate the remaining reserves, it is similar to the previous model as far as the range of the reservoir characteristics and the number of wells are concerned. There are two major differences between models 1 and 2. First, although the ranges of the reservoir characteristics are the same as shown in Table 4, the distribution of reservoir properties are quite different between the two models. These distribution are shown in Appendix B for Model \#2 which can be compared to that of the Model \#1.

The initial reservoir pressure in Model 2 is 4,500 psi, which is greater than the initial pressure of Model \#1. These changes were made in order to investigate the robustness of the Top Down Modeling when making predictions and also to evaluate its performance under different reservoir conditions.

Table 4. Characteristics of Model \#2.

\begin{tabular}{|lc|}
\hline \multicolumn{1}{|c|}{ Property } & Value \\
\hline Porosity (\%) & $15-30$ \\
\hline Permeability I and J (md) & $30-40$ \\
\hline Permeability k (md) & $3-4$ \\
\hline Thickness (ft) & $100-200$ \\
\hline Initial Reservoir Pressure (psi) & 4500 \\
\hline Bubble Point Pressure (psi) & 600 \\
\hline BHP (psi) & 700 \\
\hline Oil Saturation (\%) & 65 \\
\hline Water Saturation (\%) & 35 \\
\hline Depth (ft) & Top:2210 \\
\hline Total field size (acres) & Bottom:1190 \\
\hline
\end{tabular}




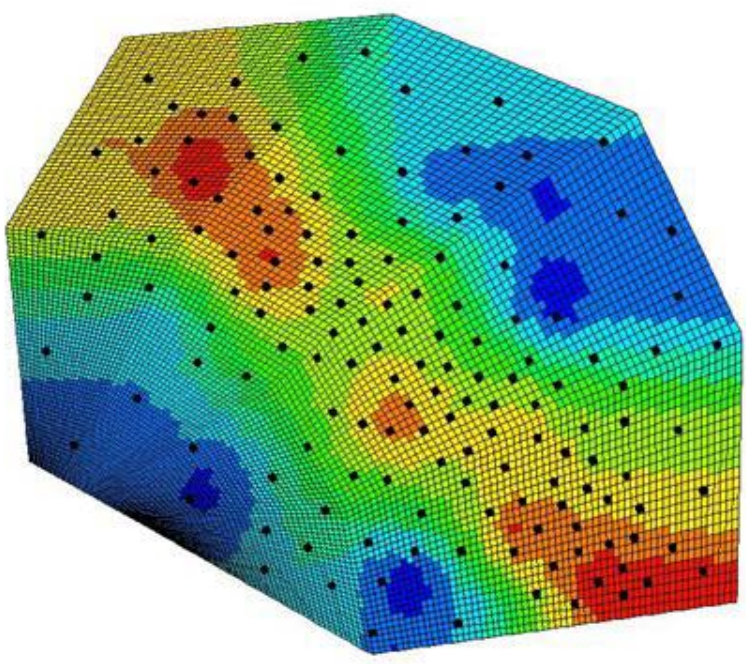

Figure 29. Heterogeneity of Model \#2.

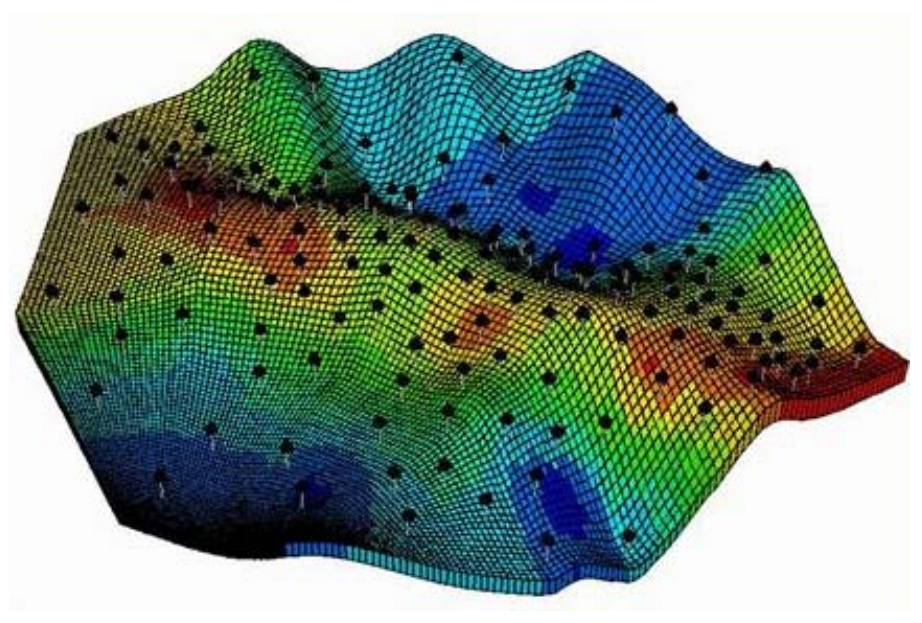

Figure 30. Well distribution of Model \#2.

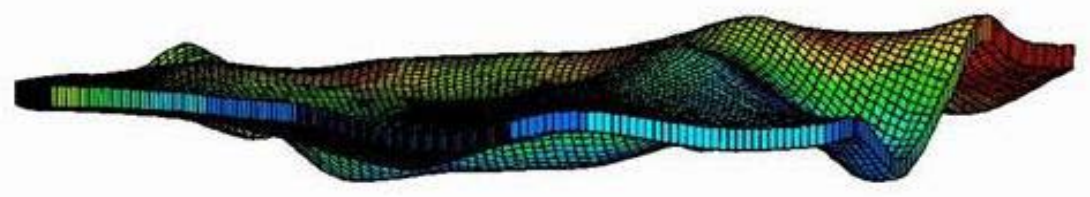

Figure 31. Horizontal View of Model \#2.

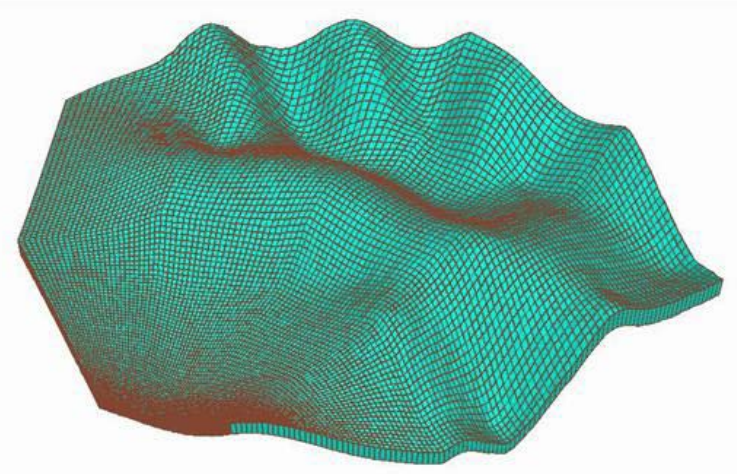

Figure 32. Grid System for 150 Wells. 
In this model 150 wells were drilled in 10 groups. Table 5 summarizes this schedule.

Table 5. Drilling Schedule for 150 wells of Model \#2.

\begin{tabular}{|c|c|c|}
\hline Group & Wells & $\begin{array}{l}\text { Starting } \\
\text { Operation Date }\end{array}$ \\
\hline 1 & $\begin{array}{l}\text { Well-1001, Well-1002, Well-1003, Well-1004, Well-1005, Well-1006, Well- } \\
\text { 1007, Well-1008, Well-1009, Well-1010, Well-1011, Well-1012, Well-1013, } \\
\text { Well-1014, Well-1015 }\end{array}$ & $1 / 1 / 2000$ \\
\hline 2 & $\begin{array}{l}\text { Well-1016, Well-1017, Well-1018, Well-1019, Well-1020, Well-1021, Well- } \\
\text { 1022, Well-1023, Well-1024, Well-1025, Well-1026, Well-1027, Well-1028, } \\
\text { Well-1029, Well-1030 }\end{array}$ & $5 / 1 / 2000$ \\
\hline 3 & $\begin{array}{l}\text { Well-1031, Well-1032, Well-1033, Well-1034, Well-1035, Well-1036, Well- } \\
\text { 1037, Well-1038, Well-1039, Well-1040, Well-1041, Well-1042, Well-1043, } \\
\text { Well-1044, Well-1045 }\end{array}$ & $10 / 1 / 2000$ \\
\hline$\cdot$ & $\cdot$ & $\cdot$ \\
\hline$\cdot$ & . & . \\
\hline$\cdot$ & $\cdot$ & . \\
\hline 10 & $\begin{array}{l}\text { Well-1135, Well-1136, Well-1137, Well-1138, Well-1139, Well-1140, Well- } \\
\text { 1141, Well-1142, Well-1143, Well-1144, Well-1145, Well-1146, Well-1147, } \\
\text { Well-1148, Well-1149, Well-1150 }\end{array}$ & $10 / 1 / 2005$ \\
\hline
\end{tabular}

\section{Model \#3, Identification of Gas Cap Development within the formation}

In the two previous models the reservoir was producing above the bubble point pressure. In this model, which is quite different from the previous two models, the reservoir is producing below the bubble point pressure in order to allow the formation of gas cap in the reservoir. The objective is to observe if Top Down Modeling analysis can help identifying the locations in the reservoir where the gas cap is formed. This task is accomplished through two sets of analyses. First, an "intelligent" decline curve analysis is performed (where negative decline in GOR as a function of time is modeled adaptively) and the predictions are made on each well's GOR based on the negative decline analysis. Second, Fuzzy Pattern Recognition is used to identify the patterns in the reservoir where GOR may propagate based on the production pattern of the wells. 
Ranges of the reservoir characteristics used in this model are shown in Table 6. The reservoir properties distribution for this model (Model \#3) is shown in Appendix C and can be compared to that of models 1 and 2. Initial reservoir pressure in this model is 2,500 psi while the bottom hole pressure for the wells producing from this reservoir is kept at 300 psi. Furthermore, the bubble point is set at 1000 psi.

Table 6. Characteristics of Model \#3.

\begin{tabular}{|lc|}
\hline \multicolumn{1}{|c|}{ Property } & Value \\
\hline Porosity (\%) & $25-35$ \\
\hline Permeability I and J (md) & $30-60$ \\
\hline Permeability k (md) & $3-6$ \\
\hline Thickness (ft) & $35-200$ \\
\hline Initial Reservoir Pressure (psi) & 2500 \\
\hline Bubble Point Pressure (psi) & 1000 \\
\hline BHP (psi) & 300 \\
\hline Oil Saturation (\%) & 65 \\
\hline Water Saturation (\%) & 35 \\
\hline Depth (ft) & Top:3156 \\
\hline Total field size (acres) & Bottom:1265 \\
\hline
\end{tabular}

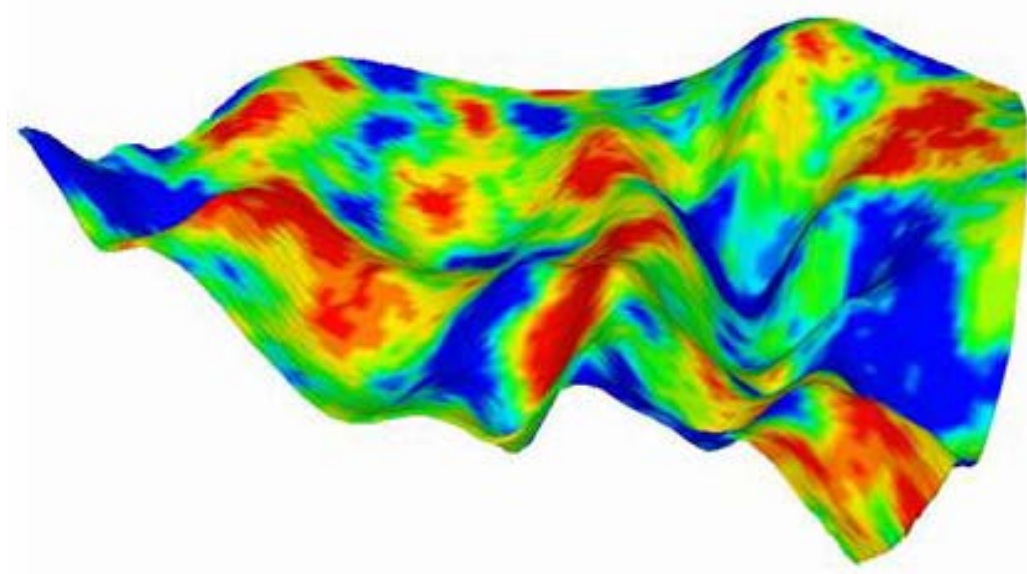

Figure 33. Heterogeneity of Model \#3. 


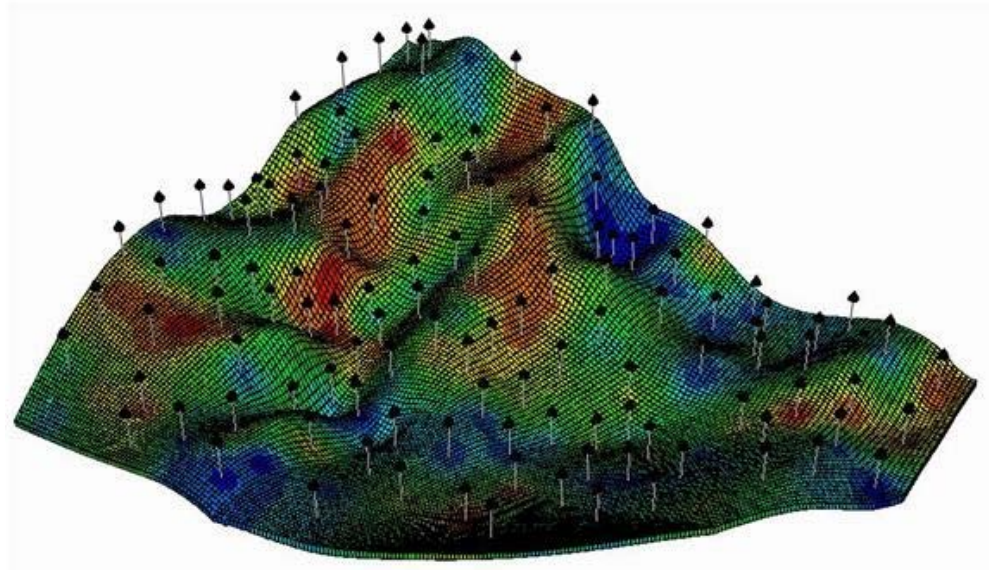

Figure 34. Well Distribution of Model \#3.

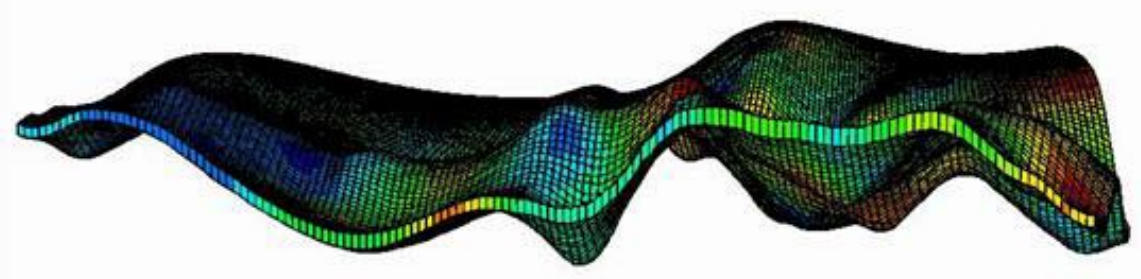

Figure 35. Horizontal View of Model \#3.

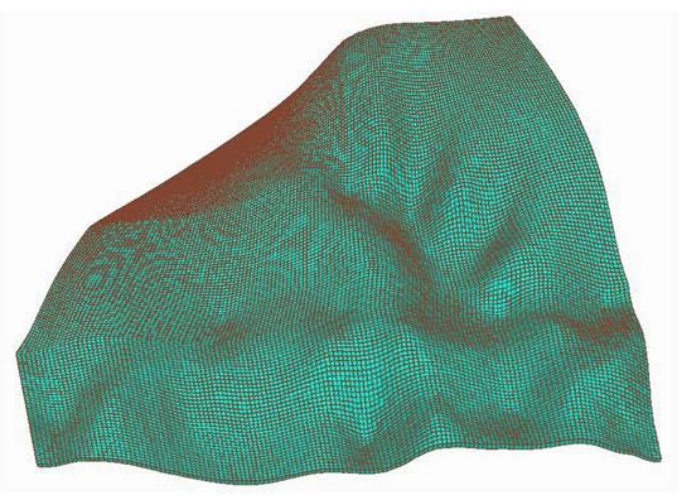

Figure 36. Grid System for 345 Wells. 
In this model 150 wells were drilled in groups of 23. Table 7 summarizes this schedule.

Table 7. Drilling Schedule for 345 wells of of Model \#3.

\begin{tabular}{|c|c|c|}
\hline Group & Wells & $\begin{array}{l}\text { Starting } \\
\text { Operation Date }\end{array}$ \\
\hline 1 & $\begin{array}{l}\text { Well-1001, Well-1002, Well-1003, Well-1004, Well-1005, Well-1006, Well- } \\
\text { 1007, Well-1008, Well-1009, Well-1010, Well-1011, Well-1012, Well-1013, } \\
\text { Well-1014, Well-1015 }\end{array}$ & $1 / 1 / 2000$ \\
\hline 2 & $\begin{array}{l}\text { Well-1016, Well-1017, Well-1018, Well-1019, Well-1020, Well-1021, Well- } \\
\text { 1022, Well-1023, Well-1024, Well-1025, Well-1026, Well-1027, Well-1028, } \\
\text { Well-1029, Well-1030 }\end{array}$ & $5 / 1 / 2000$ \\
\hline 3 & $\begin{array}{l}\text { Well-1031, Well-1032, Well-1033, Well-1034, Well-1035, Well-1036, Well- } \\
\text { 1037, Well-1038, Well-1039, Well-1040, Well-1041, Well-1042, Well-1043, } \\
\text { Well-1044, Well-1045 }\end{array}$ & $9 / 1 / 2000$ \\
\hline . & . & . \\
\hline . & . & . \\
\hline . & . & . \\
\hline 23 & $\begin{array}{l}\text { Well-1330 Well-1331 Well-1332 Well-1333 Well-1334 Well-1335 Well-1336 } \\
\text { Well-1337 Well-1338 Well-1339 Well-1340 Well-1341 Well-1342 Well-1343 } \\
\text { Well-1344 Well-1345 }\end{array}$ & $4 / 1 / 2007$ \\
\hline
\end{tabular}

It is important to note that Top-Down Intelligent Reservoir Modeling analyses are qualitative in nature and should only be used as trend and pattern identifiers. The quantities represented in these analyses may not necessarily be accurate or represent specific physical meaning. 


\section{Chapter IV}

\section{Results and Discussion}

The production profiles and well logs (not for all wells) were prepared from reservoir simulator in order to make three different reservoir configurations in TopDown, Intelligent Reservoir Modeling.

\section{Model \#1, Predicting Well Performance}

This model will prove that the Top Down Modeling is capable of characterizing an oil reservoir and forecasting the oil rate production. The model contains a total of 150 irregularly spaced wells which were drilled and produced for 10 years in this field. The well locations were imported, and the by boundary and Voroni grids for all the wells were identified. This was described previously in the methodology.

Once the individual grids are identified, The geostatistical tools are used to obtain a preliminary model (See figures below). Finally, the Initial Oil in Place (IOIP), can be calculated for each well.

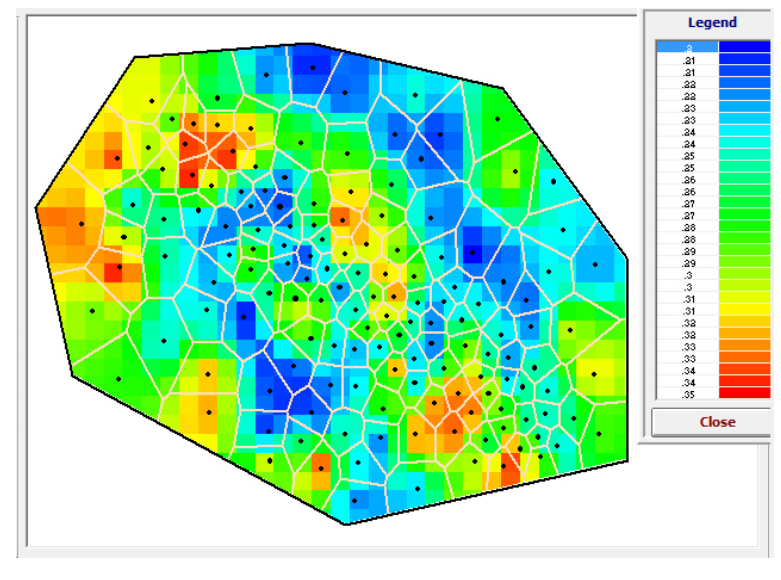

Figure 37. Porosity of Model \#1.

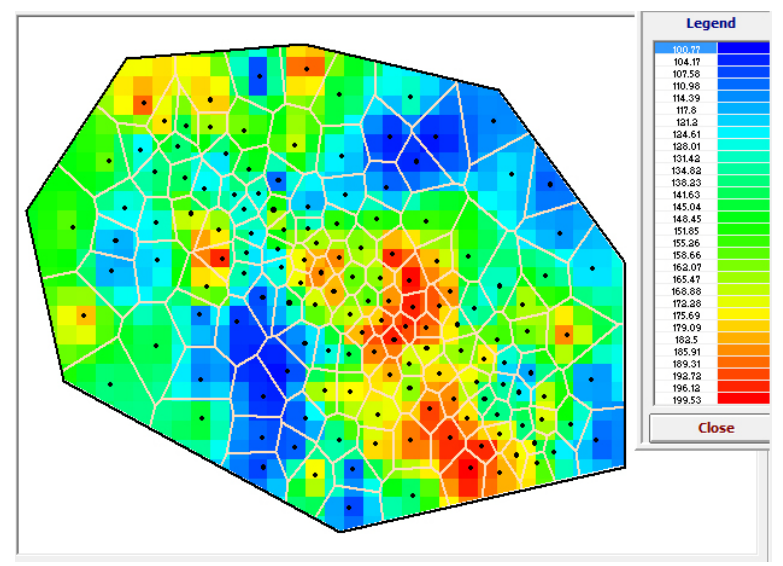

Figure 38. Thickness of Model \#1. 


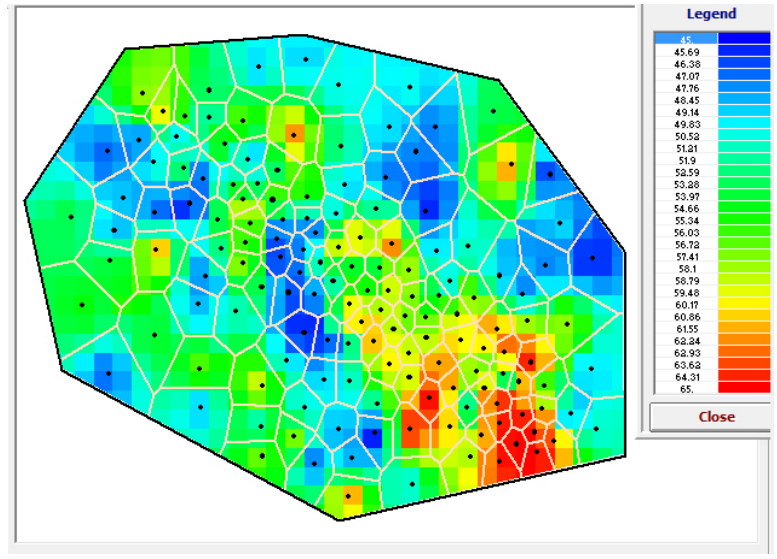

Figure 39. Permeability of Model \#1.

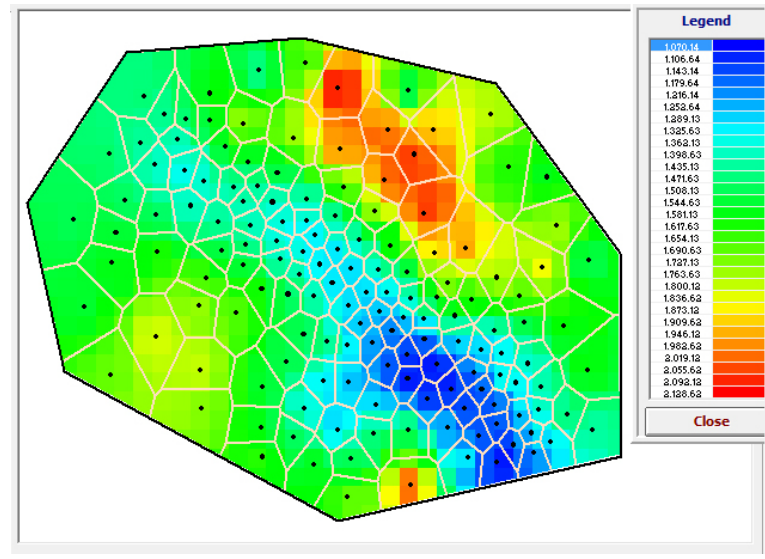

Figure 40. Top Map of Model \#1.
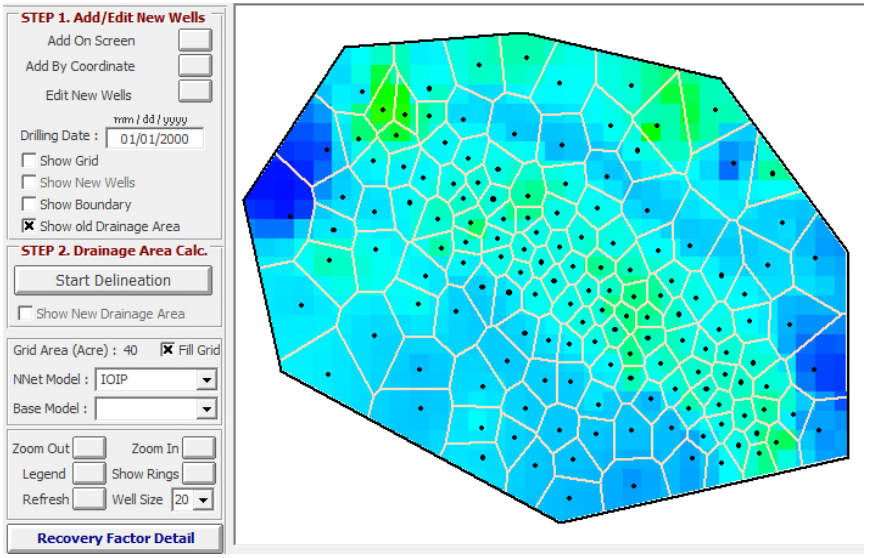

Figure 41. Initial Oil in Place (IOIP) of Model \#1.
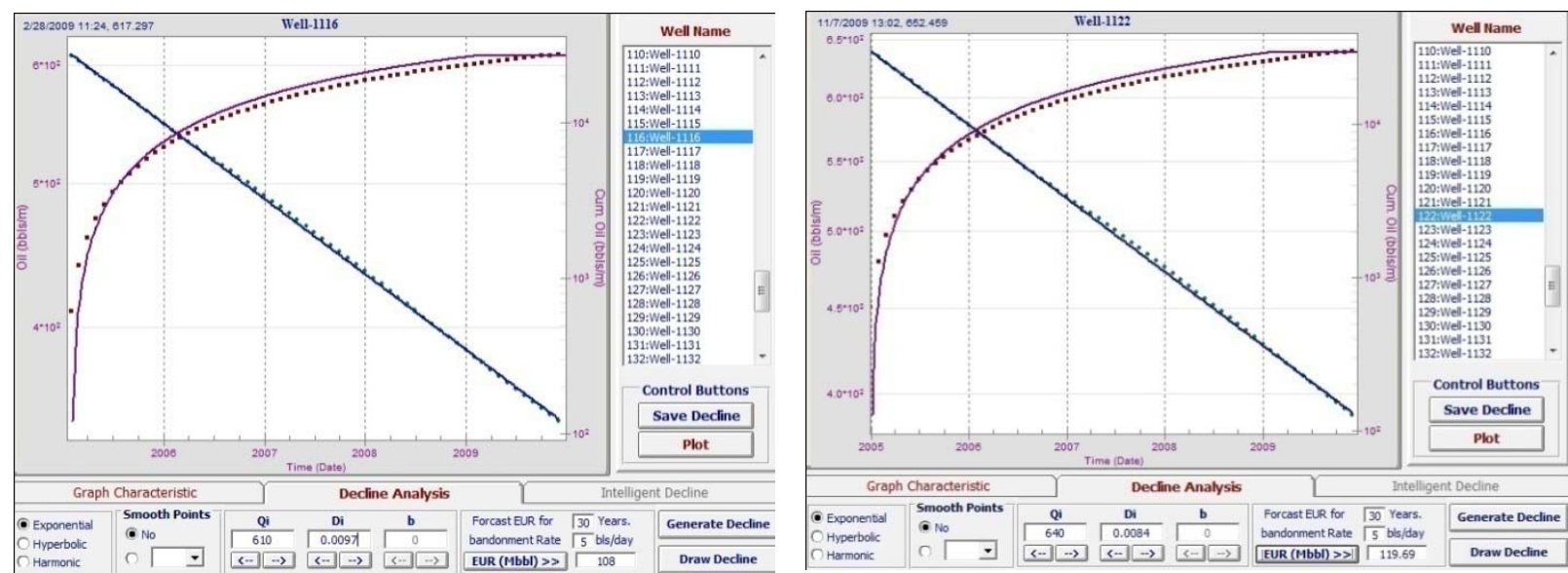

Figure 42. Decline Curve Analysis of Model \#1. 
After that, the best decline curve is identified for all individual wells. The parameters obtained from this analysis are: initial flow rate (Qi), initial decline rate (Di), and 30 Year EUR. Figure 42 shows two examples of this analysis.

Using the results of Decline Curve analysis and Volumetric Reserve Estimation, the Recovery Factor is calculated for all wells. An example can be seen in Figure 43.

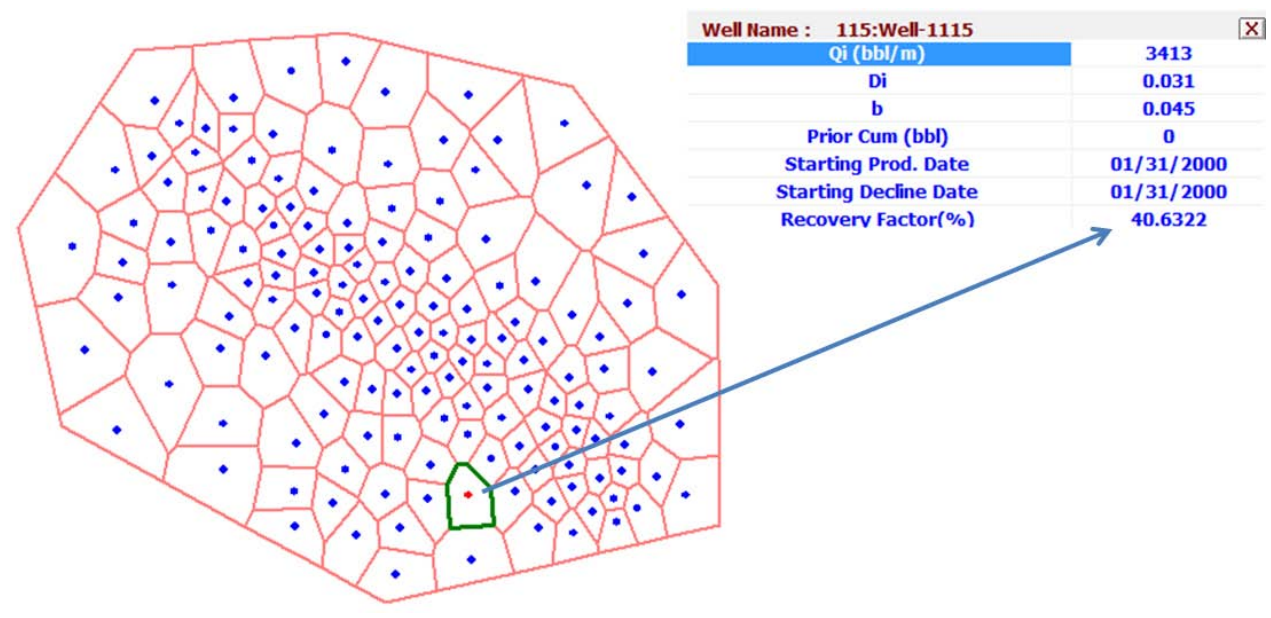

Figure 43. Recovery Factor of Well 115.

To this point, an enormous amount of data has been collected. These data were managed using Artificial Intelligent \& Data Mining through which some patterns of fluid flow and reservoir parameters were identified. In order to validate this analysis 15 wells out of 150 were randomly chosen and removed from the analysis to be used as blind verification wells.

The objective is to build a Top Down Modeling from the the remaining 135 wells and then use the model to predict the production from those 15 wells used as blind verification wells. Another important point to highlight in this study is that these 15 wells capture the interference of fluid flow between all existing wells. Figure 44 shows the location of these 15 wells. 


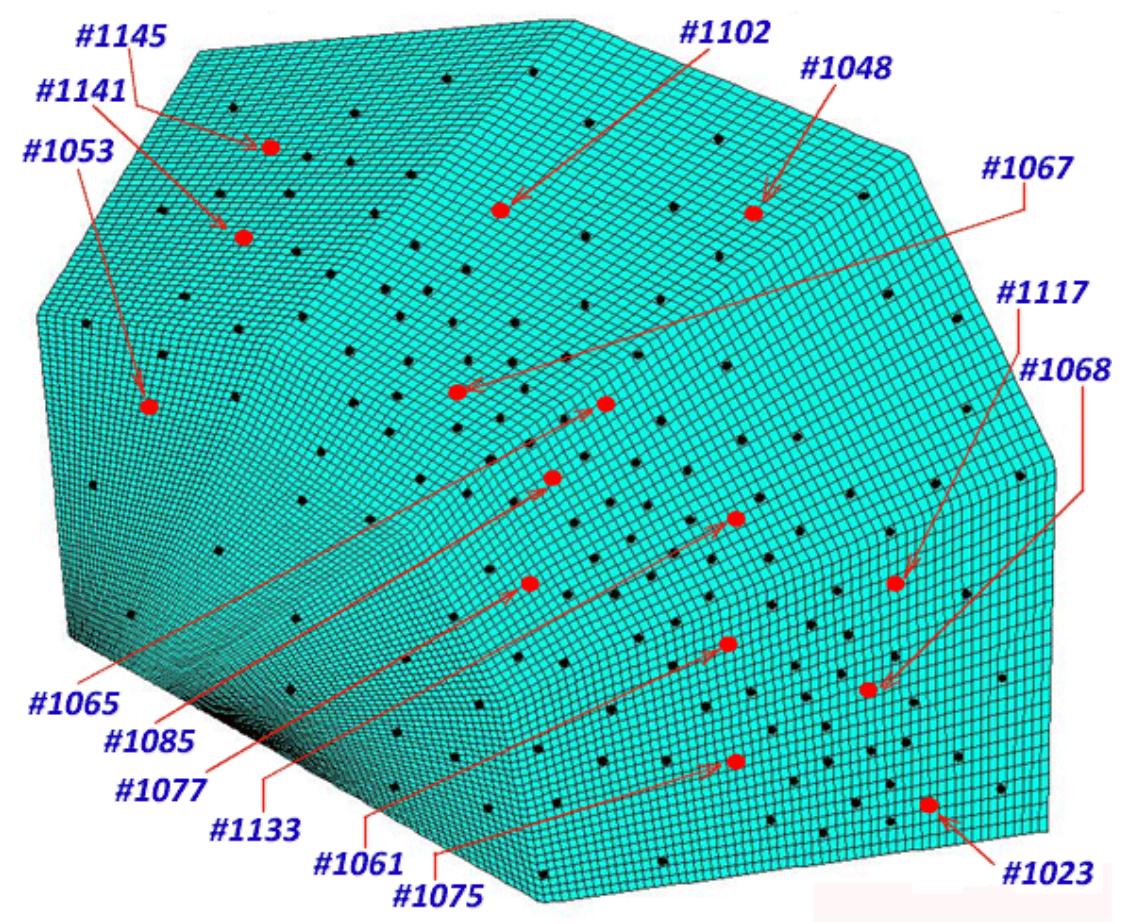

Figure 44. Wells used as blind test in this study for verification (red dots).

The comparative results of four out of the 15 blind-verification wells are presented in Figure 45. The results shown in this figure are typical of the 15 wells. In this figure cumulative production is plotted against time. The blue continuous profile is the cumulative production from each well generated by commercial simulator and the red dots are the predictions made for these wells by Top Down Modeling at 3, 6, 9, 12, and 60 months of production. In almost all cases the predictions made by Top Down Modeling are accurate. 


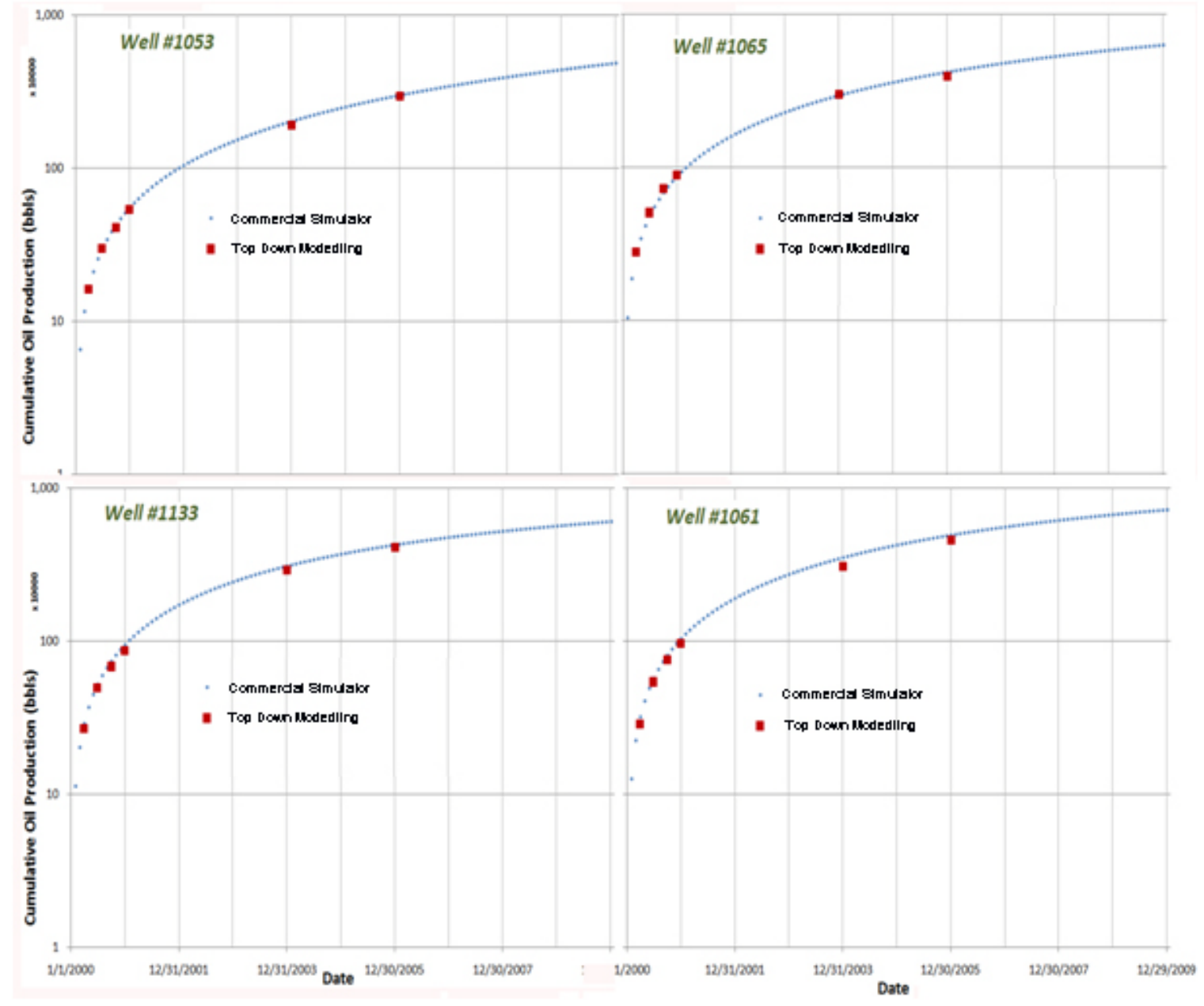

Figure 45. Top Down Modeling predictions versus the actual (modeled) production profile.

To better evaluate the accuracy of Top Down Modeling predictions, some statistical analysis have been performed on production predicted through this technique. Figure 46 provides the histogram of the error in production prediction. This figure shows that the range of Top Down Modeling production prediction error is between $-17 \%$ and $+14 \%$. Furthermore, the statistical analysis of the error shows that about $75 \%$ of the predictions made by Top Down Modeling is within $\pm 10 \%$ of the actual values and $36 \%$ of the predictions are within $\pm 5 \%$ of the productions from the reservoir simulator. 


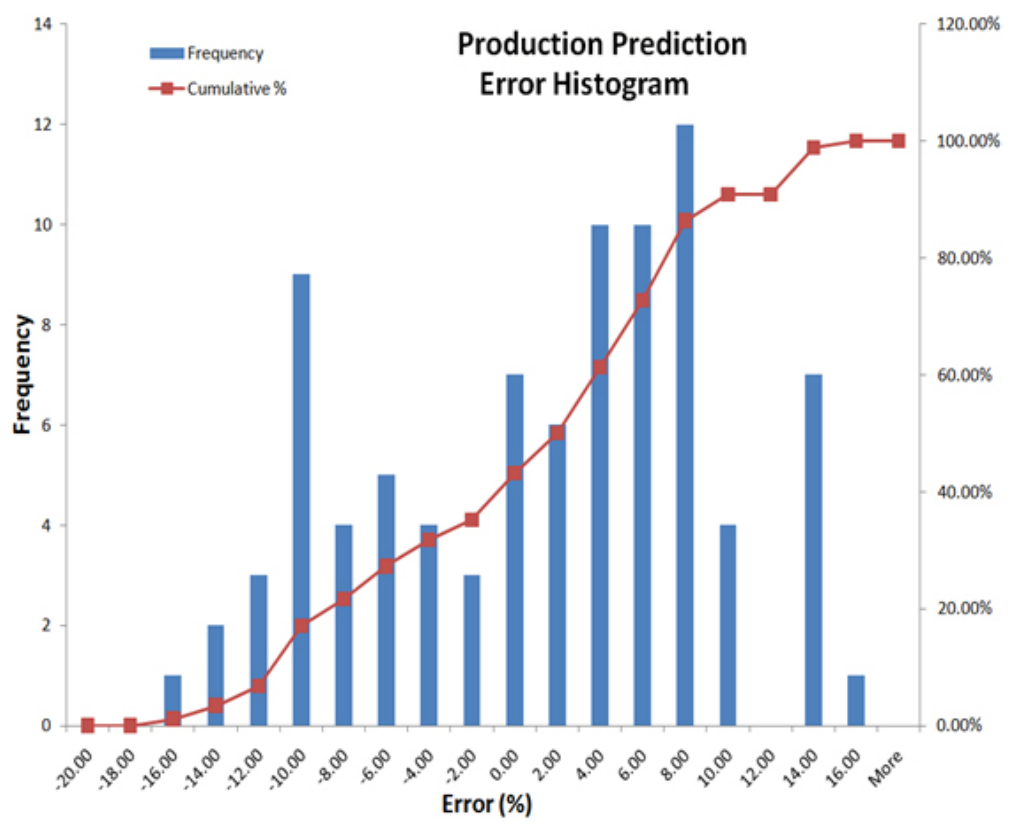

Figure 46. Error statistics for Top Down Modeling production prediction.

Based on the results of calibration and validation of the models, the oil production rate for next five and ten years can be estimated with high accuracy (See figures 47 and 48). The figures illustrate that Top Down Modeling can forecast the premium zone of oil production (dark zone). Also, the values of the RRQI (shown on the right side of the figures) are decreased during the time, which is expected to happen, and this demonstrates that this technique can keep track of the fluid flow during the time.

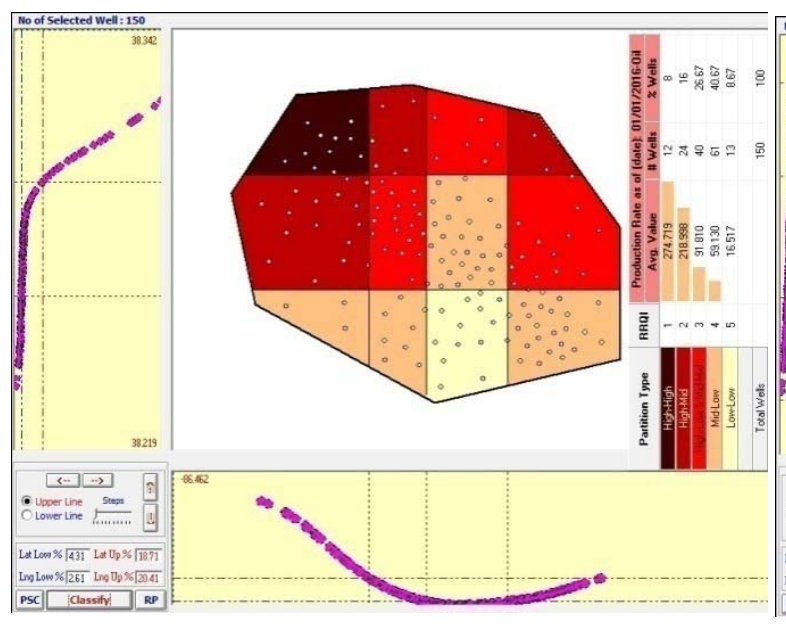

Figure 47. RRQI of Oil Production, by next five years.

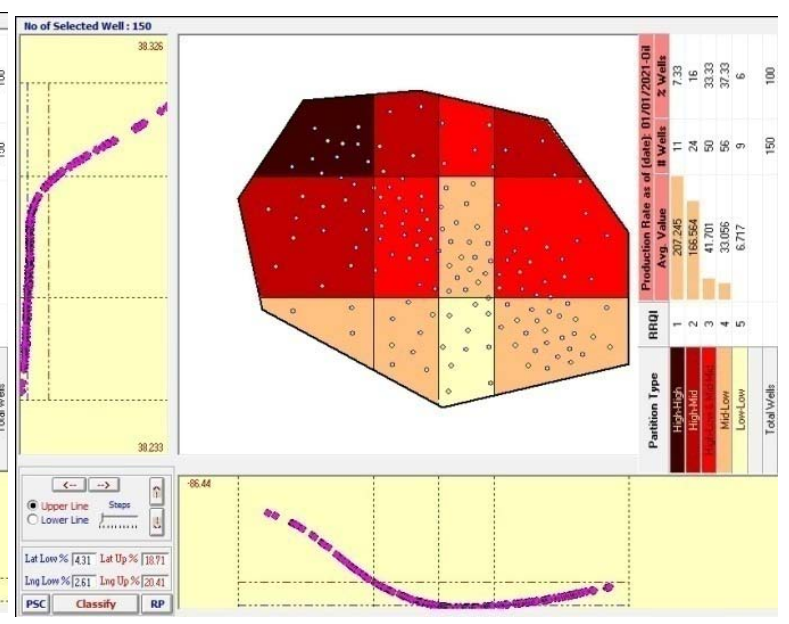

Figure 48. RRQI of Oil Production, by next ten years. 


\section{Model \#2, Estimation of Remaining Reserves}

In second model it will be proven that Top Down Modeling is capable of characterizing an oil reservoir and forecasting the remaining reserve. Analysis similar to the previous model has been detailed. The model contains a total of 150 irregularly spaced wells which were drilled and produced for 8 years in this field. This was described previously in the methodology.

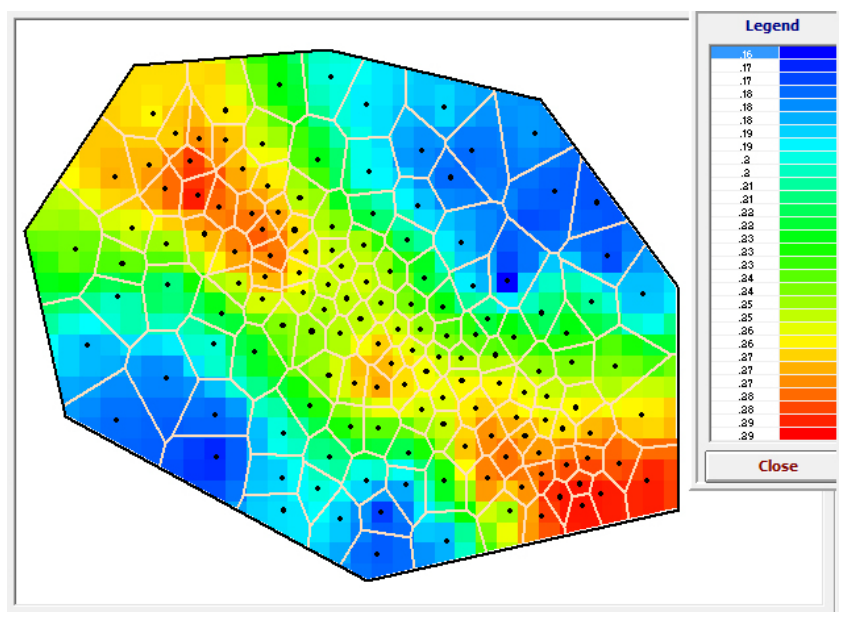

Figure 49. Porosity of Model \#2.

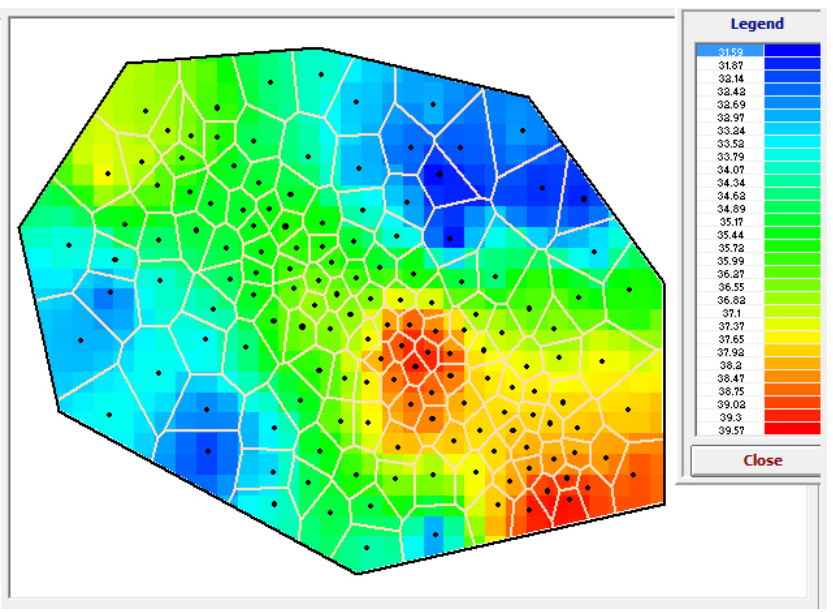

Figure 51. Permeability of Model \#2.

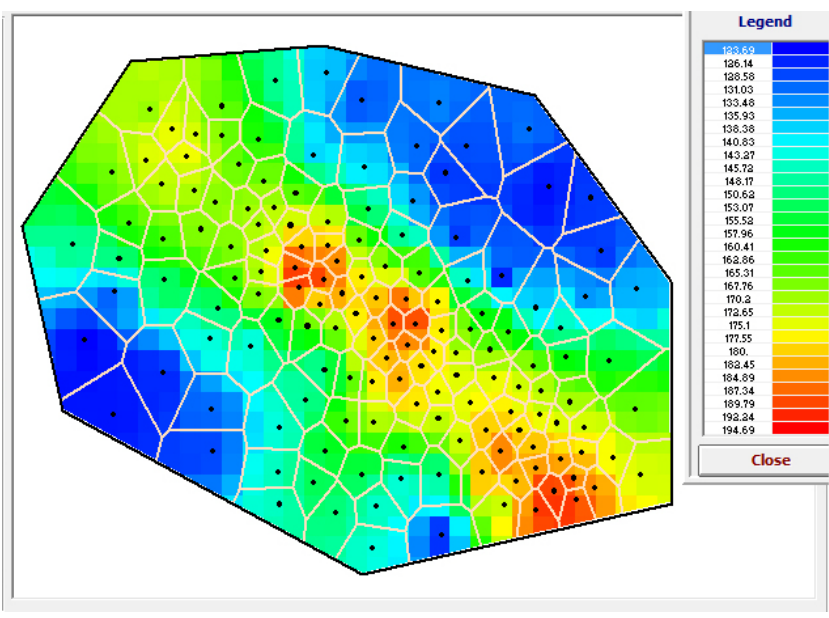

Figure 50. Thickness of Model \#2.

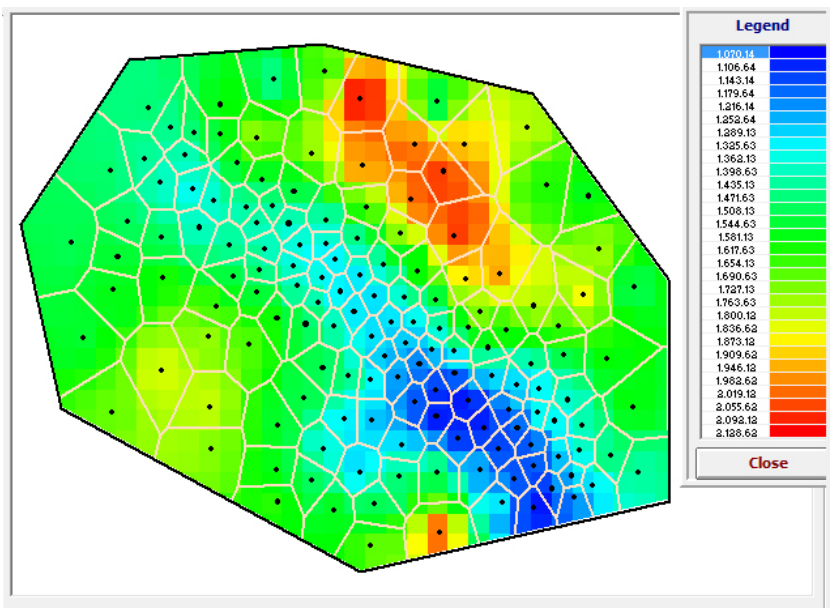

Figure 52. Top map of Model \#2. 


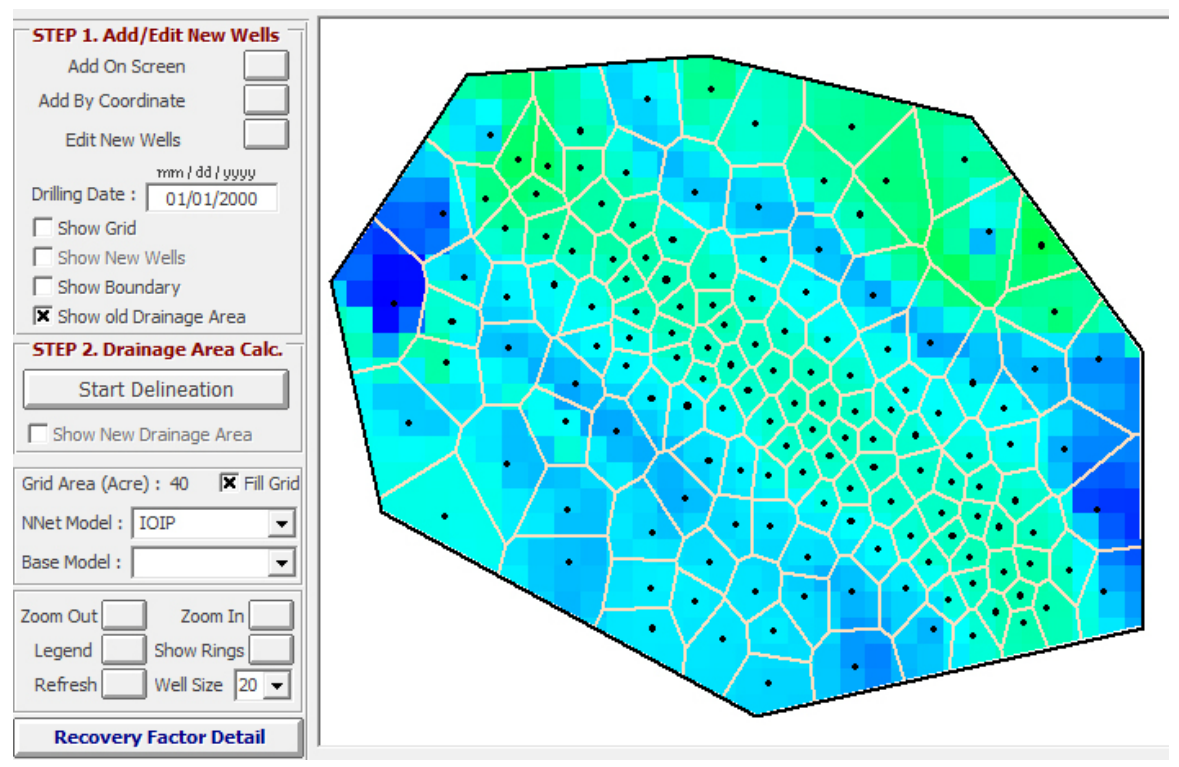

Figure 53. Initial Oil in Place of Model \#2.

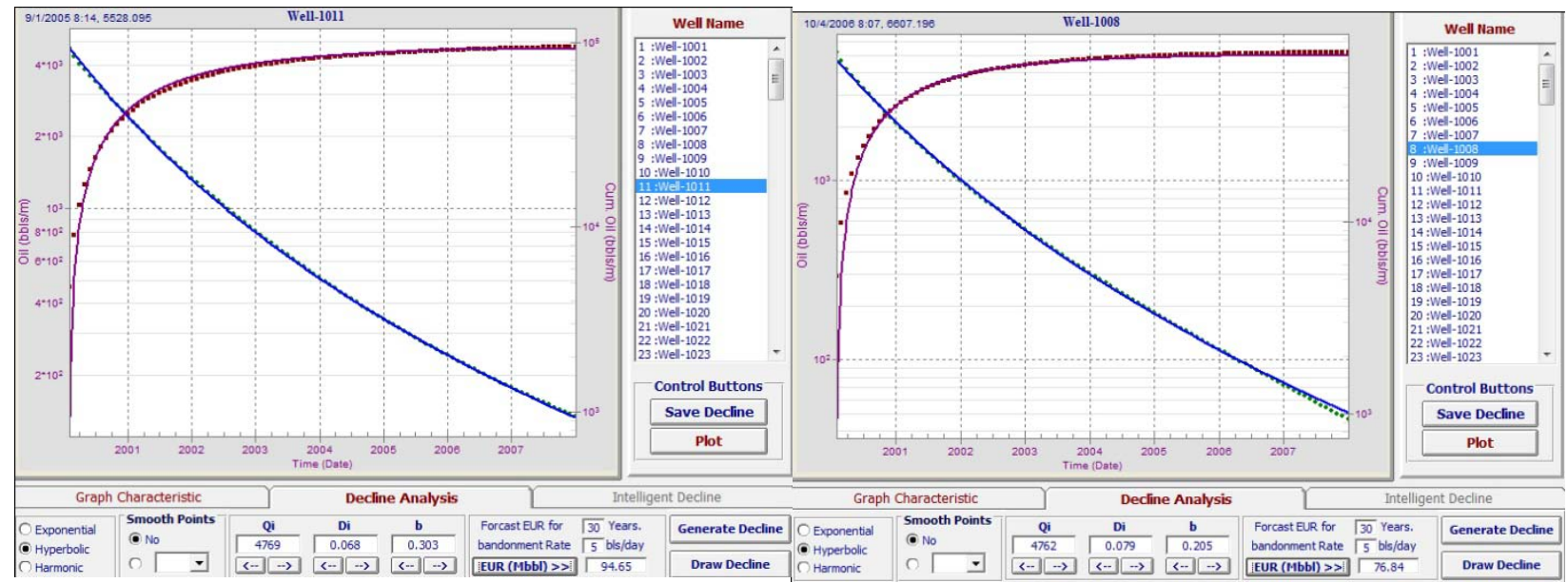

Figure 54. Decline Curve Analysis of Model \#2. 


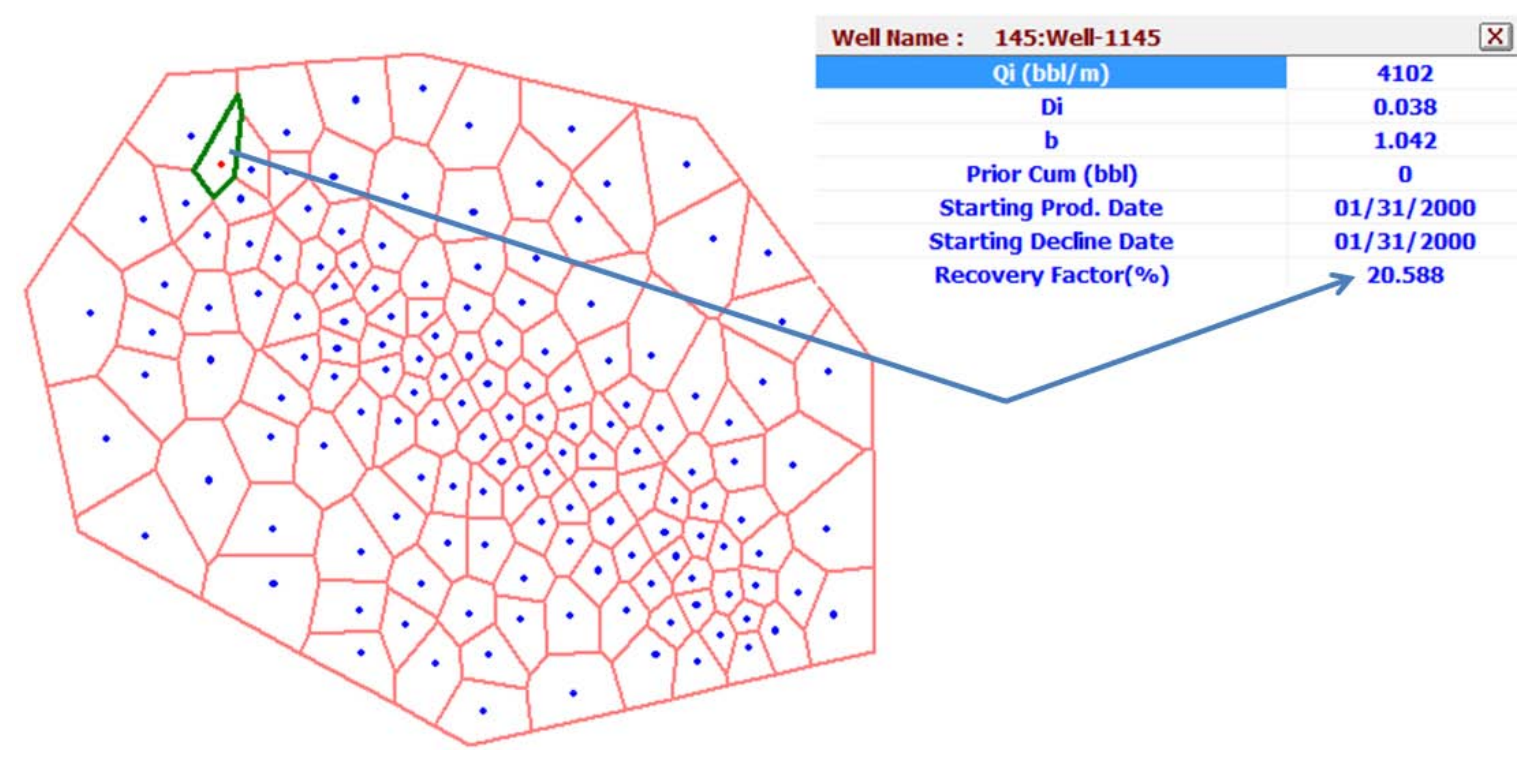

Figure 55. Recovery Factor of Well 145.

In order to investigate the validity of the remaining reserve distribution predicted by Top Down Modeling, similar maps needed to be generated in the reservoir simulator for comparison purposes (See Figure 56 to 58). Since the remaining reserve is not amongst the reservoir simulator available parameters, another parameter should be chosen which can be used as an indicator for remaining reserve. Therefore, it was decided to use pressure distribution.

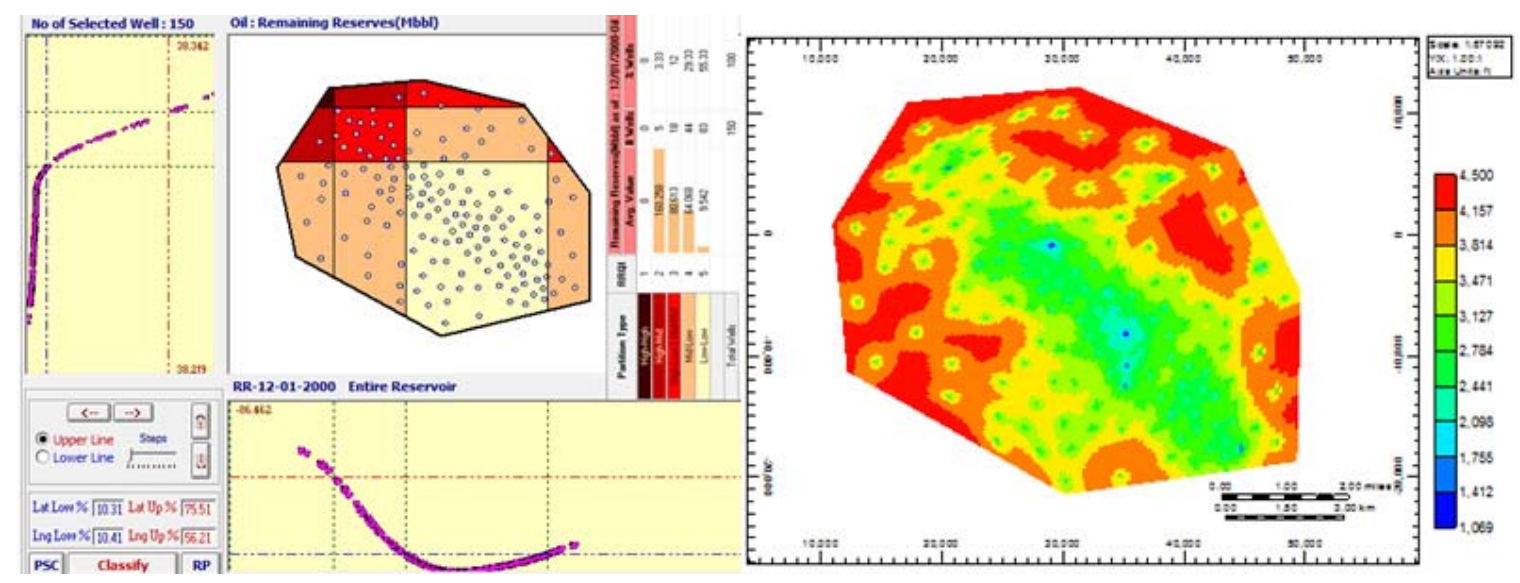

Figure 56. Map of remaining reserves from Top Down Modeling (left) compared to reservoir pressure distribution generated by the commercial simulator (right), both after one year of production by the 150 wells. 


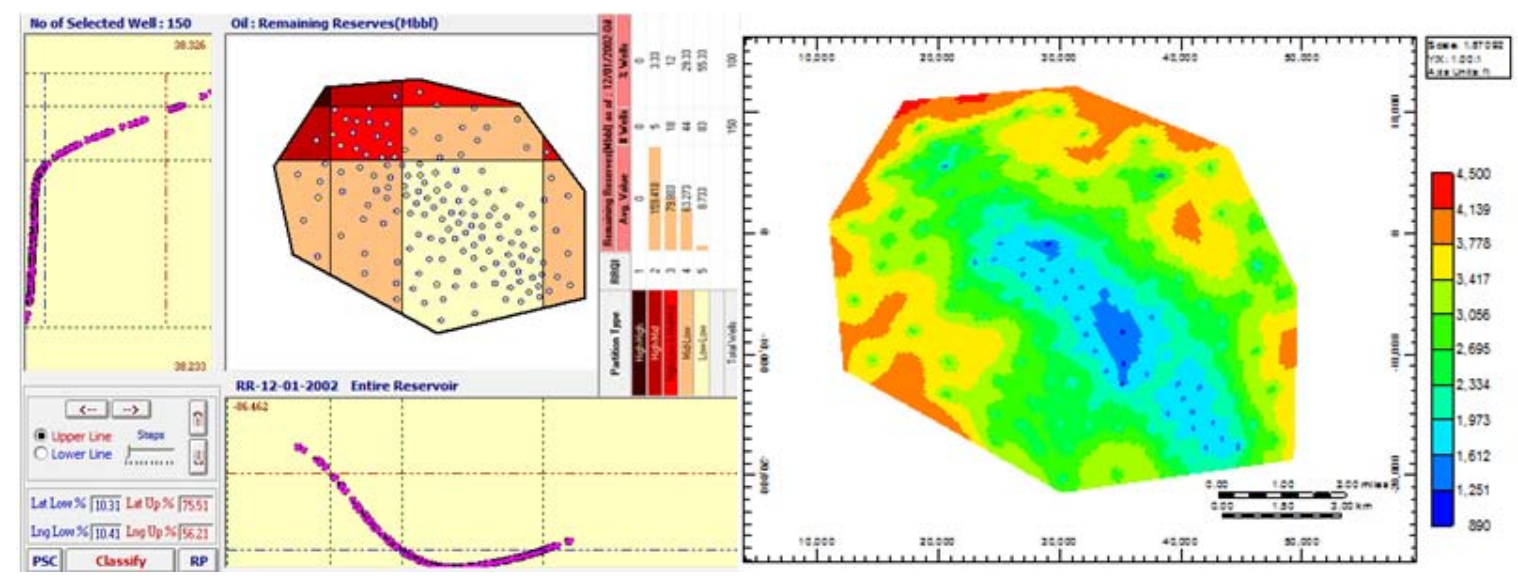

Figure 57. Map of remaining reserves from Top Down Modeling (left) compared to reservoir pressure distribution generated by the commercial simulator (right), both after three year of production by the 150 wells.

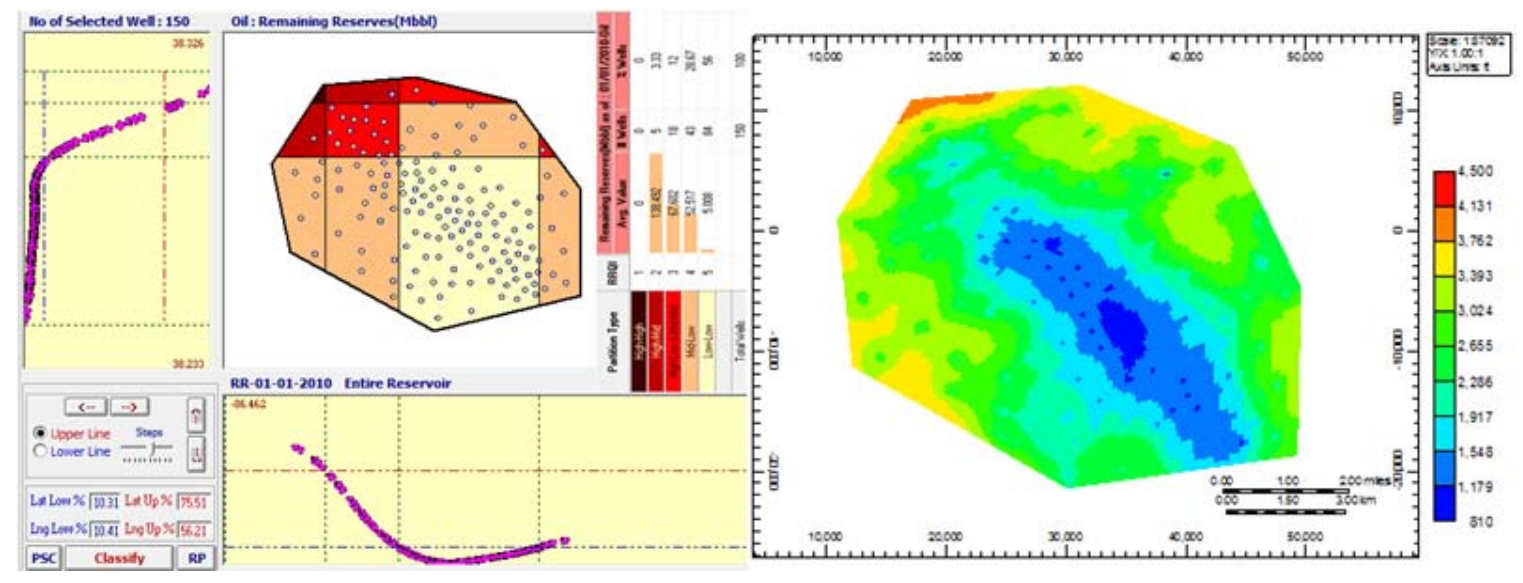

Figure 58. Map of remaining reserves from Top Down Modeling (left) compared to reservoir pressure distribution generated by the commercial simulator (right), both after ten year of production by the 150 wells.

The figures above show the comparison between the remaining reserve mapped by Top Down Modeling and the reservoir pressure distribution generated by the reservoir simulator after one, three and ten years of production. In these figures the analysis generated by Top Down Modeling are shown on the left. The pressure distribution in the reservoir generated by the commercial reservoir simulator is shown on the right in each figure. The Top Down Modeling analysis indicates the average value of remaining reserves in each of the RRQI (Relative Reservoir Quality Index) segments. It is important to mention that these numbers are to be viewed as qualitative indicators rather than quantitative numbers. 
In these figures, the Top Down Modeling analysis indicates equal to zero in the high-high section. In Figure 56 the RRQI of section high-med has a value of 160 Mbbls followed by RRQIs in med-med section through 5 with average values ranging from 80 to 9 Mbbls after one year of production. After three and ten years of production, as shown in the Figure 56 and 58, these values change slightly but the trend (in all cases) are consistent (lower RRQIs having larger value). In all cases figures show that Top Down Modeling analyses have captured the overall trend of the remaining reserves in the field and can serve as a guide for identifying infill locations especially when aggregated with other parameters through Top Down Modeling such as recovery factor, and cumulative production during the time. Once again it is important to note that this analysis was performed based on production data and well logs (porosity, thickness, and saturation) and no pressure data was furnished into this analysis.

\section{Model \#3, Identification of Gas Cap Development within the formation}

The third model will prove that the Top Down Modeling is capable of identifying gas cap formation in the reservoir. Analysis similar to the previous model has been detailed. The model contains a total of 345 wells.

To perform the analysis for gas cap formation in the reservoir, GOR profiles were calculated and modeled using an "intelligent" decline curve analysis technique which is able to model, analyze and make predictions based on negative declines. The following figures show an example of these profiles. The green line represents the GOR profile which is close to the GOR profile in the model on the right (blue line) which resulted from a reservoir simulator. 

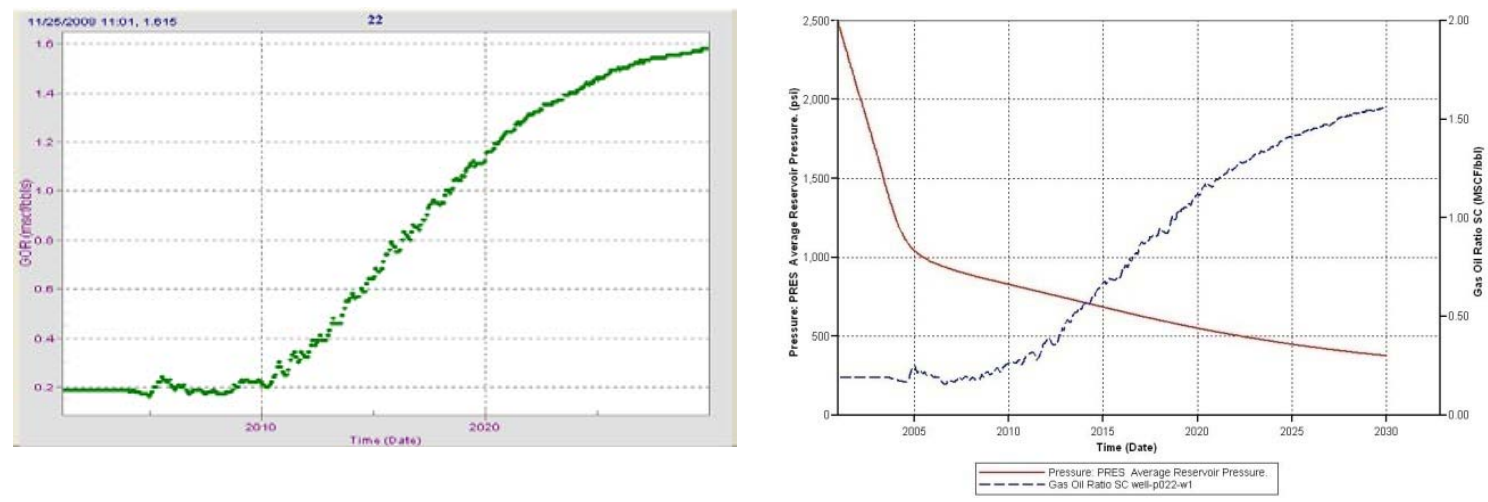

Figure 59. GOR use Top Down Modeling (left) compared to GOR generated by the commercial simulator.

The red line represents the pressure of the reservoir which is used to indicate the transition from saturated to undersaturated conditions when the reservoir reaches the bubble point pressure of 1000 psi.

Fuzzy pattern recognition was used to map GOR in the field. Reservoir was delineated in order to identify the pattern of gas saturations distribution. Figure 67 shows the result of this analysis. The figure on the left shows the Top Down Modeling analysis and different zone delineation, while the figure on the right shows the gas saturation distribution after 5 years of production from a commercial reservoir simulator.

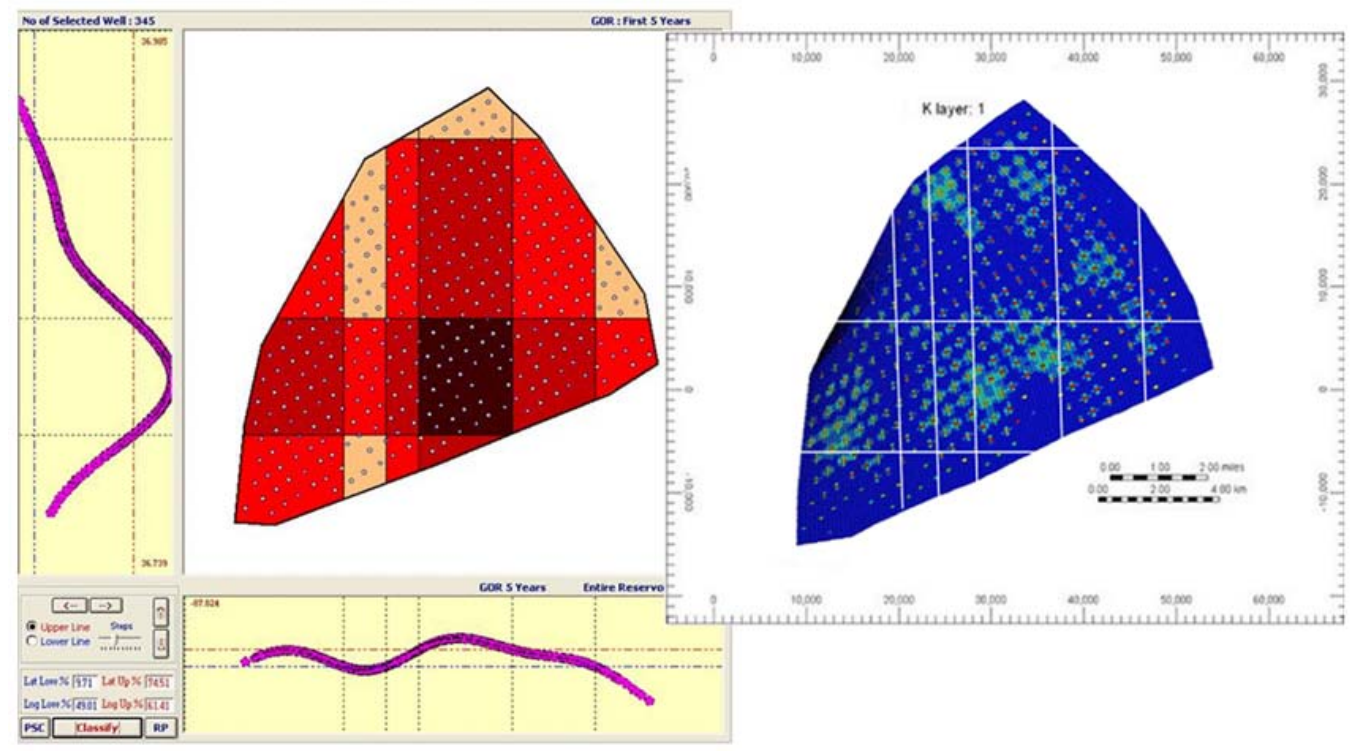

Figure 60. Gas cap analysis by Top Down Modeling and comparison with the reservoir simulator. The gas cap formation is shown after 5 years of production. 
In the figure on the left side, the darker colored areas indicate the location with highest probability of gas cap presence in this reservoir, and the lightest colored areas are the locations in the reservoir where gas cap is being formed. Comparing the Top Down Modeling's and the reservoir simulation output, it is concluded that Top Down Modeling's analysis are reasonably accurate. 


\section{Chapter IV}

\section{Concluding Remarks}

In this study three reservoirs models were built based on typical conditions of actual fields such as saturation conditions (saturated or under-saturated), different well operation starting time, and different distributions of reservoir characteristics. The total data generated and managed from the three fields is over approximately 196,560,000 pieces of spatio-temporal data.

It was demonstrated that Top-Down, Intelligent Reservoir Modeling can provide reasonably accurate results to evaluate current plans of exploration and production, and to development of new strategies to performance the reservoir.

Based on the performed analysis, Top Down Modeling can predict production profiles of new wells using production and well logs data of offset wells, with acceptable accuracy.

In addition, it was demonstrated that Top Down Modeling can be used as a tool to identify the presence of gas cap.

This study also demonstrated that Top Down Modeling may be used to track the fluid flow history in order to locate remaining reserve in the reservoir for areas were wells already exist or not.

Given the friendly environment of Top Down Intelligent Reservoir Modeling, it

gives engineers and/or geologists a fast pace update of the models as soon as the data from new wells and geologic information are available.

Also the Top Down Modeling has been tested using a commercial simulator to demonstrate that the methodology used for this investigation works for different reservoir conditions. 
Top Down Modeling integrates classic reservoir engineering analysis with Artificial Intelligence and Data Mining (AI\&DM) techniques such as artificial neural networks, fuzzy theory, and genetic optimization in order to be used as one alternative approach to simultaneously compare different strategies applied in the field. 


\section{References}

1. Group, Computer Modeling. IMEX: IMplicit-EXplicit Black Oil Simulator. [Online] http://www.cmgroup.com/software/imex.htm.

2. Schlumberger. ECLIPSE Reservoir Engineering Software. [Online]

http://www.slb.com/content/services/software/reseng/index.asp?entry=ad_google_sis_eclipse\&gclid=CMH 40ZKnsJsCFU1M5QodS1XhDw.

3. Intelligent Production Data Analysis (IPDA) \& Intelligent Data Evaluartion \& Analysis IDEA. [Online] http://www.intelligentsolutionsinc.com/ .

4. Top-Down Intelligent Reservoir Modeling; a New Approach in Reservoir Modeling by Integrating Classis Reservoir Engineering with Artificial Intelligence and Data Mining (AI\&DM). Mohaghegh, S. D. Denver, Colorado : AAPG, 2009.

5. An Integrated Technique for Production Data Analysis (PDA) with Application to Mature Fields. Gasakri, R., Mohaghegh, S.D. and and Jalali, J. 4, s.l. : SPE Production and Operations Journal, 2007, Vol. 22. pp. 403-426.

6. Field-Wide Reservoir Characterization Based on a New Technique of Production Data Analysis. Mata, D. and Gaskari, R. and Mohaghegh, S.D. Lexington, Kentucky : SPE 111205 Eastern Regional Conference, 2007.

7. Virtual Intelligence Applications in Petroleum Engineering: Part 1 ; Artificial Neural Networks. Mohaghegh, S.D. s.l. : SPE Journal of Petroleum Technology, Distinguished Author Series, September 2000. pp 64-73.

8. Virtual Intelligence Applications in Petroleum Engineering: Part 2 ; Evolutionary Computing. Mohaghegh, S. D. s.l. : Journal of Petroleum Technology, Distinguished Author Series, October 2000. pp 927-939.

9. Virtual Intelligence Applications in Petroleum Engineering: Part 3 ; Fuzzy Logic. Mohaghegh, S.D. s.l. : Journal of Petroleum Technology, Distinguished Author Series , November 2000. pp 82-87.

10. Advanced type curve analysis for low permeability gas reservoirs. Cox D.O., Hansen J.T. : SPE 35595.

11. Production Data Analysis and forecasting using a comprehensive analysis system. Poe Jr. B.D., Zheng-Poe A., Boney C.L.: SPE 52178.

12. Erwig, M. The graph Voronoi diagram with applications. s.l. : Copyright @ 2000 John Wiley \& Sons, Inc., 2000. 
Appendix A 


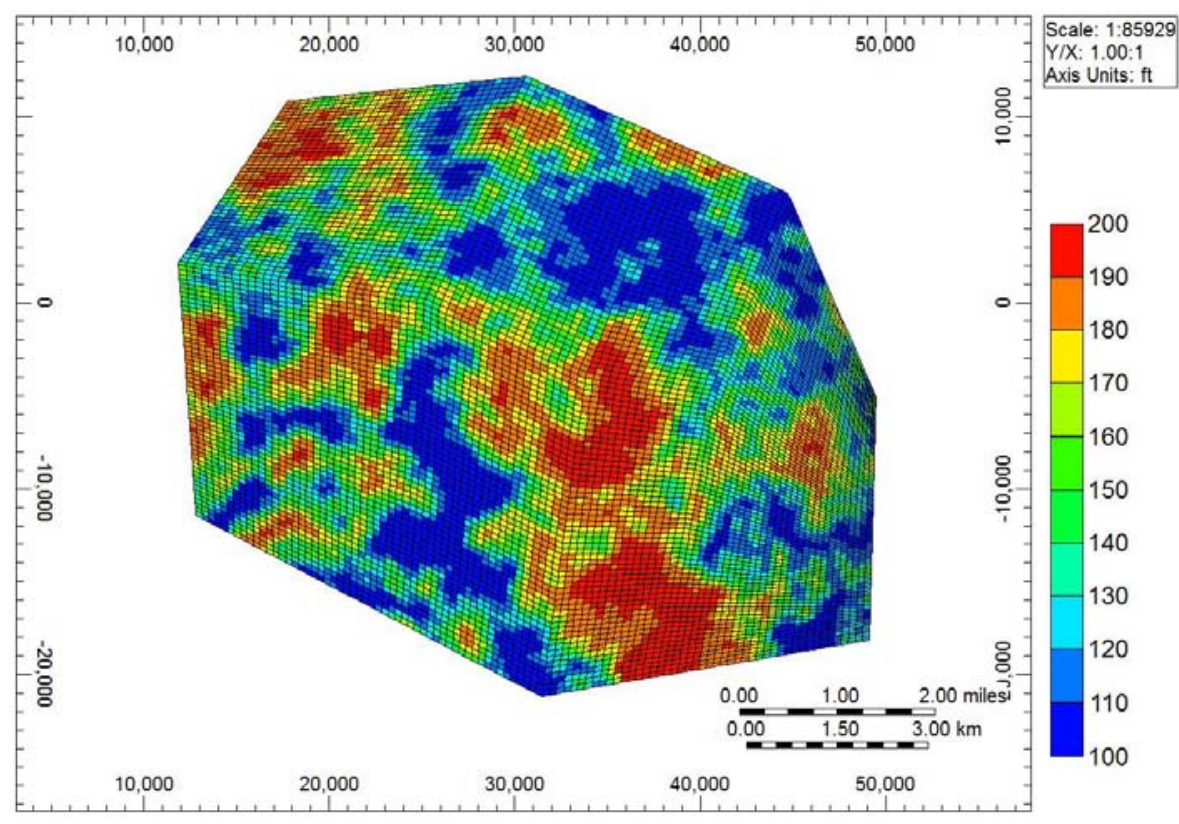

Figure 61. Grid Thickness of Model \#1.

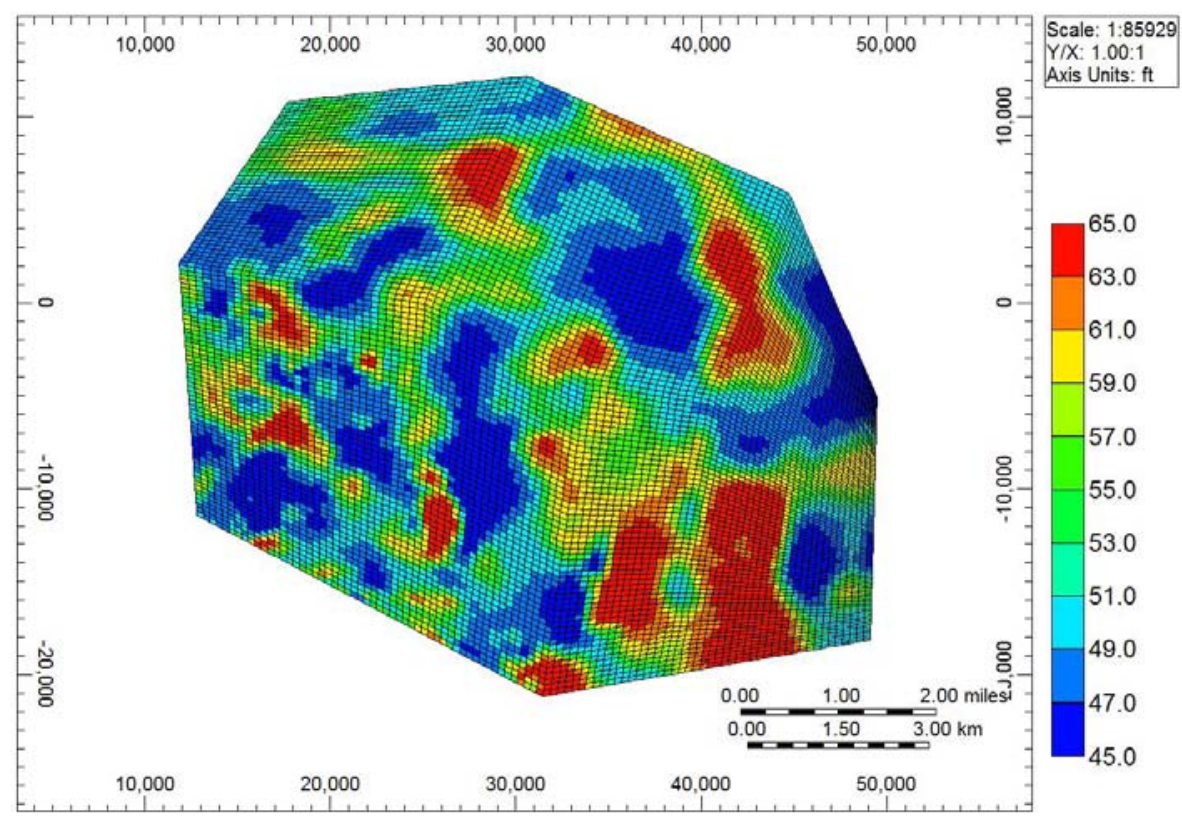

Figure 62. Permeability of Model \#1. 


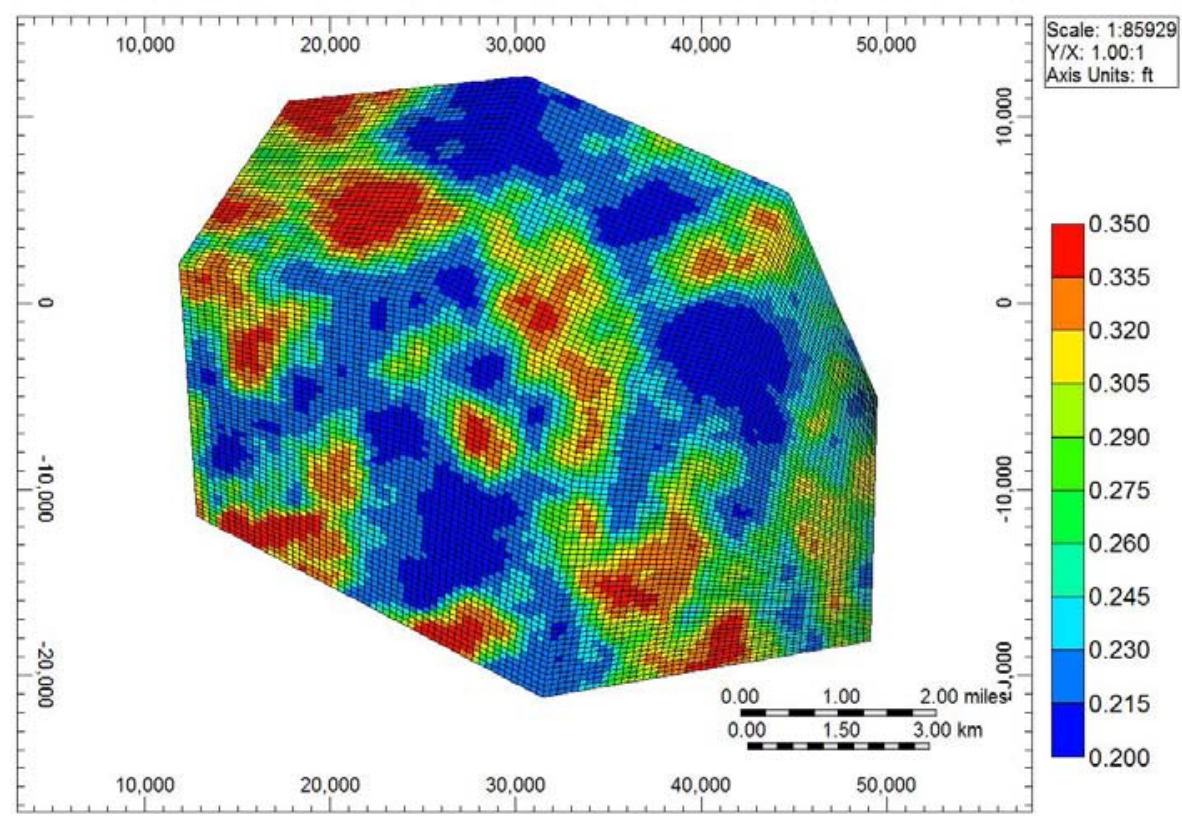

Figure 63. Porosity of Model \#1.

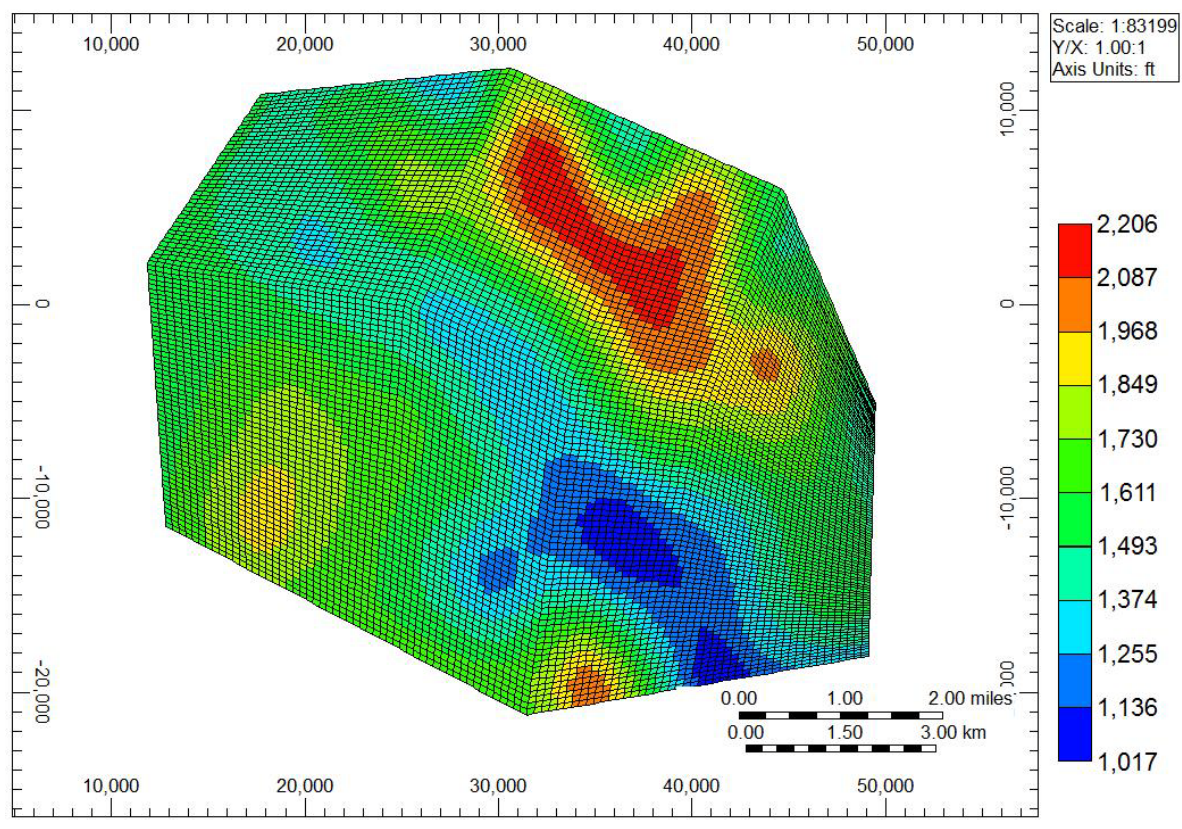

Figure 64. Grip Top of Model \#1. 


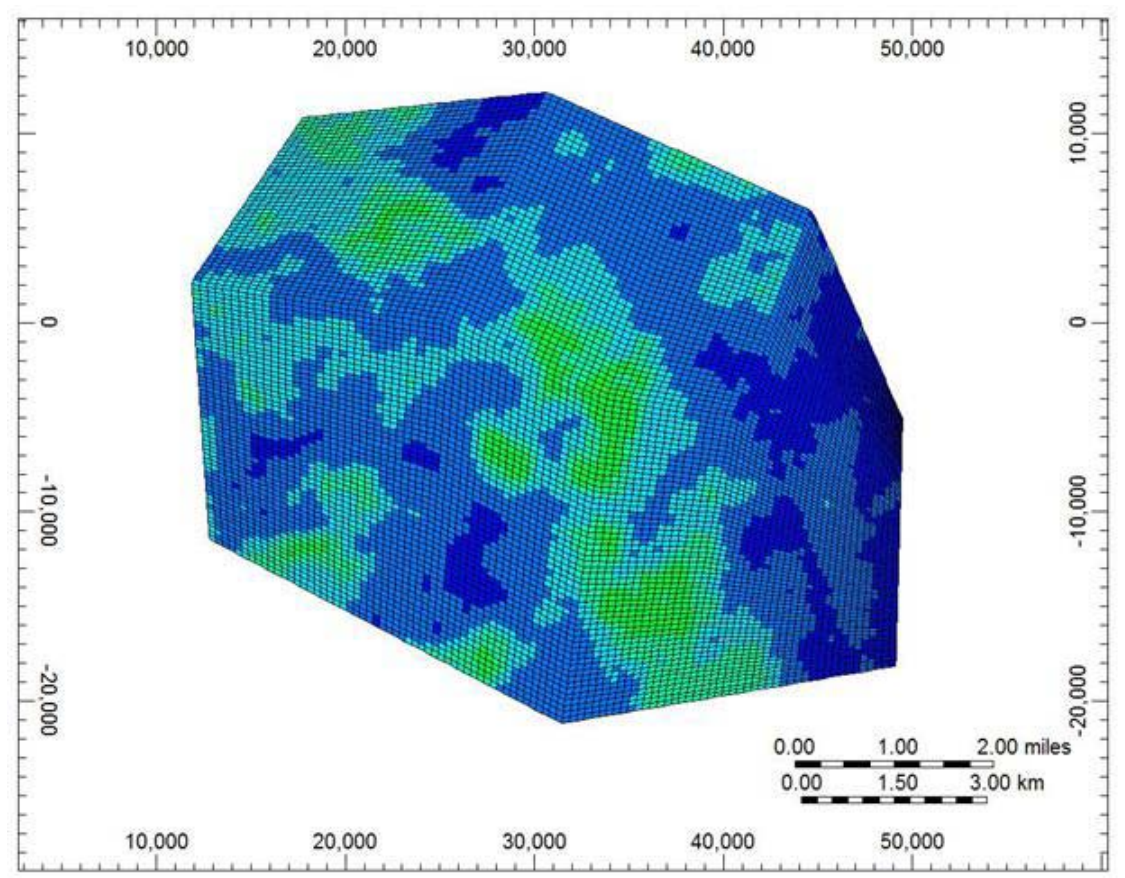

Figure 65. Initial Oil in Place of Model \#1. 
Appendix B 


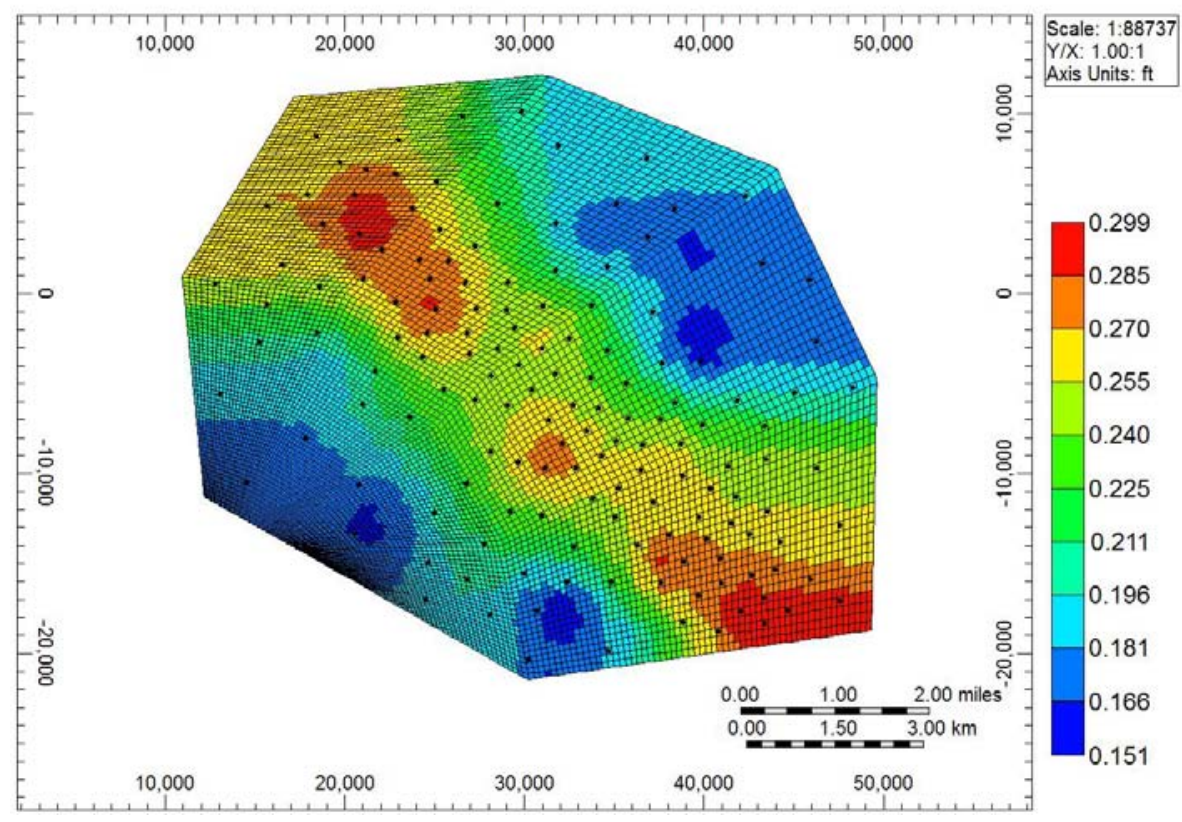

Figure 66. Porosity of Model \#2.

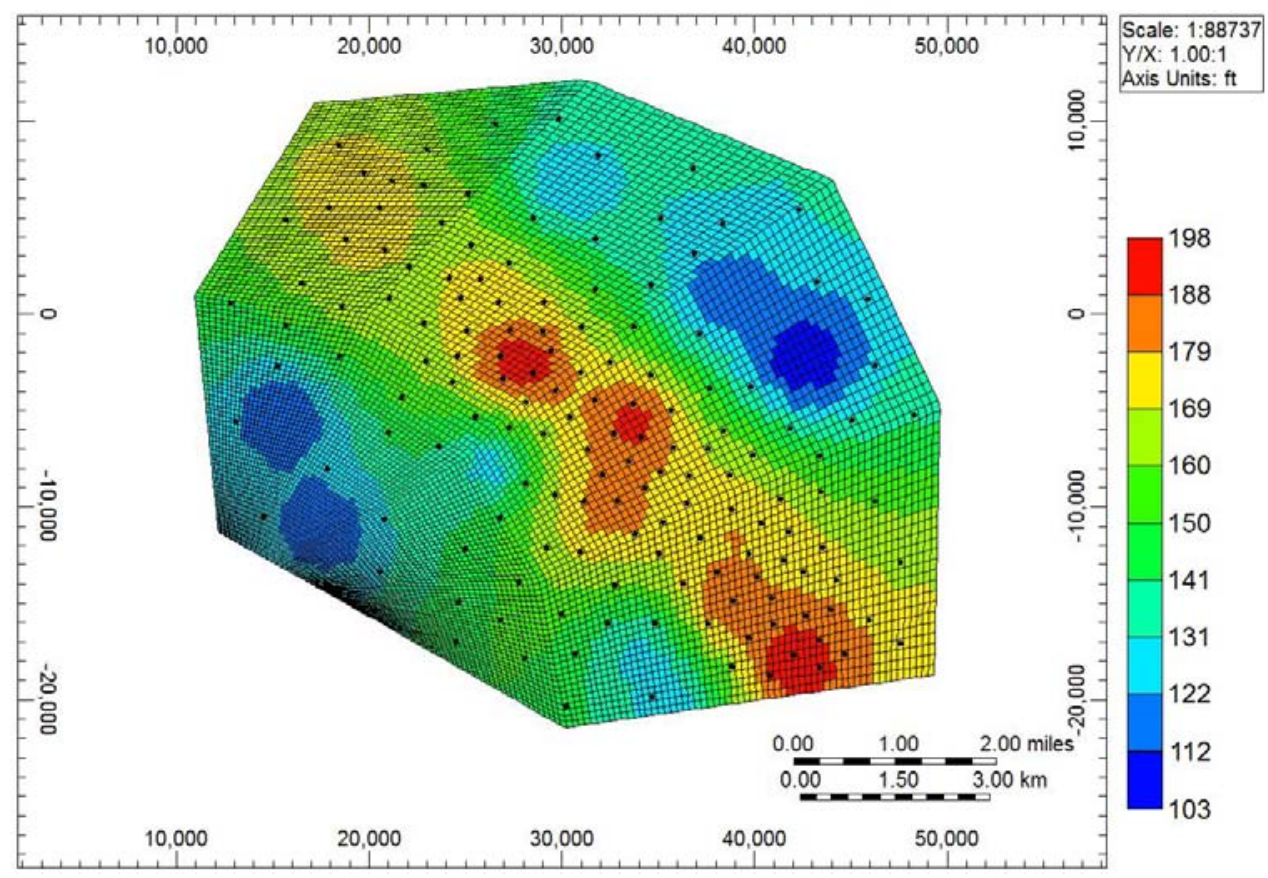

Figure 67. Grid Thickness of Model \#2. 


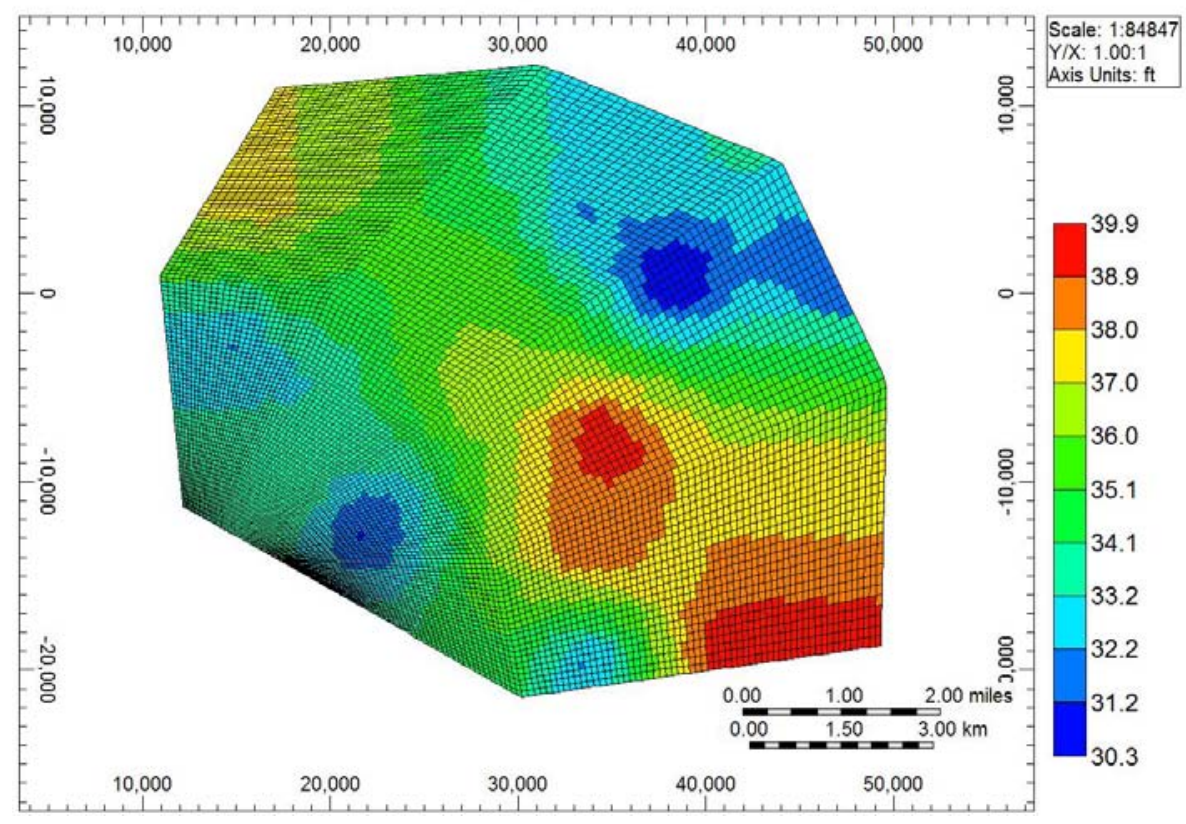

Figure 68. Permeability of Model \#2.

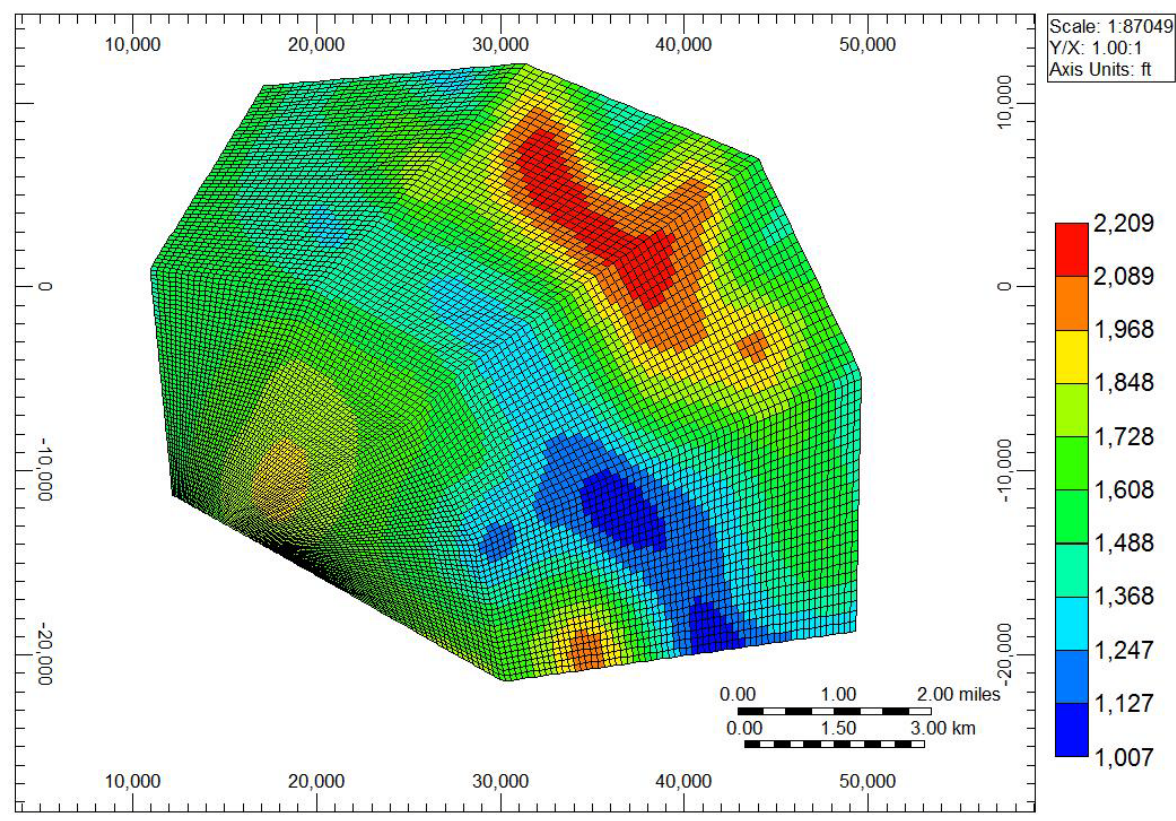

Figure 69. Grid Top of Model \#2. 
Appendix C 


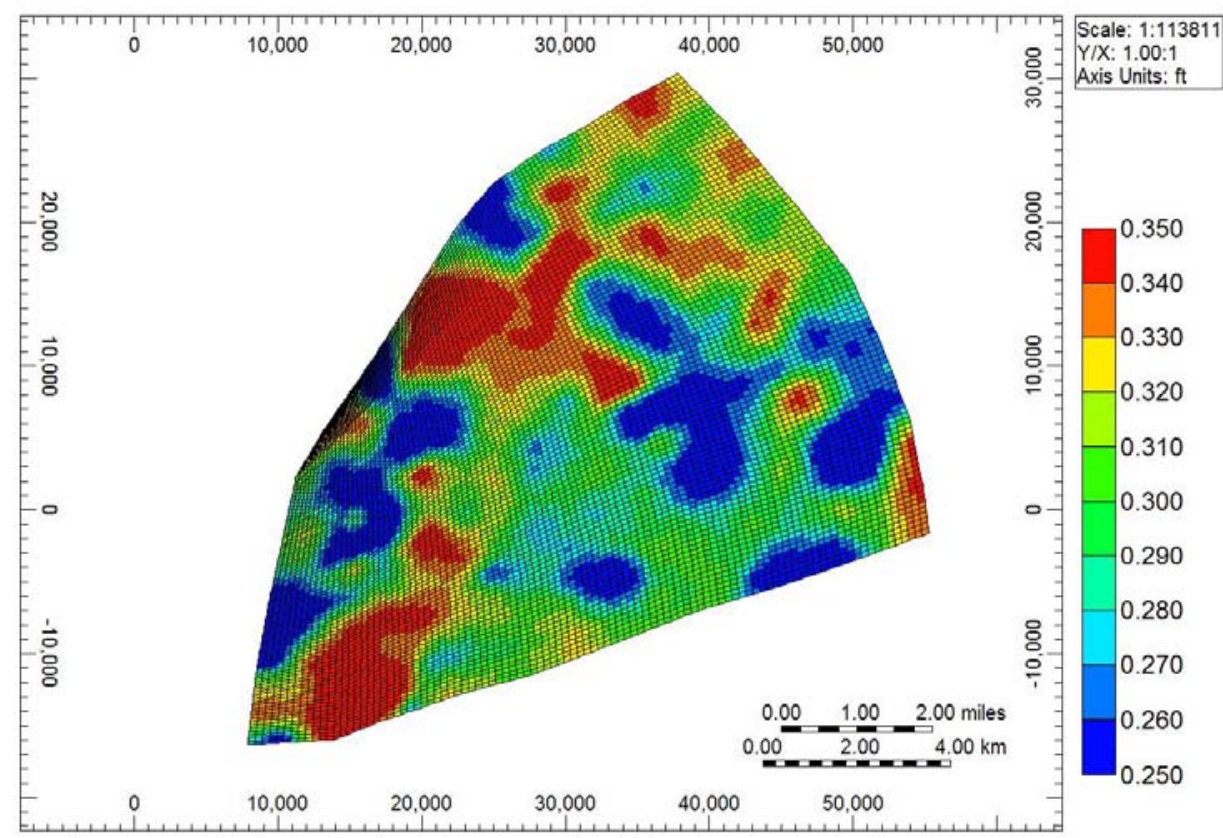

Figure 70. Porosity of Model \#3.

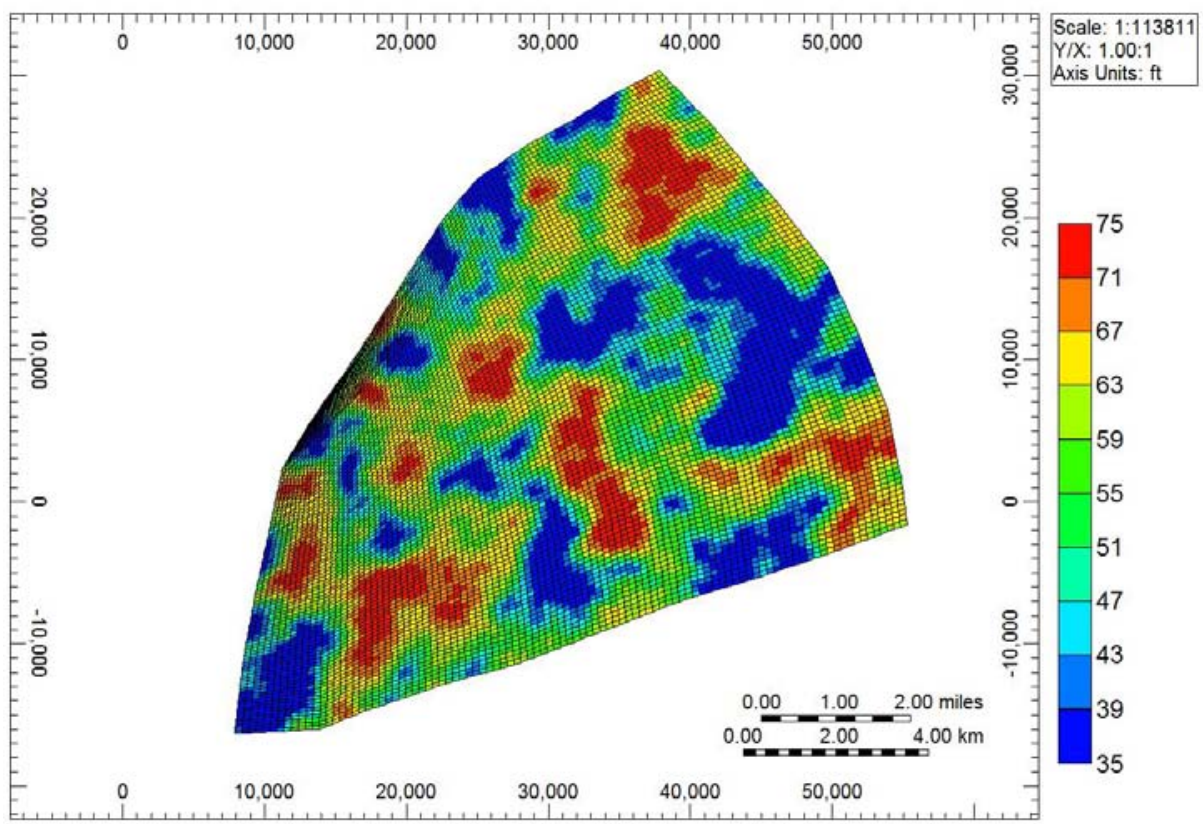

Figure 71. Grid Thickness of Model \#3. 


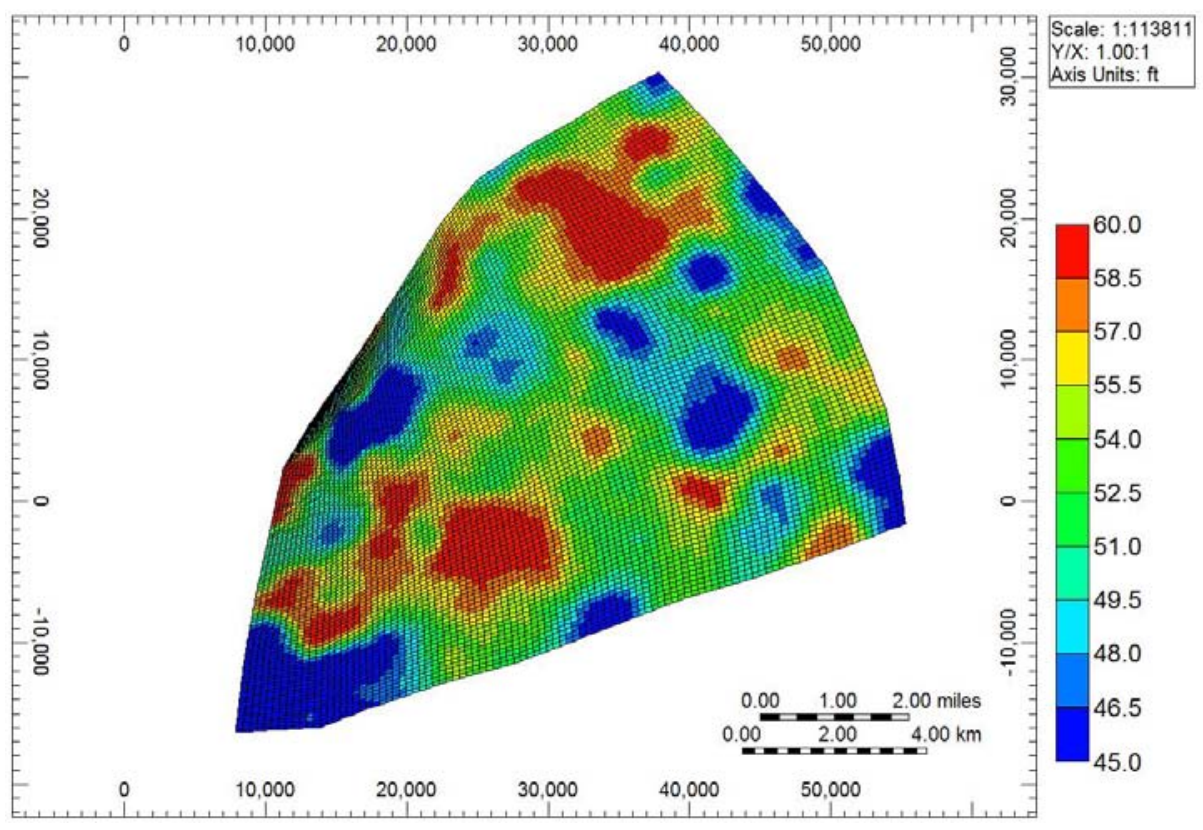

Figure 72. Permeability of Model \#3.

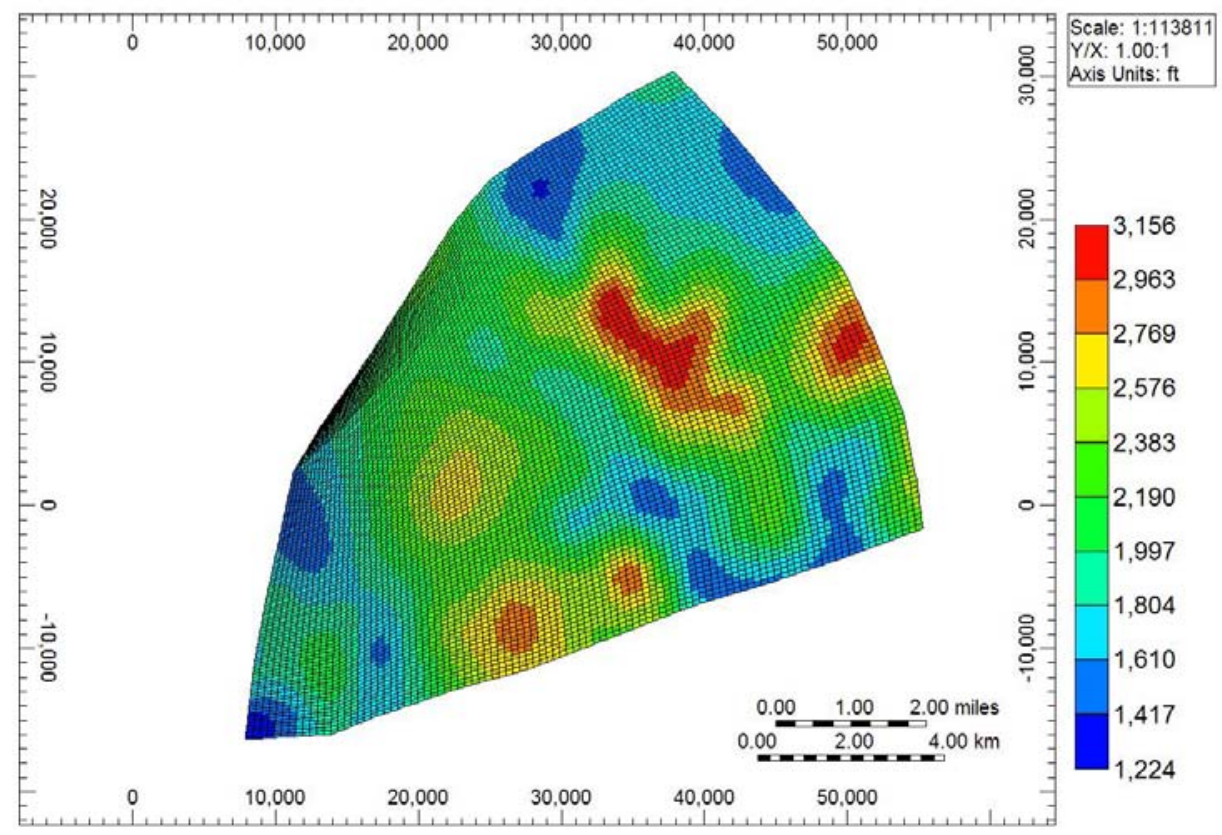

Figure 73. Grid Top of Model \#3.

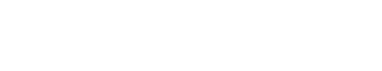

